Biomimetic Restoration of Endodontically Treated Posterior Teeth

PhD Thesis

András Forster, DMD

Supervisor:

Márk Fráter, DMD, PhD
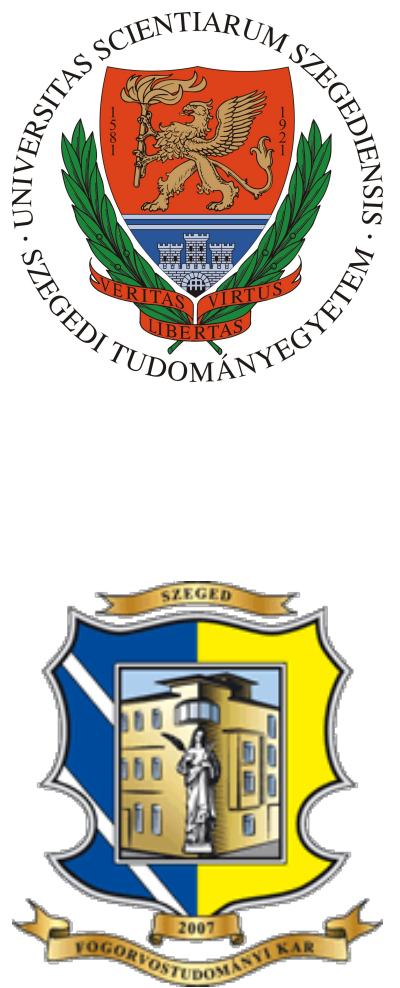

University of Szeged,

Faculty of Dentistry,

Szeged, Hungary

2019 
"Whether it be the sweeping eagle in his flight, or the open apple-blossom, the toiling work-horse, the blithe swan, the branching oak, the winding stream at its base, the drifting clouds, over all the coursing sun, form ever follows function, and this is the law. Where function does not change, form does not change. The granite rocks, the ever-brooding hills, remain for ages; the lightning lives, comes into shape, and dies, in a twinkling.

It is the pervading law of all things organic and inorganic, of all things physical and metaphysical, of all things human and all things superhuman, of all true manifestations of the head, of the heart, of the soul, that the life is recognisable in its expression, that

form ever follows function. This is the law."

$$
\text { Lonis Sullisan }
$$




\section{TABLE OF CONTENTS}

1. List of publications providing the basis of and related to the topic of the thesis

2. Introduction

2.1. Marginal ridges 5

2.2. Pericervical dentine 7

2.3. Ferrule 9

3. Methods

3.1. Mechanical changes resulting from different MOD cavity preparations 10

3.2. Restoration of endodontically treated premolar teeth with occlusal cavity preparation 13

3.3. Restoration of endodontically treated premolar teeth without ferrule effect 18

4. Results

4.1. Mechanical changes resulting from different MOD cavity preparations 22

4.2. Restoration of endodontically treated premolar teeth with occlusal cavity preparation 23

4.3. Restoration of endodontically treated premolar teeth without ferrule effect 25

$\begin{array}{ll}\text { 5. Discussion } & 27\end{array}$

6. Conclusion 34

7. Acknowledgements $\quad 35$

8. References 36

9. Other Publications of the Author 43

10. List of Abbreviations 45

11. Appendix 46 


\section{List of publications providing the basis of and related to the topic of the thesis}

\section{Publication providing the basis of the thesis:}

I. Fráter M, Forster A, Jantyik Á, Braunitzer G, Nagy K, Grandini S. In vitro fracture resistance of premolar teeth restored with fibre-reinforced composite posts using a single or a multipost technique. Aust Endod J. 2017 Apr;43(1):16-22. IF: 0.838 (2017)

II. Forster A, Sáry T, Braunitzer G, Fráter M. In vitro fracture resistance of endodontically treated premolar teeth restored with a direct layered fiber-reinforced composite post and core. $\mathrm{J}$ Adhes Sci Technol. 2016 Nov: 1454-1466 IF: 1.073 (2016)

III. Forster A, Braunitzer G, Tóth M, Szabó P. B, Fráter M. In Vitro Fracture Resistance of Adhesively Restored Molar Teeth with Different MOD Cavity Dimensions. Journal of Prosthodontics. J Prosthodont. 2019 Jan;28(1):e325-e331. IF: 1.452 (2018) 


\section{INTRODUCTION}

It is one of the everyday challenges of restorative dentistry to restore and reinforce endodontically treated teeth (ETT). It is well known and accepted that ETT are susceptible to fracture during masticatory function. In the past and still among many practitioners this phenomenon is attributed to the supposedly changed and more rigid structure of the remaining dental tissues. It has been proven to some extent that dentine quality is altered as root canal treatment is carried out. Specifically, the water content of the tissue is reduced while collagen fibers are partly dissolved by sodium hypochlorite resulting in a slightly less flexible structure(1). Even though this phenomenon has been proven, it is understood that it does not play a significant part in the fracture of root canal treated teeth.

The key factor to inferior mechanical resistance of the root canal treated teeth may be found in the tissue loss related to restorative procedures (e.g.: cavity preparation, crown preparation); tooth wear and autologous causes of mechanical damage (bruxism, attrition, erosion, abfraction); and procedures priming or enabling disinfection of the root canal (access cavity preparation, coronal flaring). As a result of dental tissue loss at neuralgic points of the tooth, mechanical stability of the structure as a whole is reduced.

According to the authors clinical observations and thorough review of the scientific literature it seems that there are three structural deficiencies that have to be examined, and if possible, reconstructed or compensated for in order to successfully restore the biomechanical resistance of posterior teeth and their masticatory function: 1. Condition of the marginal ridges 2 . Condition and quality of the pericervical dentine (PCD) 3. Preservation of the so-called ferrule. The later can also be regarded as the prosthodontic entity of the PCD, also known as three dimensional ferrule.

\subsection{MARGINAL RIDGES}

Once preparation of a tooth is commenced, regardless of instrument or degree of invasion, the biomechanical integrity of the tooth is disrupted, therefore the tooth enters the socalled restorative cycle (2). The degree of invasion seems to be an important issue and as minimal invasive concepts are trending, professionals tend to focus on this at large, however, it seems that it is more the locus of invasion in the coronal part of the tooth that is the key factor. Caries at young age tends to attack the occlusal areas of posterior teeth in the pits and fissures mostly. Removal of 
occlusal caries and resulting occlusal cavity preparation - in case if not invading the marginal and cusp ridges - does not weaken the posterior teeth majorly $(3,4)$. In case of an interproximal laesion areas, caries undermines the marginal ridges and resulting treatment according to the classical - but still clinically applied - Black principles involves occlusal entry to the interproximal area through the marginal ridge. Loss of a single marginal ridge does introduce higher deflection of the cusps during mastication, but it seems that the remaining single marginal ridge still serves well to stabilise the cusps and prevent fracture in most situations (5). Loss of both marginal ridges seems to weaken the posterior teeth to a great extent (6). As the masticatory forces push the cusps in an oralvestibular direction the "splinting" effect of these enamel structures is quintessential. According to Black, the mesial and distal cavities serving to access and remove interproximal caries need to be connected with an occlusal box as a retentive measure for non-adhesive restorations. With adhesive restorations and slot cavity preparations connecting these two cavities needs to be prevented whenever possible (7), to ensure oral-vestibular stability of the cusps by preserving occlusal enamel+dentino-enamel junction (DEJ)+dentine truss. If not preventable either as a result of excessive preparation or occlusal caries, the tooth "suffers" a so-called MOD (mesio-occlusaldistal) cavity preparation. In these cases there are no more occlusal enamel areas connecting the oral and vestibular cusps, therefore cuspal deflection is severely higher (8) and risk of a fracture is induced. In the past it was the common preconception - conceived by opinion leaders but never significantly proven - that while analysing MOD cavities it is the thickness measured at the base of the cusp $(9,10)$ that defines restorative indication. More specifically if the base of the cusp is thicker than 2-2.5 mm, the cusp is considered stabile and no cusp coverage is needed according to Scotti et al. (9) and Deliperi et al.(10). If the base is thinner, the cusp is considered unstable or vulnerable and cusp coverage (overlay or crown) is indicated. This approach disregards the fact that the depth of cavities is extremely variable. From the point that enamel connection of the oral and vestibular cusps is eliminated it is a task of the remaining dentine to prevent fracture of the cusps. The remaining cusps in these situations act like cantilever beams, therefore it is extrapolated according to basic physics of cantilevers that cavity depth - which calculates as the length of the cantilever beam - is not only to be considered but it is to be regarded as the most important influencer of forces exerted at the base of the cusp (where fractures are likely to occur). Following this logic it is easy to extrapolate and see that the weakness and fragility of ETT may partially be a result of deep cavity preparation (access cavity). 
First objective of this thesis is to understand decision making in MOD cavity situations and find a rationale for easily indicating a restoration which is minimally invasive and maximally considers long term mechanical stability of the remaining hard tissues.

\subsection{PERICERVICAL DENTINE}

Pericervical dentine (PCD) is defined as the dentine below and above the alveolar crest within 4 mm's (11). It is stated by Clark and Khademi in their groundbreaking paper on endodontic access cavity that the PCD cannot be replaced by artificial material (11). Looking at the development of endodontics towards supposedly more successful healing of the periapical areas, the orifice flaring of the root canal (coronal third of the root canal system) became more and more invasive, providing easier, straighter, strain free access to the so desired apical third of the root canal. During this effort for many, the reason of root canal treatment was seemingly lost and removing more and more pericervical tissue became state of the art. Step back technique, Crown down techniques, Gates Glidden burs used excessively for coronal preflaring and finally progressively tapered instruments, provide a simple rationale to access the apical area of the root canal system and as a side effect promote removal of the healthy PCD. Up until today it is the gold standard to use crown down methodology with rotary file systems (12) and it seems only a privilege of the most well trained and elite group of endodontists to select instruments according to the needs of each case. The usage of posts are becoming more and more debated but it is still the axiomic approach of most clinicians to place a post in all ETT, and it is still the belief of many that posts reinforce the tooth. With conventional metal posts it is clear that there is a reinforcing effect if extended apically enough (13), but it should not be forgotten that once a critical load is obtained on the tooth the rigidity of the metal post will almost surely lead to a catastrophic failure of the root canal treated tooth $(14,15)$. Metal posts and especially individually fabricated gold posts have considerable advantages (elastic modulus close to dentine; good adaptation to the prepared root canal space; individual shape; high load bearing capability; easy cementation) and numerous disadvantages (more than one visit; technician involved; high price; often catastrophic failure). To somewhat compensate for these disadvantages numerous concepts where applied. Two of these are of great importance: Nayaar amalgam core (16) and fiber reinforced composite (FRC) post. Both of these concepts hold significant improvements. In the authors view Nayaar core represents a good concept as the core fills the whole of the prepared root canal space with a non shrinking monoblock material which serves as the core material too. However, amalgam is too rigid and not tooth 
coloured which are considerable disadvantages. Also the non adhesive nature of amalgam and its final volumetric expansion should be considered as factors possibly negatively influencing or not promoting the mechanical resistance of the restored tooth. FRC posts are an esthetic alternative to previous posts and as a result of the glass fibers embedded into epoxy resin the flexural strength is very similar to that of dentine (17-20). However these prefabricated posts fail to fill out the prepared root canal space unless excess post-space preparation is done. Since it is well known that healthy dentine removal has a major biologic cost, it is not recommended any more to carry out post space preparation except for the removal of the guttapercha and root canal sealer materials (21-26). This leaves a geometrically complex space to be filled out with a prefabricated post, therefore resulting in mass bodies of luting composite occupying the rest of the root canal space. This single phenomenon causes several problems: 1. As a result of the shrinkage of luting cement (27) and high C-factor of the root canal space $(28,29)$ bond strength to root canal dentine is low $(30)$. 2 . As a result of the axial rigidity of the FRC posts (31) and low bonding strength on the luting cement-post interface (32) it is common to have separation (33). These two major issues lead to a mechanically compromised system not capable of strengthening the root canal treated teeth (21). These findings could be caused by the mismatch between fiber posts and the root canal diameter since according to modern minimal invasive principles post space preparation should not contribute to radicular dentine removal $(22,24)$. Following a minimally invasive post space preparation leaves us with unique and irregular spaces (27) which are difficult to fill out with a single conventional or even a flexible FRC post. A further problem with posts is that they are placed in the most central part of the post space (neutral axis), leaving the space originally occupied by dentine to be filled by the mechanically inferior luting composite material. A more effective reinforcement location mechanically may be on the outer surfaces of the post space close to the dentine walls where the highest tensile stresses occur (34). This is the space which, before the root canal preparation was most likely obtained by healthy radicular and pericervical dentine. So to reach a reinforced, mechanically homogenous unit it would be ideal if a restorative material could be directly bonded to the root canal dentine and it would have mechanical properties similar to that of dentine.

In a 2007 investigation by Garoushi and coworkers it was found that anterior ETT showed better load bearing capacity if restored with a short fiber reinforced composite (SFRC) restorative material opposed to an FRC post (35). These findings open the debate on the necessity of the FRC post concept and open a gateway for promotion of new types of endo-restorative techniques. 
It seems clear that there is no currently accepted concept that is capable of substituting PCD and therefore reinforcing the ETT. It is also evident that sound PCD needs to be preserved as much as possible, so there is a demand for new minimally invasive techniques for root canal access, root canal preparation and post endodontic reinforcement of these teeth.

Second objective of this thesis is to find and test endo-restorative solutions which may be capable of reinforcing the PCD.

\subsection{FERRULE}

The prosthodontic ferrule is described as a minimum $2 \mathrm{~mm}$ high, minimum $1 \mathrm{~mm}$ thick sound dentine area coronal to the preparation margin of a full veneer crown abutment (36). Preparation margin in most cases with a healthy periodontium is designed to be subgingival or epigingival for esthetic reasons. Given the fact that the marginal gingiva is approximately 2.8-3.5 $\mathrm{mm}$ distance from the alveolar crest (37) and the PCD is considered as the dentine volume $2 \mathrm{~mm}$ above the alveolar crest, it can be stated that once prosthodontic crown preparation is carried out, cervical enamel and dentine is removed to an extent of possibly compromising the PCD. Until today it has not been described if PCD loss has similar mechanical effects if it is suffered from the direction of the root canal space or if suffered from the external tooth surface. But it is clear that missing a ferrule in case of crown preparation is more likely to result in mechanical failure of the tooth as compared to a preparation with a ferrule $(38,22)$. From this well know fact it can be extrapolated that preserving dentine areas close to or invading the PCD are of key importance also in case of crown preparations.

However in case of several structurally compromised teeth it is only possible to produce a crown preparation without invading the biologic width if a proper ferrule is not prepared. It is one of the greatest challenges of endo-restorative dentistry to try and restore these teeth with a functionally stabile, long term prosthetic solution. Previously tested prosthodontic possibilities include endo crowns; cast metal posts; adhesive restorations; and glass fiber posts with different application methodologies (39) However until today there is no universally accepted solution to restoring non-ferrule teeth.

The third objective of this thesis is to find and test endo-restorative solutions that are capable of reinforcing teeth without a prosthodontic ferrule. 


\section{METHODS}

All procedures of the investigations presented where approved by the Regional Ethics Committee for Human Medical and Biological Research (University of Szeged, Hungary) and the studies where designed in accordance with the Declaration of Helsinki.

The series of investigations was designed to better understand the diagnostic aspects and mechanical restorability of the posterior teeth examining some critical elements - perceived by the authors to be - missing from contemporary scientific literature. By doing so it is expected that to some extent, more adequate diagnostic and restorative procedures may emerge in the future partially as a result of this thesis.

\subsection{Mechanical changes resulting from different size MOD cavity preparations}

The aim of this study is to assess the effect of different cavity configurations on the maximal fracture load strength of restored molar teeth, without cuspal coverage. The null hypothesis was that restored teeth are not weakened compared to the intact control specimens.

120 mandibular 3rd molars extracted for periodontal or orthodontic reasons were selected for this investigation. The freshly extracted teeth were immediately placed in $5.25 \% \mathrm{NaOCl}$ for 5 minutes and then stored in $0.9 \%$ saline solution at room temperature until use all within 2 months of extraction. During specimen preparation, the soft tissue covering the root surface was removed with hand scalers. The inclusion criteria were visual absence of caries or root cracks, absence of previous endodontic treatment, posts or crown or resorptions. Teeth with severe polymorphism of the coronal structures were excluded from the investigation.

Approximately eighty percent of the specimens ranged 10.0 to $10.9 \mathrm{~mm}$ in size, measured at the widest bucco-lingual dimension, and the rest were between 11.0 and $12.0 \mathrm{~mm}$. The mesio-distal dimension of the samples was also measured and this parameter allowed a maximum deviation of $10 \%$ from the determined mean. The height was between 8.0 and $9.0 \mathrm{~mm}$ measured from the cementoenamel-junction (CEJ). The 120 teeth were randomly distributed between 10 study groups $(\mathrm{n}=12)$ including 9 restored groups (Table 1) and a control group of intact natural teeth.

Cavity preparation

MOD cavities with different wall thicknesses and with different depths (Figure 1.) were prepared by the same trained operator in 9 of the groups. 


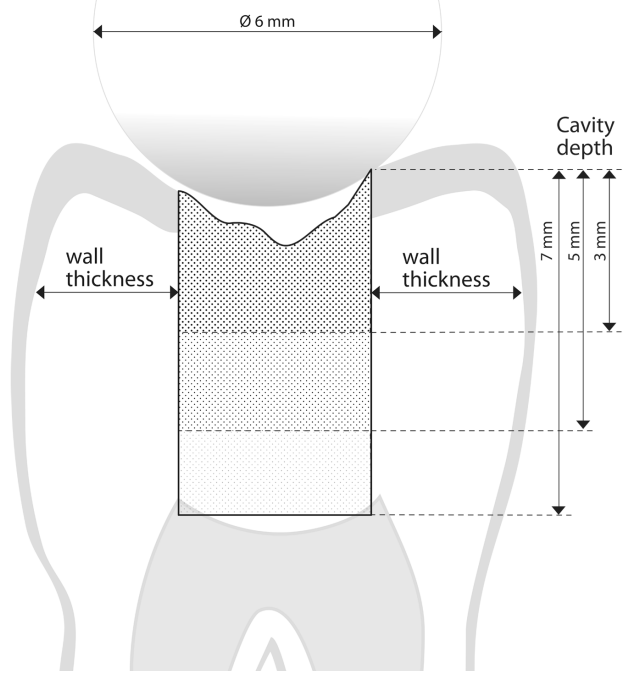

\begin{tabular}{cccc}
$\begin{array}{c}\text { Depth/Wall } \\
\text { thickness }\end{array}$ & $3.5 \mathrm{~mm}$ & $2.5 \mathrm{~mm}$ & $1.5 \mathrm{~mm}$ \\
\hline $3 \mathrm{~mm}$ & $\mathrm{~A}$ & $\mathrm{~B}$ & $\mathrm{C}$ \\
\hline $5 \mathrm{~mm}$ & $\mathrm{D}$ & $\mathrm{E}$ & $\mathrm{F}$ \\
\hline $\begin{array}{c}7 \mathrm{~mm} \\
\text { (Endo) }\end{array}$ & $\mathrm{G}$ & $\mathrm{H}$ & $\mathrm{I}$
\end{tabular}

Table 1. - Cavity parameters per tested group

Figure 1. Schematic orovestibular cross section drawing of cavity proportions prepared in mandibular third molars subject to adhesive restoration and maximal fracture strength testing. Depth/wall thickness per group: A: $3 \mathrm{~mm} / 3.5 \mathrm{~mm} \mathrm{B:} 3 \mathrm{~mm} / 2.5 \mathrm{~mm} \mathrm{C}: 3 \mathrm{~mm} / 1.5 \mathrm{~mm}$ D: $5 \mathrm{~mm} / 3.5 \mathrm{~mm}$ E: $5 \mathrm{~mm} / 2.5 \mathrm{~mm} \mathrm{~F}: 5 \mathrm{~mm} / 1.5 \mathrm{~mm} \mathrm{G}: 7 \mathrm{~mm} / 3.5 \mathrm{~mm} \mathrm{H}: 7 \mathrm{~mm} / 2.5 \mathrm{~mm}$ I: $7 \mathrm{~mm} / 1.5 \mathrm{~mm}$

The MOD cavities were prepared into each of the teeth according to the parameters listed in Table 1. The preparation was performed with a round end parallel diamond (881.31.014 FG - Brasseler USA Dental, Savannah, GA) bur initially positioned at the midline of the occlusal surface of the teeth (determined by dividing the distance between the buccal and lingual cusp tips by two). The thickness of the opposing walls at the cavity base were continuously checked during the preparation with a digital calliper (Mitutoyo Corp., Kawasaki, Japan). The cavity walls were prepared parallel to the axis of the tooth. The depth of the cavity was evaluated with a 15 UNC periodontal probe (Hu-Friedy Mfg. Co., Chicago, USA) measured from the corresponding cusp tip by touching the cavity wall with full length of the instrument. The cavity was one continuous cavity with the proximal box having exactly the same width and depth as the occlusal one.

In the samples in which the depth was meant to be $7 \mathrm{~mm}$ an endodontic access was prepared and endodontic treatment was carried out. After shaping with step-back technique (maximum file size 35-40), the root canals were filled with a thermoplasticized gutta percha delivery system (ObturaII, Obtura/Spartan, Fenton, MO, USA). Following root canal obturation a base was applied to the pulp chamber in the form of a 2.0-3.0-mm thick resin modified glass-ionomer barrier (40) (Fuji II LC, 
GC Europe, Leuven). This was cut back with a coarse diamond bur (801.36.6801 FG/Surg Brasseler USA Dental, Savannah, GA) to establish the $7 \mathrm{~mm}$ final depth of the cavity. The cavosurface margins were prepared perpendicular to the tooth surface. The cavity was rinsed with water and air-dried with an air/water syringe. After application of a Tofflemire (1101C 0.035, Hawe-Neos, Italy) matrix, the enamel was acid-etched selectively with 37\% phosphoric acid for 15 seconds, rinsed with water and air-dried. The cavity was adhesive-treated with G-aenial Bond (GC Europe, Leuven, Belgium) according to the manufacturer's instructions. The adhesive was lightcured for $40 \mathrm{~s}$ with an Optilux 501 halogen light (Kerr, Orange, CA, USA) operating in standard mode at a light intensity of $740+/-36 \mathrm{mWcm} 2$. In all groups, an approximately $0.5 \mathrm{~mm}$-thin flow composite layer (G-aenial Flo A2, GC Europe, Leuven) was applied on all walls of the cavity (41-43). This layer was light-cured for $40 \mathrm{~s}$. After applying the flowable layer, composite resin (Gradia Direct Anterior A2, GC Europe, Leuven, Belgium) was placed in several consecutive 2 mm-thick oblique increments. Each increment was light cured from the occlusal surface for $40 \mathrm{~s}$ each and after removal of the Tofflemire matrix band the mesial and distal sides were light cured for $20 \mathrm{~s}$ each (total $80 \mathrm{~s}$ ). Light curing times chosen are the double of that recommended by the manufacturer for each material used, in order to securely obtain maximal conversion at each layer. The restorations were finished with a fine granular diamond burr (FG 7406-018, Jet Diamonds, USA and FG 249-F012, Horico, Germany) and aluminum oxide polishers (OneGloss PS Midi, Shofu Dental GmbH, Ratingen, Germany) and were stored in physiological saline solution (Isotonic Saline Solution $0.9 \%$ B.Braun, Melsungen, Germany) before the fracture test.

To simulate the periodontal ligament, the root surface of each tooth was coated with a layer of liquid latex separating material (Rubber-Sep, Kerr, Orange, CA) prior to embedding. Specimens were embedded in methacrylate resin (Technovit 4004, Heraeus-Kulzer) at $2 \mathrm{~mm}$ from the CEJ to simulate the bone level.

All specimens were tested for fracture strength within 24 hours of restoration, using a universal loading device (5848 MicroTester1, Instron, Norwood, MA, USA). Each test was performed at a cross-head speed of $2 \mathrm{~mm} / \mathrm{min}$ and load was applied using a $6 \mathrm{~mm}$ diameter stainless-steel ballshaped stylus which was positioned at the centre of the occlusal surface of the tooth between the buccal and oral cusps in the central pit. A force vs. extension curve was dynamically plotted for each tooth. Fracture threshold - defined as the load at which the tooth-restoration complex exhibited the first fracture, resulting in a peak formation on the extension curve - was recorded in Newtons $(\mathrm{N})$. 
Statistical analysis was conducted in SPSS 21.0 (SPSS Inc., Chicago, USA). For the comparisons between the groups, Kruskal-Wallis ANOVA with post-hoc pairwise comparisons was used. The significance limit was set at $\alpha=0.05$.

3.2. Restoration of endodontically treated premolar teeth with occlusal cavity preparation

The aim of this investigation was to compare the mechanical properties of novel methods for the reinforcement of ETT utilizing SFRC (EverX Posterior, GC Europe, Leuven); with previously tested and accepted restorative methods. The null hypothesis was that 1 , There would be no difference in the maximal fracture resistance of the ETT restored teeth with the tested methods. 2, There would be no difference in the fracture patterns of the ETT restored with the tested methods.

Seventy-two upper premolar teeth, extracted for periodontal or orthodontic reasons were selected for this investigation. Specimen selection, exclusion criteria, root canal treatment protocol, specimen preparation and mechanical testing were carried out as described by Frater et al. (44).

The freshly extracted teeth were immediately placed in $5.25 \% \mathrm{NaOCl}$ for 5 minutes and stored in $0.9 \%$ saline solution at room temperature. Teeth were used within 6 months after extraction.

During specimen preparation the soft tissue covering the root surface was removed with hand scalers. The inclusion criteria were absence of caries or root cracks, absence of previous endodontic treatments, posts or crowns, resorptions, or evident lateral canals. Buccolingual and mesiodistal radiographs of all teeth were taken and examined to evaluate root integrity and the number of canals present. To standardize procedures and materials, all teeth used in this study had 1 root canal with a curvature of less than $5^{\circ}$, evaluated by Schneider's technique (45), and teeth with a root length of $15+/-1 \mathrm{~mm}$ and similar mesio-distal and bucco-lingual dimensions (+/-10\%) were selected.

$90 \%$ of the specimen ranged $9-10 \mathrm{~mm}$ in size, measured at the widest bucco-lingual dimension, and the rest measured were 6.5 to $8 \mathrm{~mm}$. Regarding the mesio-distal dimension, $90 \%$ of the specimen ranged $7-7.5 \mathrm{~mm}$, and the rest were 6.5 to $8 \mathrm{~mm}$.

The teeth were randomly distributed over six study groups of 12 specimens each.

Access cavity was prepared by the same trained operator in five groups of the six, and one group was left intact to serve as control (Group 6.).

Access cavity preparation was carried out with a round-end, tapered, medium grit, $0.8 \mathrm{~mm}$ tip diameter, $10 \mathrm{~mm}$ length diamond bur (850-014M SSWhite, Lakewood, NJ, USA) with water cooling in the approximated centre of the occlusal surface according to standardized parameters: the 
access cavity involved one-third of the intracuspal distance in the bucco-lingual dimension, and one-third of the mesio-distal distance, measured at the level of the central fissure.

The working length was established with the direct method by subtracting $1 \mathrm{~mm}$ from the real root length determined by introducing a no. $10 \mathrm{~K}$-file (Maillefer-Dentsply, Ballaigues, Switzerland) until it was visible through the apical foramen. The canals were instrumented using rotary ProTaper Universal files (Dentsply, Maillefer, Ballaigues, Switzerland). The ProTaper sequence (S1, S2, F1, F2) was used for the preparation at the working length.

Irrigation was performed after every instrument with 2 milliliters of $2.5 \% \mathrm{NaOCl}$ solution and the canal space was filled with irrigant during the instrumentation phase. After the shaping and cleaning of the root canal the roots were dried with $96 \%$ alcohol and paper points. Root canal filling was done by matched-single-cone obturation with a master cone (F2 gutta-percha, Maillefer-Dentsply, Ballaigues, Switzerland) and sealer (AH plus; Dentsply De Trey GmbH, Konstanz, Germany). The access cavity was temporarily filled with Fuji Triage Pink (GC Europe, Leuven, Belgium). Fuji Triage Pink was applied to the apical part of the root in order to prevent leakage through the apex. The teeth were stored in an incubator (mco-18aic, Sanyo, Japan) for 1 week (at $37{ }^{\circ} \mathrm{C}, 100 \%$ relative humidity).

Group 1 and 2 received a minimal invasive post space preparation with a depth of $8 \mathrm{~mm}$, as measured from the CEJ on the buccal aspect of the tooth, but no post preparation drills recommended by the manufacturer were used in order to preserve the individual anatomy of the specimen teeth. Only the root canal filling was removed with size 3 Gates Glidden burs and ISO standard Hedstrom files leaving a minimum apical seal of $6-8 \mathrm{~mm}$ of gutta-percha in the canal. The No. 3 Gates Glidden bur was used on the full $8 \mathrm{~mm}$ length.

In Group 3.-5. the gutta-percha was only cut back $2 \mathrm{~mm}$ below the CEJ with an $0,1 \mathrm{~mm}$ diameter ball shaped carbide bur (H1SM.205.010,Gebr. Brasseler GmbH \& Co. KG, Lemgo, Germany) but no post space preparation was performed. After cutting back the gutta-percha, the orifice was sealed with resin modified glass ionomer cement (Fuji VIII, GC Europe, Leuven, Belgium).

All specimen received the same adhesive treatment. Prior to the adhesive treatment of the cavity and the root canal, enamel was acid-etched selectively with $37 \%$ phosphoric acid for $15 \mathrm{~s}$ and rinsed with water. The root canal and the coronal cavity were rinsed with 2 millilitres of water and dried with paper points and air. For bonding, a dual-cure one-step self-etch adhesive system (Gradia Core Self-Etching Bond, GC Europe, Leuven, Belgium) was used, according to the manufacturer's 
instructions using a microbrush-X disposable applicator (Pentron Clinical Technologies, LLC, USA). Excess adhesive was removed by suction drying (Evacuation Tip - Starryshine, Anaheim, CA, USA) within $0.5 \mathrm{~cm}$ from the occlusal cavity (without contact). Excess adhesive resin at the bottom of the canal was removed with a paper point. The adhesive was light-cured for $60 \mathrm{~s}$ using an Optilux 501 quartz-tungsten-halogen light-curing unit (Kerr Corp., Orange, CA, USA). The average power density of the light source, measured with a digital radiometer (Jetlite light tester; J. Morita USA Inc. Irvine, CA, USA) prior to the bonding procedure, was $840+/-26.8 \mathrm{~mW} / \mathrm{cm} 2$.

Five different techniques were used to restore the specimens (Figure 2):

Group 1: The teeth received a prefabricated, conventional FRC post (0,8 GC Fiber post, GC Europe, Leuven, Belgium). Before the adhesive treatment the conventional translucent FRC posts of $0.8 \mathrm{~mm}$ diameter (GC Fiber Post, GC Europe, Leuven, Belgium) was tried in and cut to a length $1 \mathrm{~mm}$ below the level of the occlusal cavity margins with a water-cooled diamond disc (Isomet 2000; Buehler Ltd., Lake Bluff, IL, USA) and cleaned with alcohol after try in. The posts received silanization of the surface (Ceramic Primer, GC Europe, Leuven, Belgium) following the manufacturer's recommendation. After silanization, the post surface was bonded with the same bonding agent used for the cavity. Luting of the posts and the core build-up was performed with a dual-cure resin composite core material (Gradia Core, GC Europe, Leuven, Belgium). Gradia Core was applied using its own automix cartridge with an 'elongation tip' for direct root canal application. After insertion of the post, 5 minutes of chemopolymerization time was provided to reduce polymerisation stress, then cement was polymerized with an Optilux 501 quartz tungstenhalogen light-curing unit for $60 \mathrm{~s}$ from each side (a total of $240 \mathrm{~s} /$ tooth). The outlines of the restoration were finished with dental composite (G-aenial Posterior P-JE, GC Europe, Leuven, Belgium).

Group 2: The teeth were reconstructed with a novel method of building a direct layered fiberreinforced composite post and core (DLFRC post and core) from SFRC (EverX Posterior, GC Europe, Leuven, Belgium). The DLFRC post and core was horizontally layered in 1-2 mm segments. An increment of SFRC was packed to the apical portion of the post space using a microbrush-X disposable applicator (Pentron Clinical Technologies, LLC, USA). A light transmitting FRC post (0,8 GC Fiber post, GC Europe, Leuven, Belgium) was inserted into the post space in order to aid the transmission of the light to the apically positioned layers. The "light transmitting" post was withdrawn with 0,5-1 $\mathrm{mm}$ from the surface of the uncured SFRC layer not to 
Figure2. Restored study groups, layering concepts and restorative materials applied.
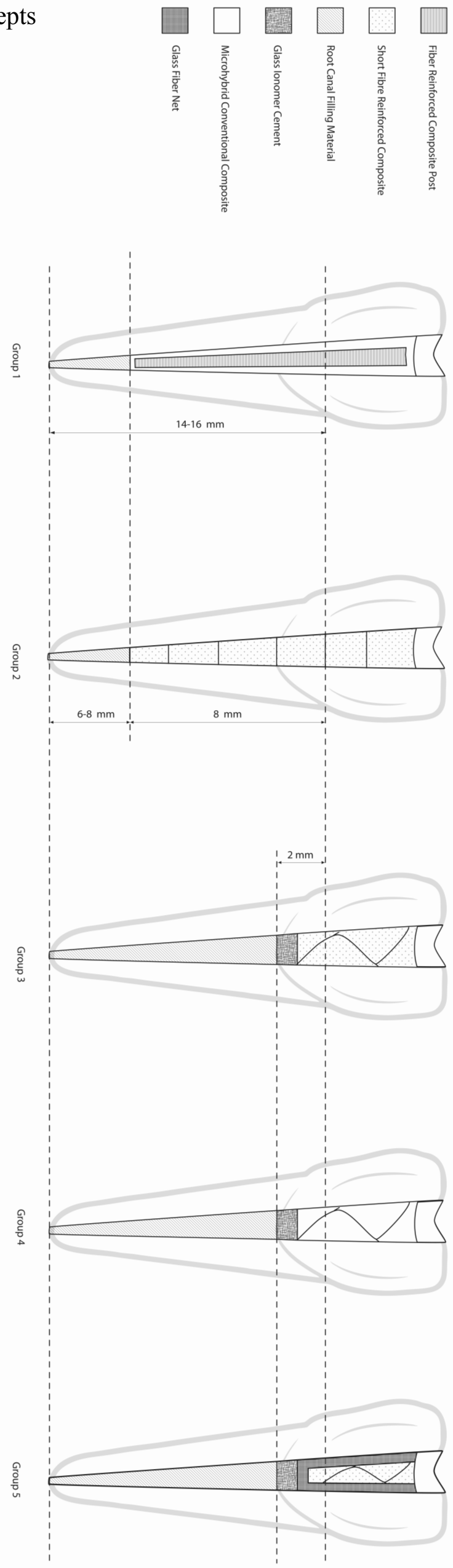
have direct contact with it.

After each layer 80 seconds of light curing through the fiber post was carried out. After incrementally filling the root canal to the level of the CEJ with repeating the previously described procedure, SFRC was layered in the coronal cavity until $1 \mathrm{~mm}$ below the margin of the occlusal cavity in a concave shape. Each increment was light cured from the occlusal surface for 40 seconds. The outlines of the restoration were finished with dental composite (G-aenial Posterior P-JE, GC Europe, Leuven, Belgium).

Group 3: The cavities were restored with SFRC material applied in an oblique incremental technique. The material was placed in consecutive $2 \mathrm{~mm}$ thick increments. Each increment was light cured from the occlusal surface for 40 seconds. The last $1 \mathrm{~mm}$ thick occlusal layer was composite material (G-aenial Posterior PJ-E, GC Europe, Leuven, Belgium) covering the SFRC.

Group 4: The cavities were restored with micro hybrid composite restorative material (G-aenial Posterior PJ-E, GC Europe, Leuven, Belgium) applied with an oblique incremental technique. The material was placed in consecutive $2 \mathrm{~mm}$ thick increments. Each increment was light cured from the occlusal surface for 40 seconds.

Group 5: The cavity walls were coated with flowable composite (G-aenial Flo, GC Europe, Leuven, Belgium)and before curing, a piece of pre-impregnated glass fiber net (Everstick net, GC Europe, Leuven, Belgium) (10 mm long, $3 \mathrm{~mm}$ width) was cut and embedded inside the flowable composite first in buccal to lingual, then a mesial to distal direction. After curing for 40s, another glass fiber band was adapted to the walls circumferentially, forming the FRC "box". The remaining central part of the cavity was restored with SFRC and a final layer of composite as described in Group 3.

Finally for all specimens glycerine gel (DeOx Gel, Ultradent Products Inc., Orange, CA, USA) was applied and final polymerization from each side for 40 seconds was performed.The restorations were finished with a fine granular diamond burr (FG 7406-018, Jet Diamonds, USA and FG 249F012, Horico, Germany) and aluminum oxide polishers (OneGloss PS Midi, Shofu Dental GmbH, Ratingen, Germany).

After the restorative procedures, the specimens were stored in physiological saline solution (Isotonic Saline Solution 0.9\% B. Braun, Melsungen, Germany) in an incubator (mco-18aic, Sanyo, 
Japan) for 1 week (at $37^{\circ} \mathrm{C}, 100 \%$ humidity) before the fracture strength test. Prior to embedding, the root surface of each tooth was coated with a layer of liquid latex separating material (RuberSep, Kerr, Orange, CA, USA) to simulate the periodontal ligament [30]. Specimens were embedded in methacrylate resin (Technovit 4004, Heraeus-Kulzer) at $2 \mathrm{~mm}$ from the CEJ to simulate the bone level. After embedding, all specimens were immediately subjected to a fracture resistance test using a universal loading device (5848 MicroTester1, Instron, Norwood, MA, USA). Each test was performed at a cross-head speed of $0.5 \mathrm{~mm} / \mathrm{min}$ and load was applied at $45^{\circ}$ using a $4.8 \mathrm{~mm}$ diameter stainless-steel ball-shaped stylus positioned to the central groove of the tooth providing 2 contacts with the triangular ridges and one with the more dominant marginal ridge. The maximum failure load was recorded in Newton's $(\mathrm{N})$.

A force vs. extension curve was dynamically plotted for each tooth.

After mechanical testing, the specimens were examined for fracture patterns. According to Scotti and co-workers, distinction was made between restorable or non-restorable fractures under optical microscope with a two-examiner agreement. A restorable fracture is above the CEJ, meaning that in case of fracture, the tooth can be restored, while a non-restorable fracture extends below the CEJ and the tooth is likely to be extracted (46).

Statistical analysis was conducted with SPSS 22.0 (IBM, USA). As the data was not normally distributed in all groups, the comparisons were performed with Kruskal-Wallis ANOVA with DunnBonferroni post-hoc pairwise comparisons. The level of significance was set at $\mathrm{p}<0.05$.

\subsection{Restoration of endodontically treated premolar teeth without ferrule effect}

The goal of the present in vitro study was to determine and compare the fracture resistance and fracture patterns of endodontically treated premolar teeth restored with different FRC posts in different configurations. The null hypotheses were the following: 1.The fracture resistance of the teeth restored with single or multiple posts would not be different. 2. The application of more elastic posts would not result in more favourable fracture patterns.

Fifty upper premolar teeth extracted for periodontal or orthodontic reasons were selected for this study. The inclusion criteria were absence of caries or root cracks, no previous endodontic treatment, no posts or crowns, no resorption and the absence of lateral canals. Furthermore, buccolingual and mesiodistal radiographs of all teeth were taken and examined to evaluate root integrity and the number of canals present. To standardise procedures and materials, all teeth used in 
this study had 1 root canal in each root with a curvature of less than $5^{\circ}$, evaluated by Schneider's technique (14), and root length of $15+/-1 \mathrm{~mm}$ and rather similar mesiodistal and buccolingual dimensions $(+/-10 \%)$ were selected.

The freshly extracted teeth were immediately placed in $5.25 \% \mathrm{NaOCl}$ for 5 minutes and then stored in $0.9 \%$ saline solution at room temperature. The teeth were used within 6 months after the extraction. During specimen preparation, the soft tissue covering of the root surface was removed with hand scalers.

Before root canal treatment, all crowns were sectioned at the level of the CEJ perpendicular to the longitudinal axis, using a slow-speed, water-cooled diamond disc (40000 rpm).

At the beginning of the root canal treatment the working length was established using a direct method, by subtracting $1 \mathrm{~mm}$ from the actual root length determined by introducing a no. $10 \mathrm{~K}$-file (Maillefer-Dentsply, Ballaigues, Switzerland) until it was visible through the apical foramen. A crown down technique was used for instrumentation with Gates Glidden (Union Broach, York, PA) \#2 to \#4 drills and then the canals were instrumented using rotary ProTaper files (Dentsply, Maillefer, Ballaigues, Switzerland). The series of the ProTaper system (S1, S2, F1, F2, F3) was used for the preparation at the working length.

Irrigation was performed after every change of instrument with 2 millilitres of $2.5 \% \mathrm{NaOCl}$ solution and the canal space was filled with irrigant during the instrumentation phase. A root canal lubricant (Glyde, Dentsply-Maillefer, Konstanz, Germany) was only used during the shaping of the coronal third. After shaping and cleaning, the roots were dried with $96 \%$ alcohol and paper points. Root canal filling was performed by matched-single-cone obturation with a master cone (F3 gutta-percha, Maillefer-Dentsply, Ballaigues, Switzerland) matching the final instrument used for preparation and sealer (AH plus; Dentsply De Trey GmbH, Konstanz, Germany). The root access was temporarily filled with Clearfil SE Bond and Clearfil AP-X (Kuraray, Tokyo, Japan). The same composite was applied to the apical part of the root in order to prevent leakage through the apex. The teeth were then stored in an incubator (mco-18aic, Sanyo, Japan) for 1 week (at $37{ }^{\circ} \mathrm{C}, 100 \%$ relative humidity).

After 1 week of incubation, post space was prepared in the root portions of the teeth with a depth of $10 \mathrm{~mm}$, as measured from the CEJ on the buccal aspect of the tooth, but no post space preparation drill was used so that the individual anatomy could be preserved. Only the root canal filling was removed with size 3 Gates Glidden burs and ISO standard Hedstrom files, leaving a minimum apical seal of 4-6 mm of gutta-percha in the canal. 
For the restorations, two different types of FRC posts were used: a prefabricated, "rigid" conventional FRC post (0,8 GC Fiber Post, GC Europe, Leuven, Belgium) and an elastic FRC post (0,9 EverStick POST, GC Europe, Leuven, Belgium).

The conventional translucent FRC posts of $0.8 \mathrm{~mm}$ diameter (Fiber Post) were tried in and cleaned with alcohol afterwards. The posts did not receive any surface treatment. The elastic FRC posts were handled according to the manufacturer's instructions, with sterile tweezers. Regardless of the exact type, the main posts were placed in a way that $5.0 \mathrm{~mm}$ was left above the level of decoronation, and $10.0 \mathrm{~mm}$ was inserted into the root canal. This way, a uniform $15.0 \mathrm{~mm}$ fiber length was achieved.

The teeth were randomly distributed in 5 study groups, each group consisting of 10 teeth.

Group 1 received one single conventional FRC post $(0.8 \mathrm{~mm})$. Group 2 received one main conventional FRC post and one collateral post ( $0.8 \mathrm{~mm}$ both) using a "multi-post technique". The collateral post was inserted next to the main post as apically as possible without causing manually perceivable stress but it was always deep enough to wedge the main post in the canal. Group 3 received one single elastic FRC post $(0.9 \mathrm{~mm})$. According to the manufacturer's instructions, the post was inserted into the root canal, and adapted to its form. Once adapted, the post was removed from the root canal with a needle-nose plier and light cured for 40 seconds so that it would retain the shape of the canal. Group 4 received one main elastic FRC post and one elastic collateral post (0.9 mm both) using a multi-post technique. The collateral post was inserted next to the main post as apically as possible without causing manually perceivable stress. The posts were removed as one unit from the root canal with a needlenose plier and then light cured for 40 seconds maintaining their position together in the canal. Group 5 received as many elastic FRC posts $(0.9 \mathrm{~mm})$ as possible bundled according to the thickness of the root canal using the lateral condensation method described by Hatta and co-workers (47). These posts were gently removed as one unit with a needlenose plier from the root canal, and then light-cured for 40 seconds. It was confirmed in all cases that the elastic FRC posts were repositioned to their original position into the canal after lightcuring. If resistance was met, the post surface was adjusted using carborundum point.

During the luting procedures all groups received the same adhesive treatment by the same trained operator who completed a three year specialisation in restorative dentistry.

For bonding, a dual-cure one-step self-etch adhesive system (Gradia Core Self-Etching Bond, GC Europe, Leuven, Belgium) was used, according to the manufacturer's instructions. Luting of the posts and the core build-up was performed with a dual-cure resin composite core material (Gradia Core, GC Europe, Leuven, Belgium). Gradia Core was applied using its own automix cartridge with 
an 'elongation tip' for direct root canal application. After the insertion of the post(s), the composite core material was polymerised from the top of the post with an Optilux 501 quartz-tungsten-halogen light-curing unit for $60 \mathrm{~s}$ from each side (a total of $240 \mathrm{~s} /$ tooth).

In order to ensure the uniformity of the specimens, the composite resin core build-ups were standardised using cellulite core-forming matrices of the same size. These matrices were fabricated as vacuum formed foils by a dental technician modelled on a healthy premolar tooth, which was previously prepared for a crown with a one millimetre shoulder. The core build-up was prepolymerised for 20 seconds, then glycerine gel (DeOx Gel, Ultradent Products Inc., Orange, CA) was applied and final polymerisation was performed from each side for $40 \mathrm{~s}$ with an Optilux 501 quartz-tungsten-halogen light-curing unit. After the cementation procedures, the specimens were stored in physiological saline solution (Isotonic Saline Solution 0.9\% B. Braun, Melsungen, Germany) in an incubator (mco-18aic, Sanyo, Japan) for 1 week (at $37^{\circ} \mathrm{C}, 100 \%$ humidity) before the fracture test. The specimens were embedded as described by Frater et al.(48).

After embedding, all specimens were immediately subjected to a fracture resistance test using a universal loading device (5848 MicroTester1, Instron, Norwood, MA, USA). Each test was performed at a cross-head speed of $0.5 \mathrm{~mm} / \mathrm{min}$. Load was applied at $45^{\circ}$ to the long axis of the tooth by adjusting a stainless steel ball shaped stylus to the occlusal surface of the abutment in a stabile position (49). The failure loads were recorded in Newtons (N). A force vs. extension curve was dynamically plotted for each tooth.

After the mechanical testing, the specimens were examined for fracture patterns. A distinction was made between restorable or non-restorable fractures, following the protocol proposed by Scotti et al., under optical microscope with a two-examiner agreement (46). A restorable fracture was recognised as one above the CEJ, meaning that in case of fracture, the tooth could be re-restored, while a non-restorable fracture extends below the CEJ and extraction is likely to become necessary (50). Statistical analysis was conducted with SPSS 17.0 (SPSS Inc., Chicago, USA). As the data were not normally distributed in all groups, the comparisons were performed with Kruskal-Wallis ANOVA with post-hoc pairwise comparisons. The level of significance was set at $\mathrm{p}<0.05$. 


\section{RESULTS}

4.1. Mechanical changes resulting from different size MOD cavity preparations

Median fracture strength values of the molar teeth restored with MOD adhesive restorations are presented in Figure 3.

Figure 3. Mean fracture strength and standard deviation of the tested groups.

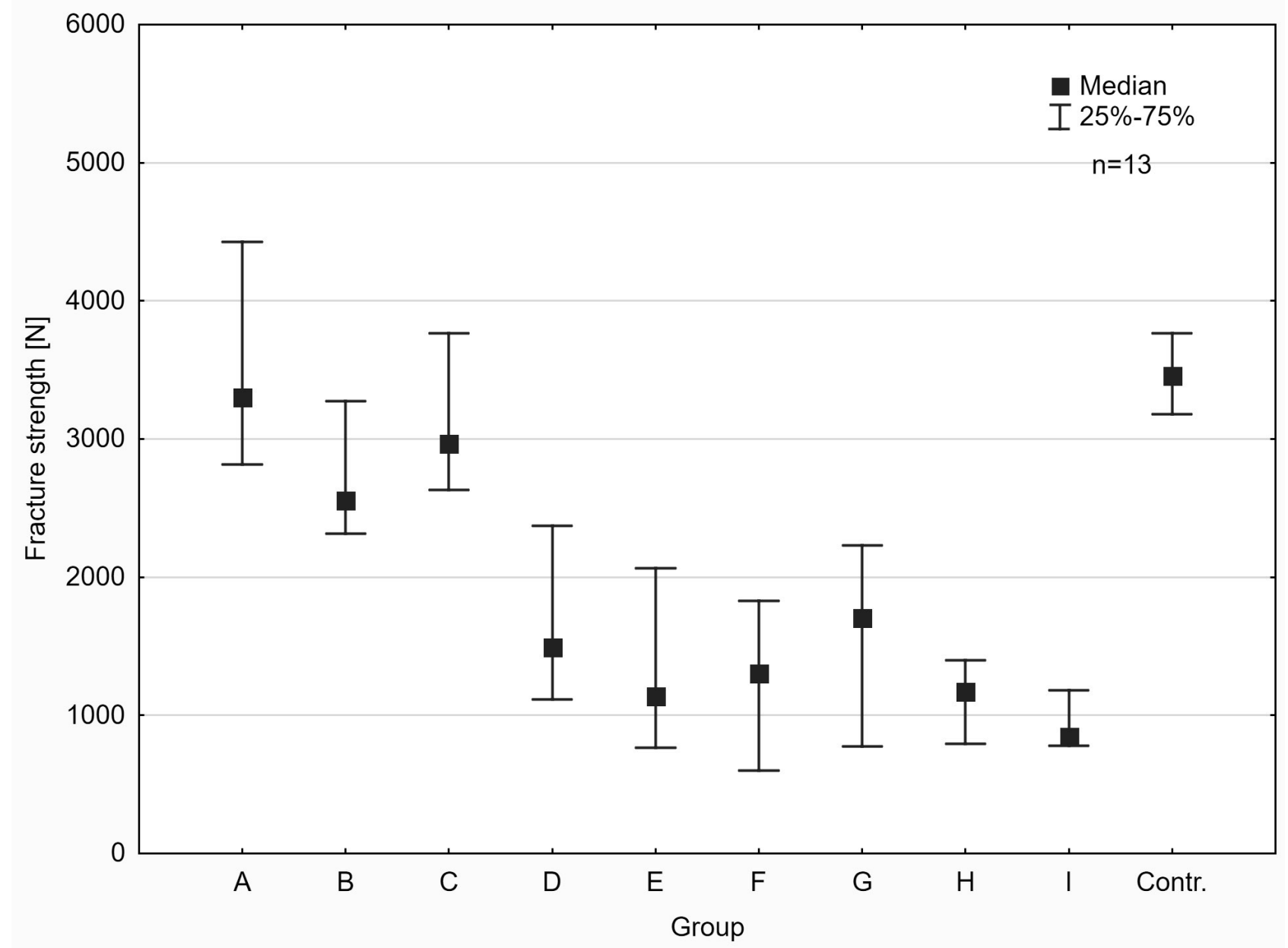

As the Kruskal-Wallis ANOVA indicated significant variance, post-hoc pairwise tests were performed. The pairwise tests indicated significant difference between the control group and all 5 and $7 \mathrm{~mm}$ groups (D,E,F,G,H,I). $3 \mathrm{~mm}$ groups (A,B,C) did not show significant difference as compared to the control. Significant difference was found between group A and all 5 and $7 \mathrm{~mm}$ groups (D,E,F,G,H,I). No significant differences were found between $3 \mathrm{~mm}$ cavity depth groups $(\mathrm{A}, \mathrm{B}, \mathrm{C})$. Comparing the 5 and $7 \mathrm{~mm}$ cavity depth groups, there was no statistical difference between any of them. The pairwise statistical analysis is detailed in Table 2. 


\begin{tabular}{|c|c|c|c|c|c|c|c|c|c|c|}
\hline Group & A & B & C & D & $E$ & $\mathbf{F}$ & G & $\mathbf{H}$ & I & Contr. \\
\hline A & & 1.000000 & 1.000000 & $0.029247 *$ & $0.000970 *$ & $0.002154 *$ & $0.021271 *$ & $0.000389 *$ & $0.000170 *$ & 1.000000 \\
\hline B & 1.000000 & & 1.000000 & 0.923576 & 0.072278 & 0.132891 & 0.732700 & $0.035687 *$ & $0.018728 *$ & 1.000000 \\
\hline C & 1.000000 & 1.000000 & & 0.300701 & $0.017307 *$ & $0.034044 *$ & 0.231264 & $0.007930 *$ & $0.003899 *$ & 1.000000 \\
\hline $\mathrm{D}$ & $0.029247 *$ & 0.923576 & 0.300701 & & 1.000000 & 1.000000 & 1.000000 & 1.000000 & 1.000000 & $0.008013 *$ \\
\hline$E$ & $0.000970 *$ & 0.072278 & $0.017307 *$ & 1.000000 & & 1.000000 & 1.000000 & 1.000000 & 1.000000 & $0.000203 *$ \\
\hline $\mathrm{F}$ & $0.002154 *$ & 0.132891 & $0.034044 *$ & 1.000000 & 1.000000 & & 1.000000 & 1.000000 & 1.000000 & $0.000478 *$ \\
\hline G & $0.021271 *$ & 0.732700 & 0.231264 & 1.000000 & 1.000000 & 1.000000 & & 1.000000 & 1.000000 & $0.005670 *$ \\
\hline $\mathrm{H}$ & $0.000389 *$ & $0.035687 *$ & $0.007930 *$ & 1.000000 & 1.000000 & 1.000000 & 1.000000 & & 1.000000 & $0.000076 *$ \\
\hline 1 & $0.000170 *$ & $0.018728 *$ & $0.003899 *$ & 1.000000 & 1.000000 & 1.000000 & 1.000000 & 1.000000 & & $0.000032 *$ \\
\hline Contr. & 1.000000 & 1.000000 & 1.000000 & $0.008013 *$ & $0.000203 *$ & $0.000478 *$ & $0.005670 *$ & $0.000076 *$ & $0.000032 *$ & \\
\hline
\end{tabular}

Table 2 - Kruskal-Wallis ANOVA pairwise statistical analysis $(\mathrm{p}<.0000)$. Significance indicated with * symbol.

The null hypothesis was rejected as fracture strength of groups D,E,F,G,H,I where significantly lower than that of the control group.

4.2. Restoration of endodontically treated premolar teeth with occlusal cavity preparation

Table 3 summarizes the fracture thresholds for the premolar study groups with only an occlusal access cavity. The control group exhibited the highest fracture resistance. The application of the DLFRC post and core technique yielded the highest fracture resistance among the restored groups. The fracture resistance of Group 2 (DLFRC post and core group) did not differ significantly $(p=1.000)$ from the intact teeth (control group). The rest of the groups proved to be significantly different from the control group in terms of fracture resistance. There was no statistically significant difference when comparing the restored groups regarding their fracture resistance. Therefore, the null hypothesis regarding fracture resistance was rejected. 
In terms of fracture patterns, the tested groups 2,3,4,5 were identical (Table 4.). Only the control group and the FRC post showed dominantly repairable fractures. Therefore, the null hypothesis regarding fracture patterns was also rejected.

\begin{tabular}{|c|c|c|c|c|c|c|}
\hline Group & $\begin{array}{c}\text { Sig. } \\
\text { compared to } \\
\text { Control } \\
\text { (p, post-hoc) }\end{array}$ & $\mathbf{N}$ & $\begin{array}{l}\text { Minimum } \\
\text { (Newtons) }\end{array}$ & $\begin{array}{l}\text { Maximum } \\
\text { (Newtons) }\end{array}$ & $\begin{array}{c}\text { Mean } \\
\text { (Newtons) }\end{array}$ & $\begin{array}{c}\text { Std. } \\
\text { Deviation }\end{array}$ \\
\hline Control & - & 12 & 605.85 & 1205.83 & 922.34 & 189.21 \\
\hline Group 1 & .005 & 12 & 208.28 & 802.61 & 501.30 & 186.65 \\
\hline Group 2 & 1.000 & 12 & 352.85 & 1171.19 & 727.98 & 287.37 \\
\hline Group 3 & .009 & 12 & 123.59 & 865.93 & 511.61 & 225.20 \\
\hline Group 4 & .005 & 12 & 216.67 & 748.44 & 456.24 & 189.75 \\
\hline Group 5 & .023 & 12 & 303.64 & 682.83 & 536.35 & 126.41 \\
\hline
\end{tabular}

Table 3.: Fracture thresholds of studied groups and the significance of their difference compared to the control group. Group 1: glass fibre- reinforced post; Group 2: direct layered glass fibre-reinforced composite core; Group 3: SFRC applied by an oblique incremental technique; Group 4: obliquely layered conventional composite; Group 5: torsion box with FRC net. As there was no significant difference among the restored groups in this respect, significances are shown as compared to the controls only.

\begin{tabular}{|l|c|c|c|c|c|c|}
\hline & Control & Group 1 & Group 2 & Group 3 & Group 4 & Group 5 \\
\hline Reparable & 0.66 & 0.58 & 0.33 & 0.33 & 0.33 & 0.33 \\
\hline Irreparable & 0.33 & 0.42 & 0.66 & 0.66 & 0.66 & 0.66 \\
\hline
\end{tabular}

Table 4.: Fracture patterns. The numbers indicate relative frequencies ( $\mathrm{n}=12$ in each group). Group 1: glass fibre- reinforced post; Group 2: direct layered glass fibre-reinforced composite core; Group 3: SFRC applied by an oblique incremental technique; Group 4: obliquely layered 
4.3. Restoration of endodontically treated premolar teeth without ferrule effect

The mean fracture resistance $(\mathrm{N})$ and the SD for each of the five premolar groups without ferrule are presented in Figure 4. As the table shows, group 4 (containing one main and one elastic FRC post) showed the highest average fracture resistance, however, this difference was only significant compared to group 1 (containing a single conventional FRC post) $(\mathrm{p}=0.027)$. Group 2 (containing one main and one collateral conventional FRC post) showed significantly higher fracture resistance compared to group $1(\mathrm{p}=0.038)$. However, neither of the multi-post techniques yielded significantly better results than the single elastic post technique. According to the findings null hypotheses 1 . was accepted as multiple post restorations investigated did not show significantly higher fracture resistance in all set-ups.

There was no statistically significant difference when comparing the rest of the groups regarding their fracture resistance. In terms of fracture patterns, the tested groups were almost perfectly identical (see Table 5,6.). Therefore, the null hypothesis 2, regarding fracture patterns was accepted. The application of more elastic posts would not result in more favourable fracture patterns.

Figure 4.: Fracture loads in the different study groups (mean $\pm \mathrm{SD}$ ). A: multiple elastic posts B: multiple conventional FRC posts C: single elastic post D: single conventional FRC post E: lateral condensation with elastic posts. ${ }^{*}$ significant difference at the level $\mathrm{p}<0.05$. (See also table)

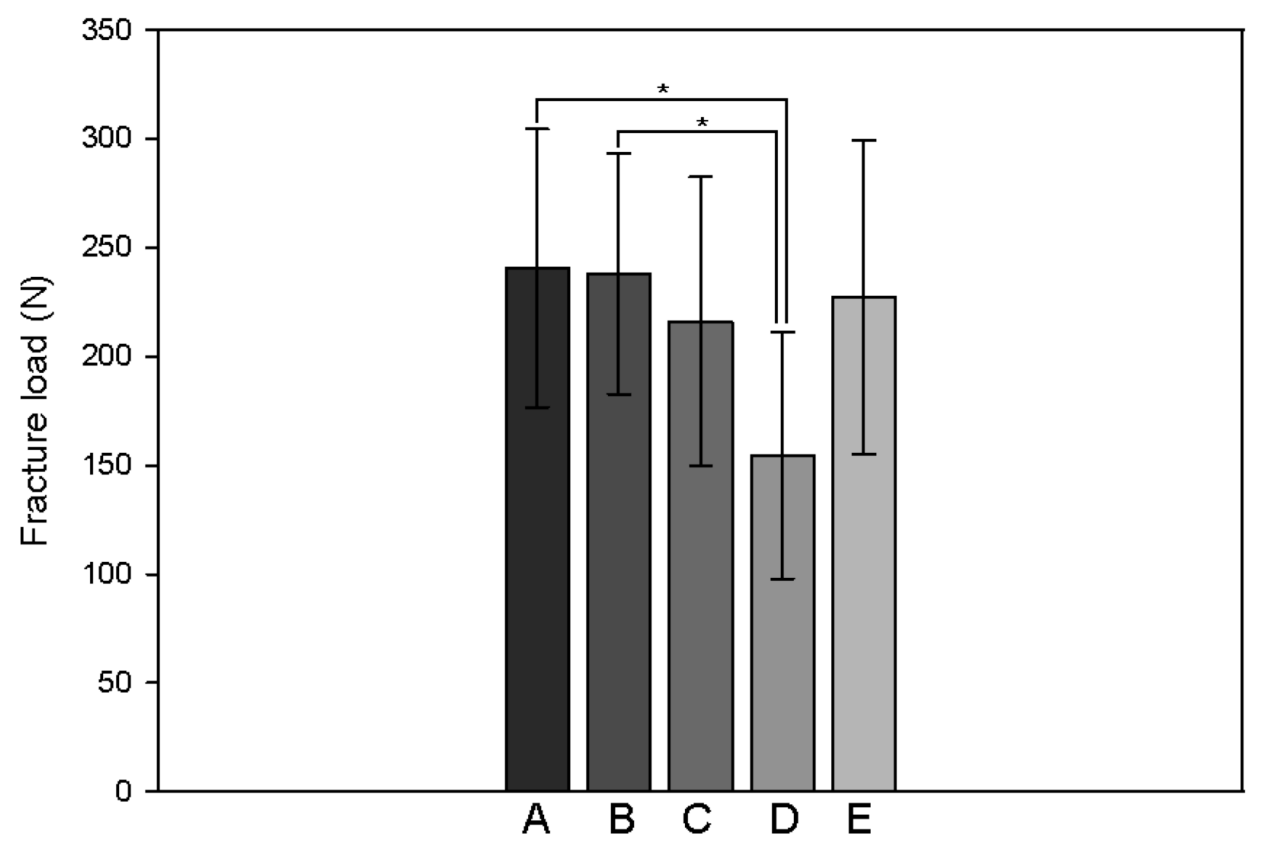




\begin{tabular}{|l|c|c|c|c|c|}
\hline Group & N & Mean & Minimum & Maximum & SD \\
\hline Multiple elastic posts & 10 & 240.64 & 146.88 & 330.12 & 63.85 \\
\hline Multiple conventional FRC posts & 10 & 237.99 & 165.93 & 361.63 & 55.26 \\
\hline Single elastic post & 10 & 215.98 & 57.22 & 312.04 & 66.33 \\
\hline Single conventional FRC post & 10 & 154.50 & 65.99 & 271.22 & 56.63 \\
\hline Lateral condensation with elastic posts & 10 & 227.30 & 142.82 & 367.88 & 72.20 \\
\hline
\end{tabular}

Table 5.: Descriptive statistics of the fracture loads measured in the different groups. The values are given in Newtons.

\begin{tabular}{|l|c|c|}
\hline & Restorable & Non-restorable \\
\hline Multiple posts/elastic & $7(70 \%)$ & $3(30 \%)$ \\
\hline Multiple posts/conventional & $7(70 \%)$ & $3(30 \%)$ \\
\hline Single post/elastic & $7(70 \%)$ & $3(30 \%)$ \\
\hline Single post/conventional & $7(70 \%)$ & $3(30 \%)$ \\
\hline Lateral condensation/elastic & $6(60 \%)$ & $4(40 \%)$ \\
\hline
\end{tabular}

Table 6.: The distribution of fracture patterns among the study groups. 


\section{DISCUSSION}

In the investigations of this thesis the two methods where utilised to examine the mechanical properties of the specimens.

Static load to fracture is considered to be one of the effective means to study the mechanical properties of posterior teeth despite the fact that functional loads are much higher and load patterns do not resemble cyclic load of physiologic mastication(51). Using a $6 \mathrm{~mm}$ steel sphere for loading is a common choice for the posterior region $(52,53)$. The geometry of the sphere provides possibility for tripodistic contacts on the triangular ridges of the posterior teeth involving the functional and non-functional cusps, providing similar conditions to natural occlusion. For molars it was considered that axial force exertion is the most clinically relevant, since a managed occlusal scheme will exhibit load on the molars in maximal intercuspation thus providing a vertical load on the coronal structures. For the premolar teeth a 45 degree load was applied as compared to the long axis of the tooth. An oblique load appears to be the worst case scenario in terms of the fracture resistance of ETT as described by Wandscher and co-workers (49). Applying this angle of force to teeth places significant stress on the cervical aspect of the restored tooth (54) and heavy shear forces on the post / luting agent / radicular dentine interfaces. This should represent a worstcase occlusal loading scenario for these teeth and acid-test the integrity of the tested restorations and tooth structure.

Fracture patterns where examined and categorised and restorability was assessed according to Scotti et al (46). Examinations were done under an optical microscope with a twoexaminer agreement. A restorable fracture is above the CEJ, clinically meaning that the tooth can be restored, while a non-restorable fracture extends below the CEJ clinically resulting in extraction of the tooth unless surgical or orthodontic procedures are applied.

\section{Marginal Ridges}

If an MOD cavity is prepared in a molar tooth, both marginal ridges are lost and the fracture resistance of the tooth is significantly reduced (55-57). It is widely accepted and published that the defining measure of assessing the stability of the cusps in such cases is the thickness of the cavity walls $(9,10,58)$. According to several authors if the cavity wall is thicker than $2-2.5 \mathrm{~mm}$ the cusps are considered stabile and if thinner than this measure they are considered to be fragile. The results of this thesis suggest that cavity wall thickness is not a major influencing factor of cusp stability. Comparing $3.5 \mathrm{~mm}, 2.5 \mathrm{~mm}$ and $1.5 \mathrm{~mm}$ cavity wall thickness in case of the 3,5 or the 7 
mm cavity depth groups, mechanically similar behaviour was measured after being restored with a conventional dental composite. In this thesis reducing only the wall thickness, without changing the depth of the cavity, did not cause a significant reduction in fracture strength. $3 \mathrm{~mm}$ can be considered a safe cavity depth for adhesive direct restorations. This is in accordance with Frater et al. who found that when restoring shallow MOD cavities with direct techniques using oblique layering, there was no significant difference between the restored groups and the intact control group (48). These findings do not support the findings of S. Batalha-Silva et al. (50), who concluded that $5 \mathrm{~mm}$ deep cavities could safely be restored with direct techniques. These results rather suggest that a cavity of 5mm depth is already in the "danger zone" when talking about direct composite restorations without cusp coverage. From the results it seems that cavity wall thickness is only secondary to cavity depth in molar MOD cavities in terms of fracture strength, as the change in cavity wall thickness did not lead to a significant difference neither between the groups in the "safety zone" nor between the "danger zone" groups. Within the limitations of this study, this leads us to the conclusion that when the fracture safety of a cavity for a direct restoration without cusp coverage is to be determined, cavity depth is the primary determining factor. This is in accordance with the results of Morin et al. and Manhart et al. who found that the depth of the preparation is the most critical factor in terms of future fractures $(59,60)$. Since groups with cuspal coverage restorations were not included in this study, the results do not offer direct guidance on cuspal coverage. Also, since the cavities were only restored with a conventional adhesive direct composite restoration, the results cannot be extrapolated to situations when, fiber-reinforced materials are used. However if the cavity depth of molar teeth with an MOD cavity reaches or exceeds $5 \mathrm{~mm}$, cusp coverage with a direct or indirect adhesive restoration could be taken into consideration as a safety measure. Future investigations with similar methodology - involving cusp coverage with direct and indirect methods - need to be conducted to further our understanding on the effect of MOD cavity dimensions on the restorability of molar teeth and limitations of adhesive restorations.

There is no statistical difference between the 5 and $7 \mathrm{~mm}$ results so endodontically treated molars with an MOD cavity are not significantly weaker mechanically as compared to molars with a vital pulp and intact pulp space with a $5 \mathrm{~mm}$ deep MOD cavity. Therefore root canal treated molars are not weaker or more fragile by nature. They are weaker as a result of tissue loss in the biomechanically sensitive anatomic locations such as the marginal ridges. 
Pericervical Dentine Reinforcement

For the isolated examination of the effect of PCD loss and possible options of restoring the function of PCD, premolar teeth with a single occlusal access cavity where selected. It was the intention of the authors to exclude the mechanical influencing effect of the loss of marginal ridges and solely concentrate on the pericervical area. In premolar teeth the cervical part is the thinnest and most vulnerable anatomic feature as a result of an unfavorable anatomy in crown volume and crown to root proportion(61).Therefore reducing the PCD of these teeth is thought to have the most radical effect. This is underlined clinically since root canal treated premolars are susceptible to fracture (51, 62). Restoration of premolars with a glass fiber post does not protect them from fracture but it seems to prevent catastrophic fracture $(21,63)$. So a premolar tooth with an occlusal access cavity, intact marginal ridges and excess root canal preparation at the orifice of the canal and the coronal third is possibly a good model for examining the biomechanical effects of PCD loss.

In this thesis, endodontically treated premolars restored with an oblique layered occlusal composite restoration (Group 4) showed the lowest fracture resistance among all groups. This justifies the model as if no attempted restoration of the pericervical tissues was done, the restored tooth as a whole behaved in a mechanically inferior way and was significantly weaker than the natural control group. However these restorations where not statistically significantly weaker than the other types of tested restorations. This supports the findings of some authors, who claim that posterior teeth with a single occlusal access preparation and no other structural loss may be restored without post with a conservative direct bonded restoration $(6,9,64,65)$. In this investigation a minimally invasive access was prepared, which could give explanation to these findings, since it is reported that additional tissue loss results in compromised structural integrity and as a result lower fracture resistance of root canal treated teeth $(1,62)$.

In the current investigation the group restored with obliquely layered SFRC (Group 3) reached higher fracture resistance figures compared to the ones restored with conventional composite (Group 4) or even the conventional FRC post group (Group 1), however, the difference was statistically not significant. This has been previously described in molar teeth with MOD cavities, where the SFRC restored groups yielded better results than the conventional composite restored ones, yet the difference was not significant (48).

The threefold usage of FRC net (FRC box) (Group 5) together with the SFRC restorative composite is aiming to reconstruct the integrity and strength of the opposing cavity walls. The values of the FRC box restorations showed an increase compared to Group 1, 3 and 4, this technique could also not emulate the values measured in case of sound premolar teeth. However in 
this study there seems to be a clear tendency of increasing fracture resistance values towards the use of individualized FRC materials compared to conventional techniques (composite restoration or FRC post placement). This observation is in accordance with the findings of Bijelic et al (66).

Prefabricated FRC posts suffer from 2 main shortcomings in clinical settings: Insufficient bonding of the interfaces $(14,32,67)$ and the fact that the post position is in the neutral axis of the root canal. Direct layering of SFRC into the root canal is intended to solve these drawbacks. Seyam et al. and other authors showed that a transparent post can transfer the light and aid the polymerization of composite resin in the root canal (68-70), enabling layering in the hollow root canal space. However, there are investigations to oppose this statement $(71,72)$. The DLFRC post and core technique (Group 2) produced the highest fracture resistance values among the restored groups in the present study. These results seem to be in accordance with Garoushi et al. showing that the thicker the applied SFRC restoration the greater the fracture resistance is (73). Although the numbers produced by group 2 were not significantly higher than the rest of the restored groups, a positive tendency could be visible with the utilisation of SFRC materials. Moreover, there was no statistically significant difference between the group 2 and the intact teeth. This result suggests a move towards a biomimetic restorative concept. It has to be noted that the reported advantages come at the price of increased application time and technically more demanding clinical procedure as compared to Group 1. Development of materials, instruments and light curing equipment specifically for such purposes could be promising and could resolve the main shortcomings of the DLFRC post and core method as described in this investigation.

Regarding fracture pattern, the tested groups were identical with dominantly unfavorable, irreparable fractures. Only the control group and Group 1 presented a shift towards favorable, repairable fractures. Therefore the null hypothesis regarding fracture pattern was rejected.

The DLFRC post and core technique according to the findings of this investigation might hold the potential of reinforcing the root and particularly the pericervical area, which is highly beneficial when shear forces are also present (f.e.: 45 degree loading). The DLFRC post and core concept theoretically could present a possibility to compensate for most of the known weaknesses of the presently accepted endo-restorative options with a not complicated, clinically feasible and reproducible methodology. 
Substituting the Prosthodontic Ferrule

Since the middle of the 17 th century when post borne restoration of non vital teeth was described, it is a basic goal of restorative treatments to reinforce and retain ETT in function. Post space preparation undermines the remaining tooth structure, which possibly increases the possibility of fracture and tooth loss $(74,75)$. Post placement should not be carried out at the cost of sacrificing radicular dentine $(22,24)$. Several publications seem to prove that up to $20 \%$ of ETT restored with a radicular post suffer a vertical fracture (76-81).

It is even bigger of a challenge to restore ETT which are missing a prosthodontic ferrule (82). In a non-ferrule situation there is not a currently known endo-restorative option that could yield a long term clinical result reproducibly (83). According to Nam et al, conventional fibre posts do not improve the fracture resistance of teeth without a dental ferrule (84). In this thesis premolar teeth without a ferrule where restored to crown abutment shape with different FRC post application techniques in order to distinguish which of them could be a mechanically more stabile solution in case of non-ferrule conditions.

Gates-Glidden burs where used to obtain minimally invasive post-space preparation by only removing guttapercha and root canal sealer, but not removing any sound dentine. This technique leads to individual post spaces. Which can not be filled with one single symmetric post, but multiple small diameter FRC posts or other means are needed. According to Sorensen et al. a the fracture resistance of restored teeth significantly increased when posts where adapted closely to the canal walls (85). Maceri and co-workers proved that a multi post technique may not only lead to better adaptation, but possibly reduces pull out risk and induces durability to long term cyclic loading (27). Therefore applying multiple posts in the same canal (multi-post technique) or using an individual post is aiming to achieve a better fit to the individual, preserved root canal anatomy and possibly enhancing long term clinical prognosis.

The results of this study appear to favour the use of multiple posts in the same root canal. Both multi-post techniques (rigid FRC (group 2.) and elastic FRC (group 4)) yielded significantly higher fracture resistance than the single post conventional FRC restoration (group 1)

It is interesting to note that neither of the two multi-post techniques yielded significantly different fracture resistance from the single elastic post technique. The non significance between the results can be explained by use of a minimally invasive post space preparation in case of using a single elastic post and a multi-post technique, since even a single elastic post can achieve a good fit, thus adequate stability in case of a preserved, relatively irregular root canal cross section. It is also noted that minimally invasive post space preparation is likely to preserve mass amount of PCD 
keeping the natural reinforcement of the tooth as compared to other techniques with an invasive post space preparation. Therefore the null hypothesis regarding fracture resistance was partially rejected (only for non-elastic FRC posts). A possible explanation is that the better adaptability of the particular type of elastic post used in this study was enough to make up for the disadvantages of using a single post only. However the limitations of this investigation cannot lead to this conclusion, so further studies on the adaptive properties of the elastic FRC posts are necessary.

There are several methods of creating individual root canal posts $(47,86-88)$. In this study the "lateral condensation method" of Hatta and colleagues was used (47). In the present study the individual posts (group 5) yielded better results than restoration with a single FRC post (groups 1 and 3). However, the difference did not reach the level of statistical significance. These results are in agreement with those of Hatta et al. (47) and Le Bell-Ronnlof et al. (34) in this respect.

Based on the results of this investigation, fracture resistances yielded by the individual post technique and the two multi-post techniques were not significantly different. The reason might be the minimally invasive post space preparation, as the number of posts insertable to approximately the same depth is reduced by the limited space. In this case the cement-glass fiber ratio of the single post techniques can be relatively similar to that of the multiple post techniques. However most likely the preservation of tooth structure is the key influencing factor of mechanical behaviour of ETT as supported by Wandscher et al. (49).

\section{Limitations}

In all three investigations of this thesis mechanical testing was carried out with a static "load to fracture" methodology. Cyclic loading of dental specimens and ageing prior to testing resemble the phisiological circumstances better. According to Taha et al, "In experimental studies, fracture resistance to static loading has been used as a measure of the effect of cavity preparation and/or restoration on tooth strength. Although the fracture load is typically much higher than functional occlusal loads, it is still a valid method for comparing restorative materials and different cavity designs" (51)

Non-ferrule conditions were tested without fabricating and cementing a crown on the prepared abutments. The decision to not use crowns in this study was based on the observations of a number of authors where subtle differences in post behaviour and performance may be masked when teeth are definitively restored (22, 89-92). Despite these recommendations, the lack of a crown makes it impossible to extrapolate the results of this investigation to a clinical situation and there is a need for further experiments to bridge this gap. 
In these investigations 10-12 specimens were prepared per group. By raising this number the level of significance could be better established and discrete differences among restorative techniques could be more pronounced. 


\section{CONCLUSION}

The investigations described in the thesis attempt to find a biomimetic rationale of restoring posterior teeth by the means of applying novel diagnostic measures and utilising new endo restorative techniques. Within the limitations of this thesis the following conclusions can be drawn:

Marginal ridges of molar teeth and PCD of premolar teeth are some of the key anatomic features to be preserved in order to maintain the biomechanical integrity of the posterior root canal treated teeth.

Molar teeth with a $3 \mathrm{~mm}$ or shallower MOD cavity are considered to be safely restorable with conventional adhesive restorations. Molar teeth with MOD cavities of $5 \mathrm{~mm}$ or deeper including endodontically treated molar teeth - are considered to be in the "danger zone" if placing adhesive composite restorations. In these situations cusp coverage should be considered. It is also understood that cavity wall thickness does not significantly influence fracture resistance in the described circumstances.

Natural premolar teeth exhibit higher fracture resistance then the ones that are endodontically treated through an occlusal access and restored except for the DLFRC post and core restored group. DLFRC post and core behaves mechanically similarly in the described conditions as the natural control tooth therefore it can be considered a biomimetic endo-restorative solution. In terms of fracture patterns conventional FRC posts exhibited more favourable fracture patterns then the other restored groups. The direct layered short fibre-reinforced post and core is a promising alternative to the currently accepted restorations of ETT, and as such should be further investigated.

Single rooted premolars restored in absence of a ferrule show significantly higher fracture resistance, when a multi post technique or a single elastic post is applied as compared to a conventional rigid single FRC post. Once utilizing a multipost technique the elasticity of the post did not yield any significant difference in the described circumstances. Single canal teeth restored with multiple posts achieved superior fracture resistance to teeth restored with single, conventional FRC posts. 


\section{ACKNOWLEDGEMENTS}

This thesis represents my utmost gratitude to all those special people who helped me on the way. Thankfully enough for my good fortune there are too many of them to mention. So for those most special individuals:

First of all I have to thank my friend, past student and current supervisor Dr. Márk Fráter. The fact that we made this happen together is amazing for both of us.

It would have never happened without the great mentors and colleagues who guided me and inspired me: Dr. Paul Gerloczy who guided my first steps as a proper restorative dentist; Dr. András Volom who taught me the first thoughts about biomechanics and fibre reinforcement; Prof. István Urbán who gives me the best possibility I could have dreamt of to clinically fulfil my potential and Prof. Pascal Magne who made me fall in love with biomimetic dentistry the first time I read his book. I also owe a lot to Prof. Katalin Nagy, Dr. Kinga Turzó, Prof. Francesco Mangani, Prof. Camillo D'Arcangelo, Prof. Simone Grandini, Dr. Gianfranco Politano, Dr. Jason Smithson, Dr. János Grosz, János Makó MDT, Dr. Petra Borbély, Dr. Attila Halász, Dr. Tamás Würsching, Dr. Ádám Lőrincz, Dr. Tibor Olasz, Dr. István Pelsőczy-Kovács, Dr. János Perényi, Dr. János Hoppenthaler, Dr, Márk Antal, Dr. Gábor Braunitzer and the late "Facebook Dental Friends" community.

Special thanks to my parents Dr. Mária "Babi" Faragó and Prof. Dr. Tamás Forster, for guiding me to always think critically, never accept the status quo and dare to dream. I hope for once you are proud.

Thank you Hanna and Ákos for loving me honestly like I was always there. One day when you read this I hope you are proud. I believe that both of you are exceptional. Always follow your heart as dad does. It will lead you to the best places.

Thank you to my brother Ádám Forster and my friends, Ákos Réder, Zsombor Holler, Dave Winkler, Krisztián Rózsa, Róbert Lengyel. I am so lucky to know you guys.

They say that behind every successful man there is a smart woman. I always had the privilege of having wonderful and smart women supporting me. Thank you for your belief Dr. Krisztina Ungvári.

And of course all my love and gratitude goes to the unbelievable and exceptional Dr. Lili Papp Fehérke.

"True success is reaching our potential without compromising our values." 


\section{REFERENCES}

1. Dietschi D, Duc O, Krejci I, Sadan A. Biomechanical considerations for the restoration of endodontically treated teeth: a systematic review of the literature--Part 1. Composition and microand macrostructure alterations. Quintessence Int. 2007 Oct;38(9):733-43.

2. Elderton RJ. Clinical studies concerning re-restoration of teeth. Adv Dent Res. 1990 Jun;4:4-9.

3. T.D. Larson, W.H. Douglas, R.E. Geistfeld. Effect of prepared cavities on the strength of teeth, Oper Dent 1981;6:2-5.

4. Tay FR, Pashley DH. Monoblocks in root canals: a hypothetical or a tangible goal. J Endod. 2007 Apr;33(4):391-8.

5. Rocca GT, Krejci I. Crown and post-free adhesive restorations for endodontically treated posterior teeth: from direct composite to endocrowns. Eur J Esthet Dent. 2013 Summer;8(2): 156-79.

6. Reeh ES, Messer HH, Douglas WH. Reduction in tooth stiffness as a result of endodontic and restorative procedures. J Endod 1989;15:512-6.

7. Magne P, Oganesyan T. Premolar cuspal flexure as a function of restorative material and occlusal contact location. Quintessence Int. 2009 May;40(5):363-70.

8. Lee MR, Cho BH, Son HH, Um CM, Lee IB. Influence of cavity dimension and restoration methods on the cusp deflection of premolars in composite restoration.

Dent Mater. 2007 Mar;23(3):288-95.

9. Scotti N, Rota R, Scansetti M, Paolino DS, Chiandussi G, Pasqualini D, Berutti E. Influence of adhesive techniques on fracture resistance of endodontically treated premolars with various residual wall thicknesses. J Prosthet Dent. 2013 Nov;110(5):376-82.

10. Deliperi S, Bardwell DN. Multiple cuspal-coverage direct composite restorations: functional and esthetic guidelines. J Esthet Restor Dent. 2008;20(5):300-8; discussion 309-12.

11. Clark D, Khademi J. Modern molar endodontic access and directed dentin conservation. Dent Clin North Am. 2010 Apr;54(2):249-73.

12. Hargreaves K, Berman L. Cohen's Pathways of the Pulp 11th edition. Elsevier Publishing, 2nd October 2015. Chapter 6.

13. Fragou T, Tortopidis D, Kontonasaki E, Evangelinaki E, Ioannidis K, Petridis H, Koidis P. The effect of ferrule on the fracture mode of endodontically treated canines restored with fibre posts and metal-ceramic or all-ceramic crowns. J Dent. 2012 Apr;40(4):276-85. 
14. Chieruzzi M, Pagano S, Pennacchi M, Lombardo G, D'Errico P, Kenny JM. Compressive and flexural behaviour of fibre reinforced endodontic posts. J Dent. 2012 Nov;40(11):968-78

15. Fernandes AS, Shetty S, Coutinho I. Factors determining post selection: a literature review. J Prosthet Dent 2003;90:556-62.

16. Nayyar A, Walton RE, Leonard LA. An amalgam coronal-radicular dowel and core technique for endodontically treated posterior teeth. J Prosthet Dent. 1980 May;43(5):511-5.

17. Sorensen JA, Martinoff MD. Intracoronal reinforcement and coronal coverage: a study of endodontically treated teeth. J Prosthet Dent 1984;51:780-4.

18. Lassila LVJ, Tanner J, Le Bell AM, Narva K, Vallittu PK. Flexural properties of fiber reinforced root canal posts. Dent Mater 2004;20:29-36.

19. Drummond JL, Bapna MS. Static and cyclic loading of fiber-reinforced dental resin. Dent Mater 2003;19:226-31.

20. Mannocci F, Sherriff M, Watson TF. Three-point bending test of fiber posts. J Endod 2001;27:758-61.

21. Zicari F, Van Meerbeek B, Scotti R, Naert I. Effect of fibre post length and adhesive strategy on fracture resistance of endodontically treated teeth after fatigue loading. J Dent. 2012 Apr;40(4): $312-21$.

22. Meyenberg K. The ideal restoration of endodontically treated teeth - structural and esthetic considerations: a review of the literature and clinical guidelines for the restorative clinician. Eur J Esthet Dent. 2013 Summer;8(2):238-68. Review.

23. Al-Omiri MK, Mahmoud AA, Rayyan MR, Abu-Hammad O. Fracture resistance of teeth restored with post-retained restorations: an overview. J Endod. 2010 Sep;36(9):1439-49.

24. Paolone G, Saracinelli M, Devoto W, Putignano A. Esthetic direct restorations in endodontically treated anterior teeth. Eur J Esthet Dent. 2013 Spring;8(1):44-67.

25. Aurélio IL, Fraga S, Rippe MP, Valandro LF. Are posts necessary for the restoration of root filled teeth with limited tissue loss? A structured review of laboratory and clinical studies. Int Endod J. 2015 Sep 1.

26. Nicola S, Alberto F, Riccardo MT, Allegra C, Massimo SC, Damiano P, Mario A, Elio B. Effects of fiber-glass-reinforced composite restorations on fracture resistance and failure mode of endodontically treated molars. J Dent. 2016 Oct;53:82-7.

27. Maceri F, Martignoni M, Vairo G. Mechanical behaviour of endodontic restorations with multiple prefabricated posts: a finite-element approach. J Biomech. 2007;40(11): 2386-98. 
28. Aksornmuang J, Nakajima M, Senawongse P, Tagami J. Effects of C-factor and resin volume on the bonding to root canal with and without fibre post insertion. J Dent. 2011 Jun;39(6):422-9. 29. Albashaireh ZS, Ghazal M, Kern M. Effects of endodontic post surface treatment, dentin conditioning, and artificial aging on the retention of glass fiber-reinforced composite resin posts. J Prosthet Dent. 2010 Jan;103(1):31-9.

30. Bouillaguet S, Troesch S, Wataha JC, Krejci I, Meyer JM, Pashley DH. Microtensile bond strength between adhesive cements and root canal dentin. Dent Mater. 2003 May;19(3):199-205. 31. Silva NR, Castro CG, Santos-Filho PC, Silva GR, Campos RE, Soares PV, et al. Influence of different post design and composition on stress distribution in maxillary central incisor: finite element analysis. Indian Journal of Dental Research 2009;20:153-8.

32. Bell AM, Lassila LV, Kangasniemi I, Vallittu PK. Bonding of fibre-reinforced composite post to root canal dentin. J Dent. 2005 Aug;33(7):533-9.

33. Zicari F, De Munck J, Scotti R, Naert I, Van Meerbeek B. Factors affecting the cement-post interface. Dent Mater. 2012 Mar;28(3):287-97.

34. Le Bell-Ronnlof AM, Lassila LV, Kangasniemi I, Vallittu PK. Load-bearing capacity of human incisor restored with various fiber-reinforced composite posts. Dent Mater 2011;27:e107-15

35. Garoushi S, Vallittu PK, Lassila LV. Direct restoration of severely damaged incisors using short fiber-reinforced composite resin. J Dent 2007;35:731-6.

36. Juloski J, Radovic I, Goracci C, Vulicevic ZR, Ferrari M. Ferrule effect: a literature review. J Endod. 2012 Jan;38(1):11-9.

37. Newman M, Takei H, Klokkevold P, Carranza F. Newman and Carranza's Clinical Periodontology 13th Edition. Elsevier Publishing,17th July 2018. Part 2, Section 1.

38. Carvalho MA, Lazari PC, Gresnigt M, Del Bel Cury AA, Magne P. Current options concerning the endodontically-treated teeth restoration with the adhesive approach. Braz Oral Res. 2018 Oct 18;32(suppl 1):e74.

39. Ree M, Schwartz RS. The endo-restorative interface: current concepts. Dent Clin North Am. 2010 Apr;54(2):345-74.

40. Magne P, Carvalho AO, Bruzi G, Anderson RE, Maia HP, Giannini M. Influence of no-ferrule and no-post buildup design on the fatigue resistance of endodontically treated molars restored with resin nanoceramic CAD/CAM crowns. Oper Dent. 2014;39:595-602.

41. Jayasooriya PR, Pereira PN, Nikaido T, Tagami J. Efficacy of a resin coating on bond strengths of resin cement to dentin. J Aesthet Restor Dent 2003;15:105-13. 
42. Tay FR, Pashley DH. Have dentin adhesives become too hydrophilic? J Can Dent Assoc. 2003 Dec;69:726-31.

43. Pongprueksa P, Kuphasuk W, Senawongse P. Effect of elastic cavity wall and occlusal loading on microleakage and dentin bond strength. Oper Dent. 2007;32:466-75.

44. Fráter M, Forster A, Jantyik Á, Braunitzer G, Nagy K. Fracture strength of elastic and conventional fibre-reinforced composite intraradicular posts--an in vitro pilot study. Fogorv Sz. 2015 Dec;108(4):115-9.

45. Schneider SW. A comparison of canal preparations in straight and curved root canals. Oral Surg Oral Med Oral Pathol 1971;32:271-5.

46. Scotti N, Coero Borga FA, Alovisi M, Rota R, Pasqualini D, Berutti E. Is fracture resistance of endodontically treated mandibular molars restored with indirect onlay composite restorations influenced by fiber post insertion? J Dent 2012;40:814-20.

47. Hatta M, Shinya A, Vallittu PK, Shinya A, Lassila LV. High volume individual fibre post versus low volume fibre post: the fracture load of the restored tooth. J Dent. 2011;39(2011):65-71.

48. Frater M, Forster A, Kereszturi M, Braunitzer G, Nagy K. In vitro fracture resistance of molar teeth restored with a short fibre-reinforced composite material. J Dent. 2014;42(2014):1143-50. 49. Wandscher VF, Bergoli CD, Limberger IF, Ardenghi TM, Valandro LF. Preliminary results of the survival and fracture load of roots restored with intracanal posts: weakened vs nonweakened roots. Operative dentistry. 2014;39(2014):541-55.

50. Batalha-Silva S, de Andrada MA, Maia HP, Magne P. Fatigue resistance and crack propensity of large MOD composite resin restorations: direct versus CAD/CAM inlays. Dent Mater 2013;29(3): 324-31.

51. N.A. Taha, J.E. Palamara, H.H. Messer. Fracture strength and fracture patterns of root filled teeth restored with direct resin restorations, J Dent 2011;39:527-35

52. D. Dietschi, M. Maeder, J.M. Meyer, J. Holz. In vitro resistance to fracture of porcelain inlays bonded to tooth, Quintessence Int 1990;21:823-31.

53. C.J. Soares, L.R. Martins, J.M. Pfeifer, M. Giannini. Fracture resistance of teeth restored with indirect-composite and ceramic inlay systems, Quintessence Int 2004;35:281-6.

54. Meira JB, Esposito CO, Quitero MF, Poiate IA, Pfeifer CS, Tanaka CB, Ballester RY. Elastic modulus of posts and the risk of root fracture. Dental traumatology : official publication of International Association for Dental Traumatology. 2009;25(2009):394-8.

55. Y. Wu, P. Cathro, V. Marino. Fracture resistance and pattern of the upper premolars with obturated canals and restored endodontic occlusal access cavities, J Biomed Res 2010;24:474-8. 
56. M.R. Lee, B.H. Cho, H.H. Son, C.M. Um, I.B. Lee. Influence of cavity dimension and restoration methods on the cusp deflection of premolars in composite restoration, Dent Mater 2007;23:288-95.

57. N. Meredith, D.J. Setchell. In vitro measurement of cuspal strain and displacement in composite restored teeth, J Dent 1997;25:331-7.

58. N. Scotti, C. Eruli, A. Comba, D.S. Paolino, M. Alovisi, D. Pasqualini et al. Longevity of class 2 direct restorations in root-filled teeth: A retrospective clinical study, J Dent 2015;43:499-505.

59. D. Morin, R. DeLong, W.H. Douglas. Cusp reinforcement by the acid-etch technique, J Dent Res 1984;63:1075-8.

60. J. Manhart, K.H. Kunzelmann, H.Y. Chen, R. Hickel. Mechanical properties and wear behavior of light-cured packable composite resins, Dent Mater 2000;16:33-40.

61. Soares PV, Santos-Filho PC, Martins LR, Soares CJ. Influence of restorative technique on the biomechanical behavior of endodontically treated maxillary premolars. Part I: fracture resistance and fracture mode. J Prosthet Dent 2008;99:30-7.

62. Mohammadi N, Kahnamoii MA, Yeganeh PK, Navimipour EJ. Effect of fiber post and cusp coverage on fracture resistance of endodontically treated maxillary premolars directly restored with composite resin. J Endod 2009;35:1428-32

63. Trope M, Maltz DO, Tronstad L. Resistance to fracture of restored endodontically treated teeth. Endod Dent Traumatol 1985;1:108-11.

64. Yamada Y, Tsubota Y, Fukushima S. Effect of restoration method on fracture resistance of endodontically treated maxillary premolars. Int J Prosthodont 2004;17:94-8.

65. Fokkinga WA, Le Bell AM, Kreulen CM, Lassila LV, Vallittu PK, Creugers NH. Ex vivo fracture resistance of direct resin composite complete crowns with and without posts on maxillary premolars. Int Endod J 2005;38:230-7.

66. Bijelic J, Garoushi S, Vallittu PK, Lassila LV. Short fiber reinforced composite in restoring severely damaged incisors. Acta Odontol Scand. 2013;71:1221-31.

67. Belli S, Eraslan O, Eskitascioglu G, Karbhari V. Monoblocks in root canals: a finite elemental stress analysis study. Int Endod J 2011;44:817-26.

68. Seyam RS, Mobarak EH. Reinforcement of teeth with simulated coronal fracture and immature weakened roots using resin composite cured by a modified layering technique. Oper Dent 2014;39:128-36.

69. Galhano GA, de Melo RM, Barbosa SH, Zamboni SC, Bottino MA, Scotti R. Evaluation of light transmission through translucent and opaque posts. Oper Dent 2008;33:321-24. 
70. Aksornmuang J, Nakajima M, Panyayong W, Tagami J. Effects of photocuring strategy on bonding of dual-cure one-step self-etch adhesive to root canal dentin. Dent Mater J 2009;28:133-41. 71. Goracci C, Corciolani G, Vichi A, Ferrari M. Light-transmitting ability of marketed fiber posts. J Dent Res. 2008;87:1122-6.

72. Faria e Silva AL, Arias VG, Soares LE, Martin AA, Martins LR. Influence of fiber-post translucency on the degree of conversion of a dual-cured resin cement. J Endod. 2007;33:303-5. 73. Garoushi S, Mangoush E, Vallittu M, Lassila L. Short fiber reinforced composite: a new alternative for direct onlay restorations. Open Dent J. 2013;7:181-5.

74. Bolhuis HPB, De Gee AJ, Feilzer AJ, Davidson CL. Fracture strength of different core build-up designs. American journal of dentistry. 2001;14(2001):286-90

75. Manning KE, Yu DC, Yu HC, Kwan EW. Factors to consider for predictable post and core build-ups of endodontically treated teeth. Part I: Basic theoretical concepts. Journal. 1995;61(1995): $685-8,90,93-5$.

76. Fuss Z, Lustig J, Katz A, Tamse A. An evaluation of endodontically treated vertical root fractured teeth: impact of operative procedures. Journal of endodontics. 2001;27(2001):46-8. 77. Ferrari M, Vichi A, Garcia-Godoy F. Clinical evaluation of fiber-reinforced epoxy resin posts and cast post and cores. American journal of dentistry. 2000;13(2000):15B-8B.

78. Butz F, Lennon AM, Heydecke G, Strub JR. Survival rate and fracture strength of endodontically treated maxillary incisors with moderate defects restored with different post-andcore systems: an in vitro study. The International journal of prosthodontics. 2001;14(2001):58-64. 79. Lertchirakarn V, Palamara JE, Messer HH. Patterns of vertical root fracture: factors affecting stress distribution in the root canal. Journal of endodontics. 2003;29(2003):523-8.

80. Fuss Z, Lustig J, Tamse A. Prevalence of vertical root fractures in extracted endodontically treated teeth. International endodontic journal. 1999;32(1999):283-6.

81. Tamse A, Fuss Z, Lustig J, Kaplavi J. An evaluation of endodontically treated vertically fractured teeth. Journal of endodontics. 1999;25(1999):506-8.

82. Juloski J, Radovic I, Goracci C, Vulicevic ZR, Ferrari M. Ferrule effect: a literature review. J Endod. 2012 Jan;38(1):11-9.

83. Jotkowitz A, Samet N. Rethinking ferrule--a new approach to an old dilemma. Br Dent J. 2010 Jul 10;209(1):25-33.

84. Nam SH, Chang HS, Min KS, Lee Y, Cho HW, Bae JM. Effect of the number of residual walls on fracture resistances, failure patterns, and photoelasticity of simulated premolars restored with or without fiber-reinforced composite posts. Journal of endodontics. 2010;36(2010):297-301. 
85. Sorensen JA, Engelman MJ. Effect of post adaptation on fracture resistance of endodontically treated teeth. The Journal of prosthetic dentistry. 1990;64(1990):419-24.

86. Cecchin D, de Almeida JF, Gomes BP, Zaia AA, Ferraz CC. Influence of chlorhexidine and ethanol on the bond strength and durability of the adhesion of the fiber posts to root dentin using a total etching adhesive system. Journal of endodontics. 2011;37(2011):1310-5.

87. Eskitascioglu G, Belli S, Kalkan M. Evaluation of two post core systems using two different methods (fracture strength test and a finite elemental stress analysis). Journal of endodontics. 2002;28(2002):629-33.

88. Newman MP, Yaman P, Dennison J, Rafter M, Billy E. Fracture resistance of endodontically treated teeth restored with composite posts. The Journal of prosthetic dentistry. 2003;89(2003): $360-7$.

89. Heydecke G, Peters MC. The restoration of endodontically treated, single-rooted teeth with cast or direct posts and cores: a systematic review. The Journal of prosthetic dentistry. 2002;87(2002): $380-6$.

90. Ambica K, Mahendran K, Talwar S, Verma M, Padmini G, Periasamy R. Comparative evaluation of fracture resistance under static and fatigue loading of endodontically treated teeth restored with carbon fiber posts, glass fiber posts, and an experimental dentin post system: an in vitro study. Journal of endodontics. 2013;39(2013):96-100.

91. Ozcan M, Valandro LF. Fracture strength of endodontically-treated teeth restored with post and cores and composite cores only. Operative dentistry. 2009;34(2009):429-36.

92. Dietschi D, Duc O, Krejci I, Sadan A. Biomechanical considerations for the restoration of endodontically treated teeth: a systematic review of the literature, Part II (Evaluation of fatigue behavior, interfaces, and in vivo studies). Quintessence international. 2008;39(2008):117-29. 


\section{OTHER PUBLICATIONS OF THE AUTHOR}

\section{Peer reviewed publications:}

1.Forster A, Ungvári K, Györgyey Á, Kukovecz Á, Turzó K, Nagy K. Human Epithelial tissue culture study on restorative materials. J Dent. 2014 Jan;42(1):7-14. Epub 2013 Nov 20.

2. Forster A, Velez R, Antal M, Nagy K. Width Ratios in the anterior maxillary region in a hungarian population: addition to the golden proportions debate. J Prosthet Dent. 2013 Sep;110(3): 211-5.

3. Fráter M, Forster A, Keresztúri M, Braunitzer G, Nagy K. In vitro fracture resistance of molar teeth restored with a short fibre-reinforced composite material. J Dent. 2014 Sep;42(9):1143-50. Epub 2014 May 21.

4. Antal M, Forster A, Zalai Z, Barabás K, Ramseier C, Nagy K. Attitudes of Hungarian dental professionals to tobacco use and cessation. Cent Eur J Public Health 2012 Mar;20(1):45-49.

5. Mesmer, C, Forster A, Antal M, Nagy K: Alsó részleges kivehető fogpótlást viselő páciensek mikrobiológiai és immunológiai vizsgálata peri-implantitiszes és egészséges kontrollcsoportba tartozó esetekben. (12 hónapos utánkövetés). Fogorvosi Szemle 2012 Jun;105(2):59-64.

6. Antal M, Ramseier, A, Barabás K, Forster A, Zalai Zs, Nagy K: A dohányzás megelőzése és a leszokás támogatásának lehetőségei. Fogorvosi Szemle 2012 Sep;105(3):99-103.

7. Antal M, Forster A, Zalai Z, Barabas K, Spangler J, Braunitzer G, Nagy K. A video feedbackbased tobacco cessation counselling course for undergraduates-preliminary results. Eur J Dent Educ 2013 Feb;17(1):e166-172.

8. Fráter M, Forster A, Jantyik Á, Braunitzer G, Nagy K. Fracture strength of elastic and conventional fibre-reinforced composite intraradicular posts--an in vitro pilot study. Fogorv Sz. 2015 Dec;108(4):115-9.

\section{Non peer reviewed publications:}

1. Forster A.: Üvegszálas csapok használata mechanikai elvek alapján. Dental Hírek 13; (4) 44-47, 2009.

2. Forster A., Grosz J.: A fogorvosi fényképezés alapjai. 1. rész. Dental Hírek 13; (4) 64-69, 2009.

3. Forster A., Grosz J.: A fogorvosi fényképezés alapjai. 2. rész. Dental Hírek 13; (5) 42-46, 2009.

4. Nagy K., Barabás K., Antal M. Forster A.: A dohányzásról való leszoktatás lehetőségei a fogorvosi praxisban. Dental Hírek 13; (6): 66-67, 2009.

5. Forster A., Grosz J.: A fogorvosi fényképezés alapjai. 3. rész. Dental Hírek 14; (1) 48-54, 2010. 
6. Forster A., Grosz J.: Preparálás nélküli héjak szerepe és alkalmzása a modern helyreállító fogászatban Dental Hírek 15; (2) 38-42, 2011.

7. Forster A., Grosz J.: Preparálás nélküli héjak szerepe és alkalmazása a modern helyreállító fogászatban. Fogtechnika 8; (4-5): 174-179, 2011.

8. Grosz J., Forster A.: Hátsó fogak ellátása indirekt adhezív restaurációval. Dental Hírek 15; (5): 40-44, 2011.

9. Handbook of dental hygienist; section 2.3 and 2.7 (http://www.tankonyvtar.hu/en/tartalom/ tamop412A/2011-0032_angol/adatok.html)

10. Fráter M., Forster A. Új generációs, rövid üvegszál- megerősítés alkalmazása a poszterior régióban. Dental Hírek 19; (3): 18-20, 2015. 


\section{LIST OF ABBREVIATIONS:}

CEJ - Cemento-enamel junction

DEJ - Dentino-enamel junction

DLFRC - Direct layered fibre reinforced composite

ETT - Endodontically treated teeth

FRC - Fibre reinforced composite

MOD - mesio-occluso-distal

PCD - pericervical dentine

SFRC - Short fibre reinforced composite 
APPENDIX:

Copy of the publications providing the basis of the thesis 


\title{
In Vitro Fracture Resistance of Adhesively Restored Molar Teeth with Different MOD Cavity Dimensions
}

\author{
András Forster, DMD iD , ${ }^{1}$ Gábor Braunitzer, $\mathrm{PhD},{ }^{2}$ Máté Tóth, $\mathrm{DMD},{ }^{1}$ Balázs P. Szabó, $\mathrm{PhD},{ }^{3}$ \& \\ Márk Fráter, DDS ${ }^{1}$ \\ ${ }^{1}$ Department of Operative and Esthetic Dentistry, Faculty of Dentistry, University of Szeged, Szeged, Hungary \\ ${ }^{2}$ Department of Oral Surgery, Faculty of Dentistry University of Szeged, Szeged, Hungary \\ ${ }^{3}$ Faculty of Engineering, Department of Food Engineering, University of Szeged, Szeged, Hungary
}

\author{
Keywords \\ Cavity dimensions; cusp coverage; maximal \\ fracture strength; MOD cavity.

\section{Correspondence \\ András Forster, Faculty of Dentistry, \\ University of Szeged, Tisza Lajos körút \\ 64.Szeged, H-6722, Hungary. \\ E-mail: andras.forster@me.com} \\ The authors deny any conflicts of interest \\ related to this study. \\ András Forster \\ http://orcid.org/0000-0002-3495-7105
}

Accepted November 30, 2017

doi: 10.1111/jopr.12777

\begin{abstract}
Purpose: Molar MOD (mesial-occlusal-distal) cavity preparation weakens relative cuspal stiffness by up to $63 \%$, often resulting in cuspal fracture. This investigation inspects fracture resistance of MOD cavities restored using direct composite restoration.

Materials and Methods: 120 extracted, intact mandibular molars were selected. MOD cavities with different depth/wall thickness were prepared in 9 groups $(\mathrm{n}=$ 12): A: $3 \mathrm{~mm} / 3.5 \mathrm{~mm}$, B: $3 \mathrm{~mm} / 2.5 \mathrm{~mm}, \mathrm{C}: 3 \mathrm{~mm} / 1.5 \mathrm{~mm}, \mathrm{D}: 5 \mathrm{~mm} / 3.5 \mathrm{~mm}, \mathrm{E}: 5$ mm/2.5 mm, F: $5 \mathrm{~mm} / 1.5 \mathrm{~mm}, \mathrm{G}: 7 \mathrm{~mm} / 3.5 \mathrm{~mm}, \mathrm{H}: 7 \mathrm{~mm} / 2.5 \mathrm{~mm}, \mathrm{I}: 7 \mathrm{~mm} / 1.5 \mathrm{~mm}$. Specimens with $7 \mathrm{~mm}$ deep cavities received root canal treatment. The teeth were restored with dental composite. Maximal fracture strength test was conducted. Intact natural teeth were used as control. For statistical analysis Kruskal-Wallis ANOVA with post-hoc pairwise comparisons was used $(\alpha=0.05)$

Results: Significant difference was indicated between the control and groups D, E, F, G, H, and I. No significant differences were found between the A, B, C groups and the control. Comparing the 5 and $7 \mathrm{~mm}$ cavity depth groups, there was no statistical difference between any of them.

Conclusions: Within the limitations of this investigation, the following conclusions can be drawn regarding molar teeth with a MOD cavity: $3 \mathrm{~mm}$ or shallower cavities can be restored to the physiological fracture strength with direct composite restorations; $5 \mathrm{~mm}$ or deeper cavities cannot be restored to the physiological fracture strength with direct composite restorations. Cusp thickness does not significantly influence fracture strength in molar MOD cavities with a direct composite restoration.
\end{abstract}

Loss of tooth structure as a result of caries, trauma, or restorative and endodontic procedures has a negative influence on the fracture resistance of teeth and increases the risk of cusp fracture. ${ }^{1}$ Studies have pointed out that the primary reason for tooth fragility in the posterior region is the presence of extensive cavity preparations ${ }^{2}$ and endodontic therapy. ${ }^{3}$ Endodontically treated posterior teeth present specific restorative challenges due to their more brittle behavior compared to vital teeth. ${ }^{4}$ According to Dietschi et $\mathrm{al}^{5}$ this difference cannot be explained by their altered moisture content or dentine toughness, but rather the structural defect generated during tooth preparation; however, according to several studies a conservative endodontic access cavity preparation in posterior teeth reduced the relative cuspal stiffness only by $5 \%$ to $20 \% .^{6,7}$ Meanwhile a standardized MOD cavity preparation in maxillary premolar teeth was shown to result in an average loss of $63 \%$ in relative cuspal stiffness, ${ }^{8}$ which is related principally to the loss of marginal ridge integrity. ${ }^{9}$ This causes a reduction in fracture strength of approximately $54 \% .{ }^{10,11}$ Complete cusp fracture of posterior teeth, especially with class II amalgam restorations, is a common phenomenon, ${ }^{12}$ highlighting the importance of the marginal ridges regarding the stability of the remaining opposing walls. It seems that posterior cavities with intact marginal ridges are less susceptible to serious cusp deflection and resulting cuspal fracture than those with discontinued marginal ridges.

Depth and design of the cavity preparation have been shown to be the most critical factors for generating stress in enamel. ${ }^{13,14}$ Cuspal deflection increases with increasing cavity dimensions, ${ }^{15}$ meaning the larger the restoration's volume, the higher the stress generated in the remaining dental structure. Hood $^{16}$ reported that the remaining cusp after cavity preparation acts as a cantilever beam under occlusal load. The floor of the cavity serves as a fulcrum for cusp bending, and the 
cantilever length increases with the depth of the cavity. Granath and Svensson ${ }^{17}$ found that cusp displacement was directly related to the extent of cavity width and depth. The width of the cavity correlates with the width of remaining cavity walls. The residual cavity wall thickness represents the quantity of remaining enamel and dentin and is directly correlated with the residual sound tissue, ${ }^{1}$ thus, measuring this parameter could be a simple but effective way to aid the selection of the appropriate type of future restoration.

Another important question in MOD (mesial-occlusal-distal) cavities both in vital and nonvital cases is the necessity of cuspal coverage. In endodontically treated teeth the provision of cuspal coverage is considered a key element in long-term success, ${ }^{18}$ since lowering of the remaining sound cusp to create cuspal coverage for protection of the intact cusp increased the fracture resistance. ${ }^{19}$ There is evidence to suggest that large preparations require cuspal coverage to prevent possible fracture. ${ }^{20,21}$ Since the point at which onlays should be preferred over bonded inlays is a matter of debate, ${ }^{22}$ this study aims to provide clinically useful and easily measurable information regarding cavity configuration and its prognosis on restorative decision making.

The question arises: What cavity depth and remaining wall thickness is restorable without cuspal coverage? The aim of this study is to assess the effect of different cavity configurations on the maximal fracture load strength of restored molar teeth, without cuspal coverage.

\section{Materials and methods}

All procedures of the study were approved by the local Ethics Committee, and the study was designed in accordance with the Declaration of Helsinki. One hundred and twenty mandibular third molars extracted for periodontal or orthodontic reasons were selected for this investigation. The freshly extracted teeth were immediately placed in $5.25 \% \mathrm{NaOCl}$ for 5 minutes and then stored in $0.9 \%$ saline solution at room temperature until use, all within 2 months of extraction. During specimen preparation, the soft tissue covering the root surface was removed with hand scalers. The inclusion criteria were visual absence of caries or root cracks, absence of previous endodontic treatment, posts or crown, or resorptions. Teeth with severe polymorphism of the coronal structures were excluded from the investigation.

Approximately $80 \%$ of the specimens ranged 10.0 to $10.9 \mathrm{~mm}$ in size, measured at the widest bucco-lingual dimension, and the rest were between 11.0 and $12.0 \mathrm{~mm}$. The mesio-distal dimension of the specimens was also measured, and this parameter allowed a maximum deviation of $10 \%$ from the determined mean. The height was between 8.0 and $9.0 \mathrm{~mm}$ measured from the cementoenamel-junction (CEJ). The 120 teeth were randomly distributed between 10 study groups $(\mathrm{n}=$ $12)^{3,18,22}$ including 9 restored groups (Table 1 ) and a control group of intact natural teeth.

\section{Cavity preparation}

MOD cavities with different wall thicknesses and with different depths (Fig 1) were prepared by the same trained operator in 9 of the groups. The MOD cavities were prepared into each of the teeth according to the parameters listed in Table 1.
Table 1 Cavity parameters per tested group

\begin{tabular}{lccc}
\hline Depth/wall thickness & $3.5 \mathrm{~mm}$ & $2.5 \mathrm{~mm}$ & $1.5 \mathrm{~mm}$ \\
\hline $3 \mathrm{~mm}$ & $\mathrm{~A}$ & $\mathrm{~B}$ & $\mathrm{C}$ \\
$5 \mathrm{~mm}$ & $\mathrm{D}$ & $\mathrm{E}$ & $\mathrm{F}$ \\
$7 \mathrm{~mm}$ (Endo) & $\mathrm{G}$ & $\mathrm{H}$ & $\mathrm{I}$ \\
\hline
\end{tabular}
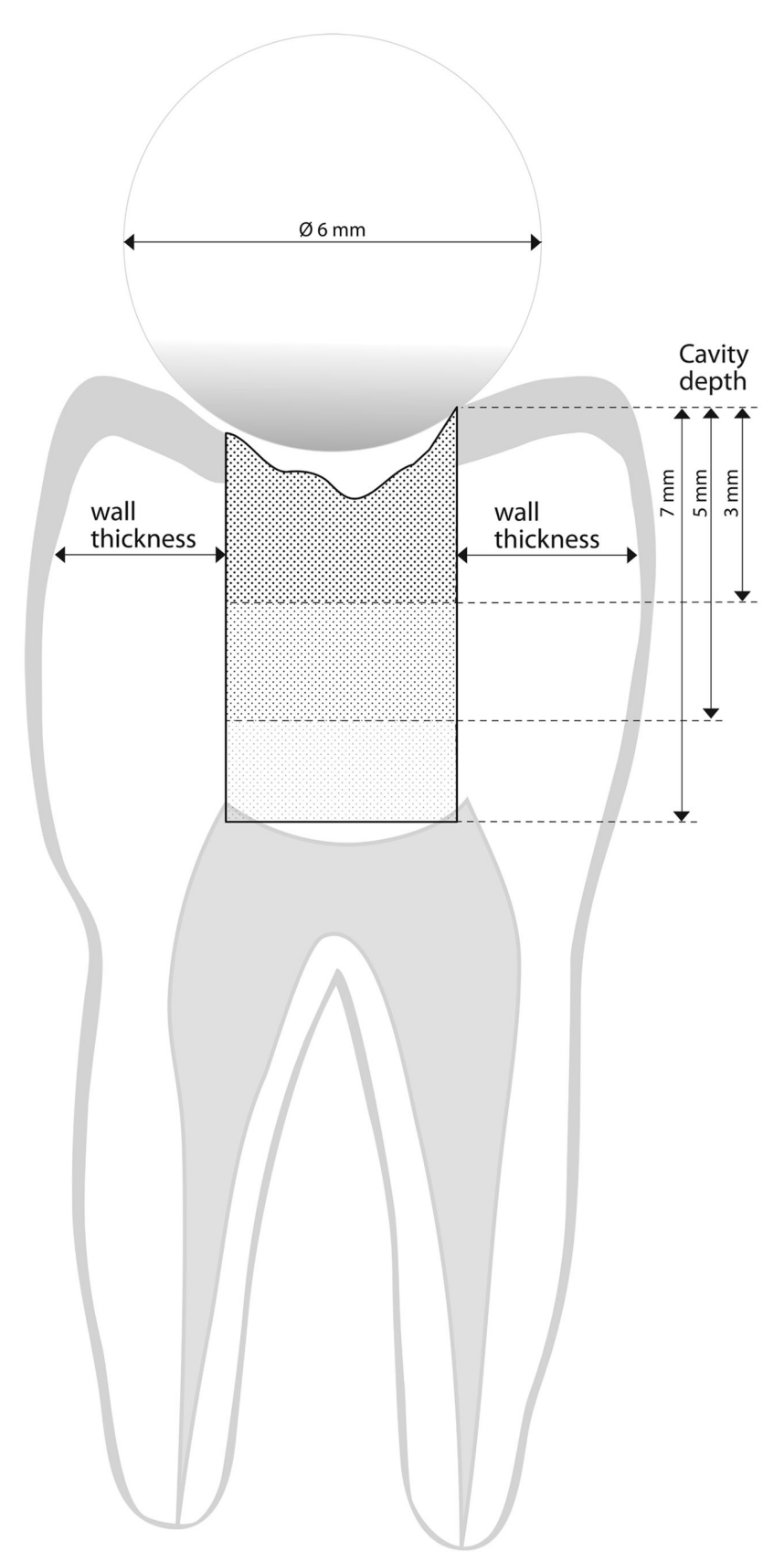

Figure 1 Schematic orovestibular cross section of cavity proportions prepared in mandibular third molars subject to adhesive restoration and maximal fracture strength testing. Depth/wall thickness per group: A: $3 \mathrm{~mm} / 3.5 \mathrm{~mm}, \mathrm{~B}: 3 \mathrm{~mm} / 2.5 \mathrm{~mm}, \mathrm{C}: 3 \mathrm{~mm} / 1.5 \mathrm{~mm}, \mathrm{D}: 5 \mathrm{~mm} / 3.5 \mathrm{~mm}$, E: $5 \mathrm{~mm} / 2.5 \mathrm{~mm}, \mathrm{~F}: 5 \mathrm{~mm} / 1.5 \mathrm{~mm}, \mathrm{G}: 7 \mathrm{~mm} / 3.5 \mathrm{~mm}, \mathrm{H}: 7 \mathrm{~mm} / 2.5 \mathrm{~mm}$, I: $7 \mathrm{~mm} / 1.5 \mathrm{~mm}$. 
The preparation was performed with a round-end parallel diamond bur (881.31.014 FG; Brasseler USA Dental, Savannah, GA) initially positioned at the midline of the occlusal surface of the teeth (determined by dividing the distance between the buccal and lingual cusp tips by two). The thickness of the opposing walls at the cavity base was continuously checked during the preparation with a digital caliper (Mitutoyo Corp., Kawasaki, Japan). The cavity walls were prepared parallel to the axis of the tooth. The depth of the cavity was evaluated with a $15 \mathrm{UNC}$ periodontal probe (Hu-Friedy $\mathrm{Mfg}$. Co., Chicago, IL) measured from the corresponding cusp tip by touching the cavity wall with the full length of the instrument. The cavity was one continuous cavity with the proximal box having exactly the same width and depth as the occlusal one.

In the specimens in which the depth was meant to be $7 \mathrm{~mm}$, an endodontic access was prepared, and endodontic treatment was carried out. After shaping with step-back technique (maximum file size 35-40), the root canals were filled with a thermoplasticized gutta percha delivery system (ObturaII; Obtura/Spartan, Fenton, MO). Following root canal obturation a base was applied to the pulp chamber in the form of a 2.0- to 3.0-mmthick resin modified glass-ionomer (Fuji II LC; GC Europe, Leuven, Belgium). barrier. ${ }^{23}$ This was cut back with a coarse diamond bur (801.36.6801 FG/Surg; Brasseler USA Dental) to establish the $7 \mathrm{~mm}$ final depth of the cavity. The cavosurface margins were prepared perpendicular to the tooth surface. The cavity was rinsed with water and air-dried with an air/water syringe. After application of a Tofflemire (1101C 0.038; Kerr, Bioggio, Switzerland) matrix, the enamel was acid-etched selectively with $37 \%$ phosphoric acid for 15 seconds, rinsed with water, and air-dried. The cavity was adhesively treated with G-aenial Bond (GC Europe) according to the manufacturer's instructions. The adhesive was light-cured for 40 seconds with an Optilux 501 halogen light (Kerr, Orange, CA) operating in standard mode at a light intensity of $740 \pm 36 \mathrm{mWcm}^{2}$. In all groups, an approximately $0.5 \mathrm{~mm}$-thin flow composite layer (G-aenial Flo A2; GC Europe) was applied on all walls of the cavity. $24-26$

This layer was light-cured for 40 seconds. After the flowable layer was applied, composite resin (Gradia Direct Anterior A2; GC Europe) was placed in several consecutive $2 \mathrm{~mm}$-thick oblique increments. Each increment was light cured from the occlusal surface for 40 seconds each, and after removal of the Tofflemire matrix band the mesial and distal sides were light cured for 20 seconds each (total 80 seconds). Light-curing times chosen were double that recommended by the manufacturer for each material used, in order to securely obtain maximal conversion at each layer.

The restorations were finished with a fine granular diamond bur (FG 7406-018, Jet Diamonds, Kerr, and FG 249-F012; Horico, Berlin, Germany) and aluminum oxide polishers (OneGloss PS Midi; Shofu Dental GmbH, Ratingen, Germany) and were stored in physiological saline solution (Isotonic Saline Solution $0.9 \%$; B. Braun, Melsungen, Germany) in an incubator (mco-18aic; Sanyo, Moriguchi, Japan) at $37^{\circ} \mathrm{C}$. Specimens were subjected to a thermocycling process consisting of 500 cycles between hot- and cold-water baths of $5^{\circ}$ and $55^{\circ} \mathrm{C}$ for 20 seconds each with an intermediate pause of 3 seconds' transfer time in between. ${ }^{27}$
To simulate the periodontal ligament, the root surface of each tooth was coated with a layer of liquid latex separating material (Rubber-Sep; Kerr) prior to embedding. Specimens were embedded in methacrylate resin (Technovit 4004; Heraeus-Kulzer, Hanau, Germany) at $2 \mathrm{~mm}$ from the CEJ to simulate the bone level.

All specimens were tested for fracture strength within 24 hours of restoration, using a universal loading device (5848 MicroTester1; Instron, Norwood, MA), according to the method described by Wu et al. ${ }^{28}$ Each test was performed at a $2 \mathrm{~mm} / \mathrm{min}$ crosshead speed, and load was applied using a $6 \mathrm{~mm}$ diameter stainless-steel ball-shaped stylus positioned at the center of the occlusal surface of the tooth between the buccal and oral cusps in the central pit. A force vs. extension curve was dynamically plotted for each tooth. Fracture threshold-defined as the load at which the tooth-restoration complex exhibited the first fracture, resulting in a peak formation on the extension curve-was recorded in Newtons $(\mathrm{N})$.

Statistical analysis was conducted in SPSS 21.0 (SPSS Inc., Chicago, IL). For the comparisons between the groups, Kruskal-Wallis ANOVA with post-hoc pairwise comparisons was used. The significance limit was set at $\alpha=0.05$. The null hypothesis was that restored teeth are not weakened compared to the intact control specimens.

\section{Results}

Median fracture strength values are presented in Figure 2. As the Kruskal-Wallis ANOVA indicated significant variance, posthoc pairwise tests were performed. The pairwise tests indicated significant difference between the control group and all 5 and $7 \mathrm{~mm}$ groups (D, E, F, G, H, I). The $3 \mathrm{~mm}$ groups (A, B, C) did not show significant difference as compared to the control. Significant difference was found between group A and all 5 and $7 \mathrm{~mm}$ groups (D, E, F, G, H, I). No significant differences were found between $3 \mathrm{~mm}$ cavity depth groups (A, B, C). Comparing the 5 and $7 \mathrm{~mm}$ cavity depth groups, there was no statistical difference between any of them. The pairwise statistical analysis is detailed in Table 2 . The null hypothesis was rejected, as the fracture strength of groups D, E, F, G, H, and I were significantly lower than that of the control group.

\section{Discussion}

A number of studies, with or without root canal preparation, have demonstrated that if the cavity involves the marginal ridge(s), the fracture resistance of the tooth is significantly reduced. ${ }^{28-30}$ In this study the fracture resistance of MOD cavities varying from small through medium to large sizes was tested. These latter ones are considered to be typical of an amalgam replacement with the indication of an indirect or large direct restoration, which is becoming more common. ${ }^{30}$ The reason for the placement of large direct restorations is not only financial, but it is also a goal to preserve the tooth structure as much as possible, according to the principles of minimal intervention dentistry. ${ }^{32-35}$ As found in previous studies, the depth of the preparation is one of the most critical factors in terms of future fracture. ${ }^{14,36}$ In addition, the choice of the restorative method is commonly based on the cavity configuration and 


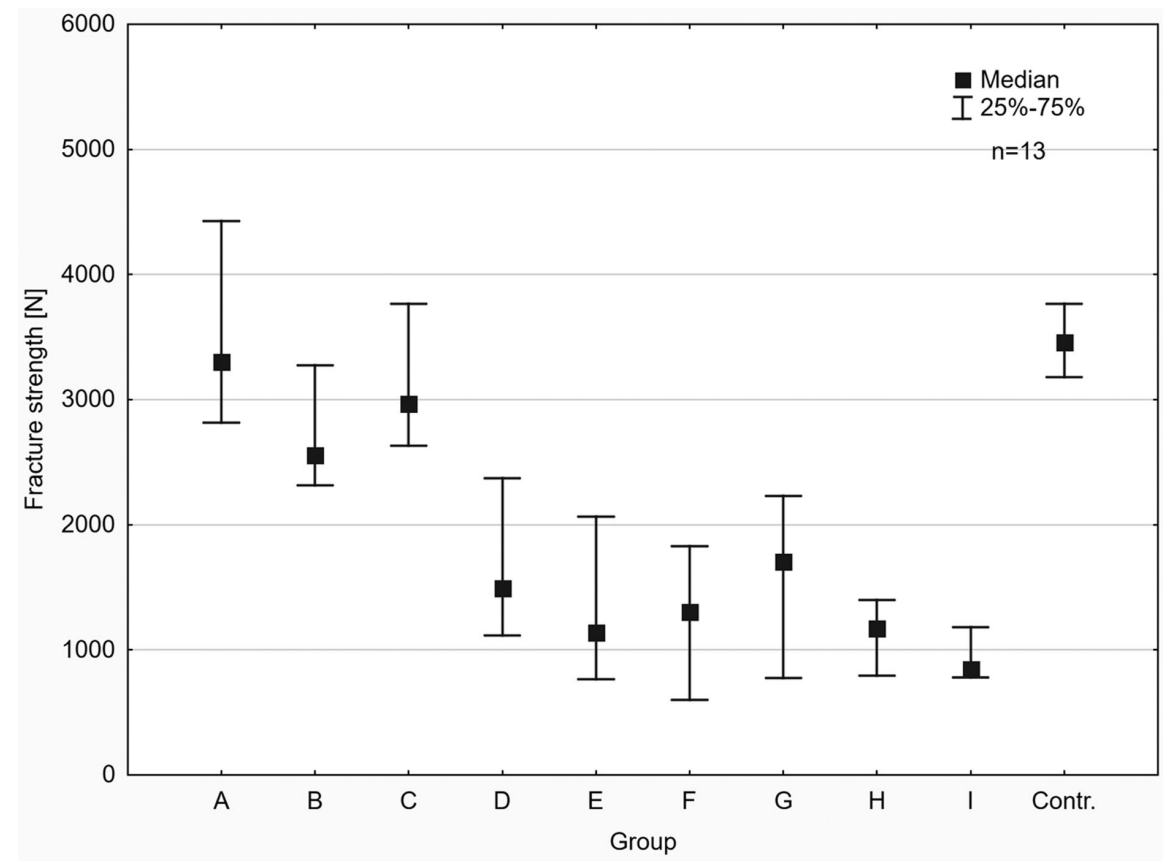

Figure 2 Mean fracture strength and standard deviation of the tested groups.

Table 2 Kruskal-Wallis ANOVA pairwise statistical analysis $(p<0.00001)$. Significance indicated with $*$ symbol

\begin{tabular}{lcccccccccc}
\hline Group & \multicolumn{1}{c}{$\mathrm{A}$} & $\mathrm{B}$ & \multicolumn{1}{c}{$\mathrm{C}$} & $\mathrm{D}$ & $\mathrm{E}$ & \multicolumn{1}{c}{$\mathrm{F}$} & $\mathrm{G}$ & $\mathrm{H}$ & $\mathrm{I}$ & Contr. \\
\hline A & & 1.000000 & 1.000000 & $0.029247^{*}$ & $0.000970^{*}$ & $0.002154^{*}$ & $0.021271^{*}$ & $0.000389^{*}$ & $0.000170^{*}$ & 1.000000 \\
B & 1.000000 & & 1.000000 & 0.923576 & 0.072278 & 0.132891 & 0.732700 & $0.035687^{*}$ & $0.018728^{*}$ & 1.000000 \\
C & 1.000000 & 1.000000 & & 0.300701 & $0.017307^{*}$ & $0.034044^{*}$ & 0.231264 & $0.007930^{*}$ & $0.003899^{*}$ & 1.000000 \\
D & $0.029247^{*}$ & 0.923576 & 0.300701 & & 1.000000 & 1.000000 & 1.000000 & 1.000000 & 1.000000 & $0.008013^{*}$ \\
E & $0.000970^{*}$ & 0.072278 & $0.017307^{*}$ & 1.000000 & & 1.000000 & 1.000000 & 1.000000 & 1.000000 & $0.000203^{*}$ \\
F & $0.002154^{*}$ & 0.132891 & $0.034044^{*}$ & 1.000000 & 1.000000 & & 1.000000 & 1.000000 & 1.000000 & $0.000478^{*}$ \\
G & $0.021271^{*}$ & 0.732700 & 0.231264 & 1.000000 & 1.000000 & 1.000000 & & 1.000000 & 1.000000 & $0.005670^{*}$ \\
H & $0.000389^{*}$ & $0.035687^{*}$ & $0.007930^{*}$ & 1.000000 & 1.000000 & 1.000000 & 1.000000 & & 1.000000 & $0.000076^{*}$ \\
I & $0.000170^{*}$ & $0.018728^{*}$ & $0.003899^{*}$ & 1.000000 & 1.000000 & 1.000000 & 1.000000 & 1.000000 & & $0.000032^{*}$ \\
Contr. & 1.00000 & 1.00000 & 1.000000 & $0.008013^{*}$ & $0.000203^{*}$ & $0.000478^{*}$ & $0.005670^{*}$ & $0.000076^{*}$ & $0.000032^{*}$ & \\
\hline
\end{tabular}

dimensions and the number of residual cavity walls. ${ }^{37-39}$ In this study the thickness of the cavity walls was measured with a dental caliper, and the depth was measured with a millimeter-scale periodontal probe.

Group A, having the most amount of dentine, showed the highest median fracture strength among the restored groups, whereas group I, having the largest cavity, thus the least amount of dentine, showed the lowest fracture resistance. This is in accordance with previous research by Goel et $\mathrm{al}^{40}$ and Torbjömer et $\mathrm{al}^{41}$ showing that preserving the anatomical structures and dentinal tissues is directly correlated with increased mechanical properties and less weakening of the tooth. The groups of $3 \mathrm{~mm}$ cavity depth (group A, B, C) presented the highest fracture resistance of all the restored specimens, and we found no significant difference in this respect between these three groups. The $3 \mathrm{~mm}$ groups were also not significantly weaker compared to the control teeth. The relatively small cantilever beam from the occlusal margin to the cavity floor, is a possible explana- tion for this finding. According to Hood's hypothesis, cusps of teeth with MOD cavity preparations function as a cantilever beam, with the extent of deflection under load influenced by both beam thickness and length. ${ }^{16}$ It seems from the results that when the cavity is shallow ( $3 \mathrm{~mm}$ deep), and thus the cantilever arm is small, the thickness of the walls is not a crucial factor in fracture strength.

When the cavity depth increased to $5 \mathrm{~mm}$, but access cavity preparation was still not needed, the fracture strength dropped to approximately half of the value measured in group A. This could be caused by the increased depth leading to a greater cantilever effect in these groups. With deeper cavity preparations the length of the freely deflectable cusp increases, and the cuspal deflection increases. ${ }^{28,29}$ Jantarat et $\mathrm{al}^{42}$ found that cusps do not deform as simple cantilever beams, which seemingly contradicts the present findings.

In this study, cavity depth corresponding to an endodontic treatment (groups G, H, I) did not cause significant weaken- 
ing, in comparison to the groups with $5 \mathrm{~mm}$ depth (groups $\mathrm{D}$, $\mathrm{E}, \mathrm{F})$. This is in accordance with previous studies conducted by Reeh et al, showing that when endodontic access is prepared after the preparation of a deep MOD cavity, the decrease measured in relative cuspal stiffness values is not significant compared to the values of MOD cavities without endodontic access. ${ }^{9,43}$

Based on the results of this investigation, $3 \mathrm{~mm}$ can be considered a safe cavity depth for adhesive direct restorations. This is in accordance with Frater et al, who found that when restoring shallow MOD cavities with direct techniques using oblique layering, there was no significant difference between the restored groups and the intact control group. ${ }^{45}$ These findings do not support the findings of Batalha-Silva et $\mathrm{al},{ }^{46}$ who concluded that $5 \mathrm{~mm}$ deep cavities could safely be restored with direct techniques. These results rather suggest that a cavity of $5 \mathrm{~mm}$ depth is already in the "danger zone" when talking about direct composite restorations without cusp coverage.

To aid clinical decision making, exact cavity dimensions or remaining tissue dimensions under which cuspal coverage must be provided would need to be established. As Seow et al found, maxillary premolars lost on average $53 \%$ of their stiffness when prepared with a MOD cavity with an isthmus width of one-third of the intercuspal distance, and if the isthmus width was half of the intercuspal distance, the prepared premolar teeth lost approximately $67 \%$ of their stiffness. ${ }^{18}$ When a MOD cavity is loaded, force and stress is concentrated at the bottom corners of the prepared cavity. ${ }^{47}$ Therefore, the thickness of the residual cusp wall at the base could be a key element in decision making when it comes to preserving or eliminating cusps. ${ }^{48}$ According to Scotti et $\mathrm{al}^{37}$ and Deliperi et al, ${ }^{48}$ cavity walls with thickness greater than $2 \mathrm{~mm}$ should not be reduced, and cuspal coverage should be avoided, whereas "sufficient" thickness was defined as $2.5 \mathrm{~mm}$ in a later study by Scotti et al. ${ }^{49} \mathrm{In}$ this study reducing only the wall thickness, without changing the depth of the cavity, did not cause a significant reduction in fracture strength. From the results it seems that cavity wall thickness is only secondary to cavity depth in molar MOD cavities in terms of fracture strength, as the change in cavity wall thickness did not lead to a significant difference between the groups in the "safety zone" or between the "danger zone" groups. Within the limitations of this study, this leads us to the conclusion that when the fracture safety of a cavity for a direct restoration without cusp coverage is to be determined, cavity depth is the primary determining factor. This is in accordance with the results of Morin et $\mathrm{al}^{50}$ and Manhart et al, ${ }^{51}$ who found that the depth of the preparation is the most critical factor in terms of future fractures. Since groups with cuspal coverage restorations were not included in this study, the results do not offer direct guidance on cuspal coverage. Also, since the cavities were only restored with a conventional adhesive direct composite restoration, the results cannot be extrapolated to situations when fiber-reinforced materials are used; however, if the cavity depth of molar teeth with a MOD cavity reaches or exceeds $5 \mathrm{~mm}$, cusp coverage with a direct or indirect adhesive restoration could be considered as a safety measure. Future investigations with similar methodology-involving cusp coverage with direct and indirect methods-need to be conducted to further our understanding on the effect of MOD cavity di- mensions on the restorability of molar teeth and limitations of adhesive restorations.

According to Taha et al, "In experimental studies, fracture resistance to static loading has been used as a measure of the effect of cavity preparation and/or restoration on tooth strength. Although the fracture load is typically much higher than functional occlusal loads, it is still a valid method for comparing restorative materials and different cavity designs." 52 The use of a $6 \mathrm{~mm}$ steel sphere for resistance to fracture testing by Dietschi et $\mathrm{al}^{53}$ and Soares et $\mathrm{al}^{54}$ was shown to be ideal for molars, because it contacts the functional and nonfunctional cusps in positions close to those found clinically. Also, in the current study, the teeth were subjected to vertical compressive loading with a stainless steel sphere $6 \mathrm{~mm}$ in diameter.

\section{Conclusions}

Within the limitations of this investigation, the following conclusions can be drawn:

1. Molar teeth with $3 \mathrm{~mm}$ or shallower depth MOD cavities can be restored to the same fracture resistance as intact teeth with a direct composite restoration, regardless of cavity wall thickness.

2. Molar teeth with $5 \mathrm{~mm}$ or higher depth MOD cavities cannot be restored to the physiological fracture resistance with a direct composite restoration, regardless of cavity wall thickness.

3. Cusp thickness does not significantly influence fracture strength in MOD cavities with a direct composite restoration.

\section{Acknowledgments}

The authors wish to thank Dean Kinga Turzó and Prof. Katalin Nagy for their support in realizing the project. We also express our gratitude to Prof. Dr. Gyula Sáry for his valuable contribution to the statistical analysis.

\section{References}

1. ElAyouti A, Serry MI, Geis-Gerstorfer J, et al: Influence of cusp coverage on the fracture resistance of premolars with endodontic access cavities. Int Endod J 2011;44:543-549

2. Larson TD, Douglas WH, Geistfeld RE: Effect of prepared cavities on the strength of teeth. Oper Dent 1981;6:2-5

3. Soares PV, Santos-Filho PC, Martins LR, et al: Influence of restorative technique on the biomechanical behavior of endodontically treated maxillary premolars. Part I: fracture resistance and fracture mode. J Prosthet Dent 2008;99:30-37

4. Magne P, Knezevic A: Thickness of CAD-CAM composite resin overlays influences fatigue resistance of endodontically treated premolars. Dent Mater 2009;25:1264-1268

5. Dietschi D, Duc O, Krejci I, et al: Biomechanical considerations for the restoration of endodontically treated teeth: a systematic review of the literature-Part 1. Composition and micro- and macrostructure alterations. Quintessence Int 2007;38:733-743

6. Rocca GT, Krejci I: Crown and post-free adhesive restorations for endodontically treated posterior teeth: from direct composite to endocrowns. Eur J Esthet Dent 2013;8:156-179

7. Tay FR, Pashley DH: Monoblocks in root canals: a hypothetical or a tangible goal. J Endod 2007;33:391-398 
8. El-Helali R, Dowling AH, McGinley EL, et al: Influence of resin-based composite restoration technique and endodontic access on cuspal deflection and cervical microleakage scores. J Dent 2013;41:216-222

9. Reeh ES, Douglas WH, Messer HH: Stiffness of endodontically-treated teeth related to restoration technique. J Dent Res 1989;68:1540-1544

10. Hannig C, Westphal C, Becker K, et al: Fracture resistance of endodontically treated maxillary premolars restored with CAD/CAM ceramic inlays. J Prosthet Dent 2005;94:342-349

11. Seo DG, Yi YA, Shin SJ, et al: Analysis of factors associated with cracked teeth. J Endod 2012;38:288-292

12. Fennis WM, Tezvergil A, Kuijs RH, et al: In vitro fracture resistance of fiber reinforced cusp-replacing composite restorations. Dent Mater 2005;21:565-572

13. Hansen EK, Asmussen E: In vivo fractures of endodontically treated posterior teeth restored with enamel-bonded resin. Endod Dent Traumatol 1990;6:218-225

14. Lin CL, Chang CH, Ko CC: Multifactorial analysis of an MOD restored human premolar using auto-mesh finite element approach. J Oral Rehabil 2001;28:576-585

15. Taha NA, Palamara JE, Messer HH: Cuspal deflection, strain and microleakage of endodontically treated premolar teeth restored with direct resin composites. J Dent 2009;37:724-730

16. Hood JA: Biomechanics of the intact, prepared and restored tooth: some clinical implications. Int Dent J 1991;41:25-32

17. Granath L, Svensson A: Elastic outward bending of loaded buccal and lingual premolar walls in relation to cavity size and form. Scand J Dent Res 1991;99:1-7

18. Seow LL, Toh CH, Wilson NH: Strain measurements and fracture resistance of endodontically treated premolars restored with all-ceramic restorations. J Dent 2015;43:126-132

19. Fennis WM, Kuijs RH, Kreulen CM, et al: Fatigue resistance of teeth restored with cuspal-coverage composite restorations. Int $\mathbf{J}$ Prosthodont 2004; 17:313-317

20. Burke FJ: Tooth fracture in vivo and in vitro. J Dent 1992;20:131-139

21. Burke FJ, Wilson NH, Watts DC: The effect of cavity wall taper on fracture resistance of teeth restored with resin composite inlays. Oper Dent 1993;18:230-236

22. St-Georges AJ, Sturdevant JR, Swift Jr EJ, et al: Fracture resistance of prepared teeth restored with bonded inlay restorations. J Prosthet Dent 2003;89:551-557

23. Magne P, Carvalho AO, Bruzi G, et al: Influence of no-ferrule and no-post buildup design on the fatigue resistance of endodontically treated molars restored with resin nanoceramic CAD/CAM crowns. Oper Dent 2014;39:595-602

24. Jayasooriya PR, Pereira PN, Nikaido T, et al: Efficacy of a resin coating on bond strengths of resin cement to dentin. J Aesthet Restor Dent 2003;15:105-113

25. Tay FR, Pashley DH: Have dentin adhesives become too hydrophilic? J Can Dent Assoc 2003;69:726-731

26. Pongprueksa P, Kuphasuk W, Senawongse P: Effect of elastic cavity wall and occlusal loading on microleakage and dentin bond strength. Oper Dent 2007;32:466-475

27. Kivanc BH, Alacam T, Gorgul G: Fracture resistance of premolars with one remaining cavity wall restored using different techniques. Dent Mater J 2010;29:262-267

28. Wu Y, Cathro P, Marino V: Fracture resistance and pattern of the upper premolars with obturated canals and restored endodontic occlusal access cavities. J Biomed Res 2010;24:474-478

29. Lee MR, Cho BH, Son $\mathrm{HH}$, et al: Influence of cavity dimension and restoration methods on the cusp deflection of premolars in composite restoration. Dent Mater 2007;23:288-295
30. Meredith N, Setchell DJ: In vitro measurement of cuspal strain and displacement in composite restored teeth. J Dent 1997;25:331-337

31. Cara RR, Fleming GJ, Palin WM, et al: Cuspal deflection and microleakage in premolar teeth restored with resin-based composites with and without an intermediary flowable layer. J Dent 2007;35:482-489

32. Mount GJ, Ngo H: Minimal intervention: a new concept for operative dentistry. Quintessence Int 2000;31:527-533

33. Yamada Y, Tsubota Y, Fukushima S: Effect of restoration method on fracture resistance of endodontically treated maxillary premolars. Int J Prosthodont 2004; 17:94-98

34. Cobankara FK, Unlu N, Cetin AR, et al: The effect of different restoration techniques on the fracture resistance of endodontically-treated molars. Oper Dent 2008;33:526533

35. Assif D, Gorfil C: Biomechanical considerations in restoring endodontically treated teeth. J Prosthet Dent 1994;71:565567

36. Khers SC, Carpenter CW, Vetter JD, et al: Anatomy of cusps of posterior teeth and their fracture potential. J Prosthet Dent 1990;64:139-147

37. Scotti N, Rota R, Scansetti M, et al: Influence of adhesive techniques on fracture resistance of endodontically treated premolars with various residual wall thicknesses. J Prosthet Dent 2013;110:376-382

38. Nam SH, Chang HS, Min KS, et al: Effect of the number of residual walls on fracture resistances, failure patterns, and photoelasticity of simulated premolars restored with or without fiber-reinforced composite posts. J Endod 2010;36:297-301

39. Mangold JT, Kern M: Influence of glass-fiber posts on the fracture resistance and failure pattern of endodontically treated premolars with varying substance loss: an in vitro study. $\mathbf{J}$ Prosthet Dent 2011;105:387-393

40. Goel VK, Khera SC, Gurusami S, et al: Effect of cavity depth on stresses in a restored tooth. J Prosthet Dent 1992;67:174-183

41. Torbjorner A, Fransson B: Biomechanical aspects of prosthetic treatment of structurally compromised teeth. Int J Prosthodont 2004; 17:135-141

42. Jantarat J, Panitvisai P, Palamara JE, et al: Comparison of methods for measuring cuspal deformation in teeth. J Dent 2001;29:75-82

43. Reeh ES, Messer HH, Douglas WH: Reduction in tooth stiffness as a result of endodontic and restorative procedures. J Endod 1989; $15: 512-516$

44. Eakle WS, Maxwell EH, Braly BV: Fractures of posterior teeth in adults. J Am Dent Assoc 1986;112:215-218

45. Frater M, Forster A, Kereszturi M, et al: In vitro fracture resistance of molar teeth restored with a short fibre-reinforced composite material. J Dent 2014;42:1143-1150

46. Batalha-Silva S, de Andrada MA, Maia HP, et al: Fatigue resistance and crack propensity of large MOD composite resin restorations: direct versus CAD/CAM inlays. Dent Mater 2013;29:324-331

47. Bell JG, Smith MC, de Pont JJ: Cuspal failures of MOD restored teeth. Aust Dent J 1982;27:283-287

48. Deliperi S, Bardwell DN: Multiple cuspal-coverage direct composite restorations: functional and esthetic guidelines. J Esthet Restor Dent 2008;20:300-312

49. Scotti N, Eruli C, Comba A, et al: Longevity of class 2 direct restorations in root-filled teeth: a retrospective clinical study. $\mathrm{J}$ Dent 2015;43:499-505

50. Morin D, DeLong R, Douglas WH: Cusp reinforcement by the acid-etch technique. J Dent Res 1984;63:1075-1078 
51. Manhart J, Kunzelmann KH, Chen HY, et al: Mechanical properties and wear behavior of light-cured packable composite resins. Dent Mater 2000;16:33-40

52. Taha NA, Palamara JE, Messer HH: Fracture strength and fracture patterns of root filled teeth restored with direct resin restorations. J Dent 2011;39:527-535
53. Dietschi D, Maeder M, Meyer JM, et al: In vitro resistance to fracture of porcelain inlays bonded to tooth. Quintessence Int 1990;21:823-831

54. Soares CJ, Martins LR, Pfeifer JM, et al: Fracture resistance of teeth restored with indirect-composite and ceramic inlay systems. Quintessence Int 2004;35:281-286 


\title{
In vitro fracture resistance of endodontically treated premolar teeth restored with a direct layered fiber-reinforced composite post and core
}

\author{
András Forster, Tekla Sáry, Gábor Braunitzer \& Márk Fráter
}

To cite this article: András Forster, Tekla Sáry, Gábor Braunitzer \& Márk Fráter (2016): In vitro fracture resistance of endodontically treated premolar teeth restored with a direct layered fiber-reinforced composite post and core, Journal of Adhesion Science and Technology, DOI: 10.1080/01694243.2016.1259758

To link to this article: http://dx.doi.org/10.1080/01694243.2016.1259758

Published online: 21 Nov 2016.

Submit your article to this journal $\square$

View related articles

View Crossmark data \lceil 


\title{
In vitro fracture resistance of endodontically treated premolar teeth restored with a direct layered fiber-reinforced composite post and core
}

\author{
András Forster ${ }^{\mathrm{a}}$ (D) , Tekla Sáry ${ }^{\mathrm{a}}$, Gábor Braunitzer ${ }^{\mathrm{b}}$ and Márk Fráter ${ }^{\mathrm{a}}$ (D) \\ aFaculty of Dentistry, Department of Operative and Esthetic Dentistry, University of Szeged, Szeged, Hungary; \\ ${ }^{\mathrm{b}}$ Faculty of Dentistry, Department of Oral Surgery, University of Szeged, Szeged, Hungary
}

\begin{abstract}
Methods for restoring endodontically treated teeth fall short of restoring the physiologic mechanical properties. Fracture of endodontically treated teeth is a common type of clinical failure. New treatment modalities or perfected versions of existing treatment concepts need to be tested to find a biomimetic solution. A novel method of restoring endodontically treated teeth is presented and compared in vitro with currently accepted restorative methods. Seventy-two extracted and endodontically treated maxillary premolar teeth were divided into six groups $(n=12)$ depending on restorative technique (Groups 1-6). Group 1: fiber-reinforced composite post (FRC), Group 2: direct layered short FRC post and core, Group 3: short fiber-reinforced obliquely layered composite restoration, Group 4: microhybrid composite restoration, Group 5: fiber-reinforced box, Group 6: control. Specimens were submitted to static fracture resistance test. Fracture thresholds and fracture patterns were evaluated. Group 6 exhibited the highest fracture resistance. Group 2 yielded the highest fracture resistance among the restored groups. The fracture resistance of Group 2 did not differ significantly from Group 6. Groups 1, 3, 4, 5 proved to be significantly different from the control group. There was no statistically significant difference among restored groups. Fracture patterns of tested groups were dominantly non repairable opposed to control groups mostly repairable fractures. Application of direct-layered short FRC post and core in endodontically treated premolars performed statistically similarly in the studied conditions as natural teeth. Therefore, it seems a promising alternative to current endo-restorative solutions. However, further testing is required.
\end{abstract}

\section{ARTICLE HISTORY}

Received 13 July 2016

Revised 5 November 2016

Accepted 7 November 2016

\section{KEYWORDS}

Fiber-reinforced composite; biomimetic; monoblock; minimal intervention dentistry

\section{Introduction}

Endodontically treated teeth (ETT) are structurally different from nonrestored vital teeth and require specialized restorative treatment.[1] According to Dietschi et al. [2], the major difference is not a consequence of tissue quality alteration, but the result of the loss of dental 
structures (e.g. marginal ridges, pericervical dentine and the arched roof of the pulp chamber) caused by caries, trauma or endodontic procedures. As a result of the compromised structural integrity, ETT are at an increased risk of fracture.[3,4] The fracture strength of these teeth is dependent on the amount and position of the remaining tooth structures and the choice of restorative material and technique.[5-13]

Several studies highlighted that postinsertion significantly increased the fracture resistance of nonvital premolars[10,14-16]; however, other studies only managed to prove the positive effect of postinsertion on the fracture pattern in premolar teeth.[17-19] The latter was also confirmed by Trope et al. [20] and Zicari et al. [21] who came to the conclusion that posts do not strengthen the tooth. These findings could be caused by the mismatch between fiber posts and the root canal diameter since according to modern minimal invasive principles postspace preparation should not contribute to radicular dentine removal. $[22,23]$ Following a minimally invasive postspace preparation leaves us with unique and irregular spaces [24] which are difficult to fill out with a single conventional or even a flexible posts. A further problem with posts is that they are placed in the most central part of the postspace (neutral axis), leaving the space originally occupied by dentine to be filled by the mechanically inferior luting composite material. A more effective reinforcement location mechanically may be on the outer surfaces of the postspace close to the dentine walls where the highest tensile stresses occur.[25] This is the space which before the root canal preparation was most likely obtained by healthy radicular and pericervical dentine. So to reach a reinforced, mechanically homogenous unit it would be ideal if a restorative material could be directly bonded to the root canal dentine and it would have mechanical properties similar to that of dentine.

In a 2007 investigation by Garoushi and coworkers, it was found that anterior ETT showed better load-bearing capacity if restored with a short fiber-reinforced composite (SFRC) restorative material opposed to a fiber-reinforced composite (FRC) post.[26] These findings open the debate on the necessity of the FRC post concept and open a gateway for the promotion of new types of endo-restorative techniques.

The aim of this investigation was to compare the mechanical properties of novel methods for the reinforcement of ETT utilizing SFRC (EverX Posterior, GC Europe, Leuven); with previously tested and accepted restorative methods. The null hypothesis was that (1) there would be no difference in the maximal fracture resistance of the ETT restored teeth with the tested methods. (2) There would be no difference in the fracture patterns of the ETT restored with the tested methods.

\section{Materials and methods}

All procedures of the study were approved by the Ethics Committee of the University of Szeged, and the study was designed in accordance with the Declaration of Helsinki.

Seventy-two upper premolar teeth, extracted for periodontal or orthodontic reasons were selected for this investigation. Specimen selection, exclusion criteria, root canal treatment protocol, specimen preparation and mechanical testing were carried out as described by Frater et al. $[27,28]$.

The freshly extracted teeth were immediately placed in $5.25 \% \mathrm{NaOCl}$ for $5 \mathrm{~min}$ and stored in $0.9 \%$ saline solution at room temperature. Teeth were used within 6 months after extraction. 
During specimen preparation the soft tissue covering the root surface was removed with hand scalers. The inclusion criteria were absence of caries or root cracks, the absence of previous endodontic treatments, posts or crowns, resorptions or evident lateral canals. Buccolingual and mesiodistal radiographs of all teeth were taken and examined to evaluate root integrity and the number of canals present. To standardize procedures and materials, all teeth used in this study had 1 root canal with a curvature of less than $5^{\circ}$, evaluated by Schneider's technique,[29] and teeth with a root length of $15 \pm 1 \mathrm{~mm}$ and similar mesiodistal and bucco-lingual dimensions $( \pm 10 \%)$ were selected.

$90 \%$ of the specimen ranged $9-10 \mathrm{~mm}$ in size, measured at the widest bucco-lingual dimension, and the rest measured were $6.5-8 \mathrm{~mm}$. Regarding the mesio-distal dimension, $90 \%$ of the specimen ranged $7-7.5 \mathrm{~mm}$, and the rest were $6.5-8 \mathrm{~mm}$.

The teeth were randomly distributed over six study groups of 12 specimens each.

Access cavity was prepared by the same trained operator in five groups of the six, and one group was left intact to serve as control (Group 6).

Access cavity preparation was carried out with a round-end, tapered, medium grit, $0.8 \mathrm{~mm}$ tip diameter, $10 \mathrm{~mm}$ length diamond bur (850-014 M SSWhite, Lakewood, NJ, USA) with water cooling in the approximated centre of the occlusal surface according to standardized parameters: the access cavity involved one-third of the intracuspal distance in the bucco-lingual dimension and one-third of the mesio-distal distance, measured at the level of the central fissure.

The working length was established with the direct method by subtracting $1 \mathrm{~mm}$ from the real root length determined by introducing a number $10 \mathrm{~K}$-file (Maillefer-Dentsply, Ballaigues, Switzerland) until it was visible through the apical foramen. The canals were instrumented using rotary ProTaper Universal files (Dentsply, Maillefer, Ballaigues, Switzerland). The ProTaper sequence (S1, S2, F1, F2) was used for the preparation at the working length.

Irrigation was performed after every instrument with $2 \mathrm{ml}$ of $2.5 \% \mathrm{NaOCl}$ solution and the canal space was filled with irrigant during the instrumentation phase. After the shaping and cleaning of the root canal, the roots were dried with $96 \%$ alcohol and paper points. Root canal filling was done by matched single-cone obturation with a master cone (F2 gutta-percha, Maillefer-Dentsply, Ballaigues, Switzerland) and sealer (AH plus; Dentsply De Trey GmbH, Konstanz, Germany). The access cavity was temporarily filled with Fuji Triage Pink (GC Europe, Leuven, Belgium). Fuji Triage Pink was applied to the apical part of the root in order to prevent leakage through the apex. The teeth were stored in an incubator (mco-18aic, Sanyo, Japan) for 1 week (at $37^{\circ} \mathrm{C}, 100 \%$ relative humidity).

Groups 1 and 2 received a minimal invasive post space preparation with a depth of $8 \mathrm{~mm}$, as measured from the CEJ on the buccal aspect of the tooth, but no post preparation drills recommended by the manufacturer were used in order to preserve the individual anatomy of the specimen teeth. Only the root canal filling was removed with size three Gates Glidden burs and ISO standard Hedstrom files leaving a minimum apical seal of 6-8 $\mathrm{mm}$ of gutta-percha in the canal. The Number 3 Gates Glidden bur was used on the full $8 \mathrm{~mm}$ length.

In Groups 3-5 the gutta-percha was only cut back $2 \mathrm{~mm}$ below the CEJ with an 0.1 mm diameter ball-shaped carbide bur (H1SM.205.010, Gebr. Brasseler GmbH \& Co. KG, Lemgo, Germany), but no post space preparation was performed. After cutting back the gutta-percha, the orifice was sealed with resin modified glass ionomer cement (Fuji VIII, GC Europe, Leuven, Belgium). 
All specimen received the same adhesive treatment. Prior to the adhesive treatment of the cavity and the root canal, enamel was acid-etched selectively with $37 \%$ phosphoric acid for $15 \mathrm{~s}$ and rinsed with water. The root canal and the coronal cavity were rinsed with $2 \mathrm{ml}$ of water and dried with paper points and air. For bonding, a dual-cure one-step self-etch adhesive system (Gradia Core Self-Etching Bond, GC Europe, Leuven, Belgium) was used, according to the manufacturer's instructions using a microbrush-X disposable applicator (Pentron Clinical Technologies, LLC, USA). Excess adhesive was removed by suction drying (Evacuation Tip - Starryshine, Anaheim, CA, USA) within $0.5 \mathrm{~cm}$ from the occlusal cavity (without contact). Excess adhesive resin at the bottom of the canal was removed with a paper point. The adhesive was light-cured for $60 \mathrm{~s}$ using an Optilux 501 quartz-tungsten-halogen light-curing unit (Kerr Corp., Orange, CA, USA). The average power density of the light source, measured with a digital radiometer (Jetlite light tester; J. Morita USA Inc. Irvine, CA, USA) prior to the bonding procedure, was $840 \pm 26.8 \mathrm{~mW} / \mathrm{cm}^{2}$.

Five different techniques were used to restore the specimens (Figure 1):

\section{Group 1}

The teeth received a prefabricated, conventional FRC post (GC Fiber post, GC Europe, Leuven, Belgium). Before the adhesive treatment, the conventional translucent FRC posts of $0.8 \mathrm{~mm}$ diameter (GC Fiber Post, GC Europe, Leuven, Belgium) was tried in and cut to a length $1 \mathrm{~mm}$ below the level of the occlusal cavity margins with a water-cooled diamond disc (Isomet 2000; Buehler Ltd., Lake Bluff, IL, USA) and cleaned with alcohol after try in. The posts received silanization of the surface (Ceramic Primer, GC Europe, Leuven, Belgium) following the manufacturer's recommendation. After silanization, the post surface was bonded with the same bonding agent used for the cavity. Luting of the posts and the core build-up was performed with a dual-cure resin composite core material (Gradia Core, GC Europe, Leuven, Belgium). Gradia Core was applied using its own automix cartridge with an 'elongation tip' for direct root canal application. After insertion of the post, $5 \mathrm{~min}$ of chemopolymerization time was provided to reduce polymerisation stress, then cement was polymerized with an Optilux 501 quartz tungsten-halogen light-curing unit for $60 \mathrm{~s}$ from each side (a total of $240 \mathrm{~s} /$ tooth). The outlines of the restoration were finished with dental composite (G-aenial Posterior P-JE, GC Europe, Leuven, Belgium).

\section{Group 2}

The teeth were reconstructed with a novel method of building a direct layered FRC post and core (DLFRC post and core) from SFRC (EverX Posterior, GC Europe, Leuven, Belgium). The DLFRC post and core was horizontally layered in 1-2 mm segments. An increment of SFRC was packed to the apical portion of the postspace using a microbrush-X disposable applicator (Pentron Clinical Technologies, LLC, USA). A light transmitting FRC post (0.8 mm GC Fiber post, GC Europe, Leuven, Belgium) was inserted into the postspace in order to aid the transmission of the light to the apically positioned layers. The 'light transmitting' post was withdrawn with $0.5-1 \mathrm{~mm}$ from the surface of the uncured SFRC layer not to have direct contact with it.

After each layer $80 \mathrm{~s}$ of light curing through the fiber post was carried out. After incrementally filling the root canal to the level of the CEJ with repeating the previously described procedure, SFRC was layered in the coronal cavity until $1 \mathrm{~mm}$ below the margin of the 

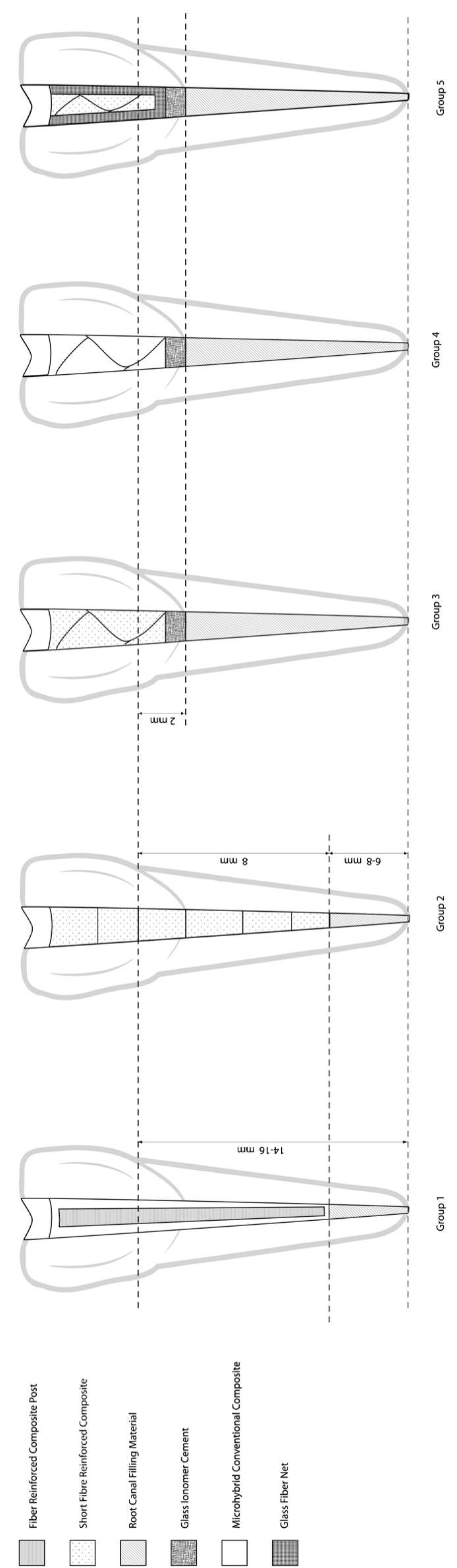

Figure 1. Restored study groups, layering concepts and restorative materials applied. 
occlusal cavity in a concave shape. Each increment was light cured from the occlusal surface for $40 \mathrm{~s}$. The outlines of the restoration were finished with dental composite (G-aenial Posterior P-JE, GC Europe, Leuven, Belgium).

\section{Group 3}

The cavities were restored with SFRC material applied in an oblique incremental technique. The material was placed in consecutive $2 \mathrm{~mm}$ thick increments. Each increment was light cured from the occlusal surface for $40 \mathrm{~s}$. The last $1 \mathrm{~mm}$ thick occlusal layer was composite material (G-aenial Posterior PJ-E, GC Europe, Leuven, Belgium) covering the SFRC.

\section{Group 4}

The cavities were restored with microhybrid composite restorative material (G-aenial Posterior PJ-E, GC Europe, Leuven, Belgium) applied with an oblique incremental technique. The material was placed in consecutive $2 \mathrm{~mm}$ thick increments. Each increment was light cured from the occlusal surface for $40 \mathrm{~s}$.

\section{Group 5}

The cavity walls were coated with flowable composite (G-aenial Flo, GC Europe, Leuven, Belgium) and before curing, a piece of preimpregnated glass fiber net (Everstick net, GC Europe, Leuven, Belgium) (10 mm long, $3 \mathrm{~mm}$ width) was cut and embedded inside the flowable composite first in buccal to lingual, then a mesial to distal direction. After curing for $40 \mathrm{~s}$, another glass fiber band was adapted to the walls circumferentially, forming the FRC 'box'. The remaining central part of the cavity was restored with SFRC and a final layer of composite as described in Group 3.

Finally, for all specimens, glycerine gel (DeOx Gel, Ultradent Products Inc., Orange, CA, USA) was applied and final polymerization from each side for $40 \mathrm{~s}$ was performed. The restorations were finished with a fine granular diamond burr (FG 7406-018, Jet Diamonds, USA and FG 249-F012, Horico, Germany) and aluminum oxide polishers (OneGloss PS Midi, Shofu Dental GmbH, Ratingen, Germany).

After the restorative procedures, the specimens were stored in physiological saline solution (Isotonic Saline Solution 0.9\% B. Braun, Melsungen, Germany) in an incubator (mco18aic, Sanyo, Japan) for 1 week (at $37^{\circ} \mathrm{C}, 100 \%$ humidity) before the fracture strength test. Prior to embedding, the root surface of each tooth was coated with a layer of liquid latex separating material (Ruber-Sep, Kerr, Orange, CA, USA) to simulate the periodontal ligament.[30] Specimens were embedded in methacrylate resin (Technovit 4004, HeraeusKulzer) at $2 \mathrm{~mm}$ from the CEJ to simulate the bone level. After embedding, all specimens were immediately subjected to a fracture resistance test using a universal loading device (5848 MicroTester1, Instron, Norwood, MA, USA). Each test was performed at a cross-head speed of $0.5 \mathrm{~mm} / \mathrm{min}$ and load was applied at $45^{\circ}$ using a $4.8 \mathrm{~mm}$ diameter stainless-steel ball-shaped stylus positioned to the central groove of the tooth providing two contacts with the triangular ridges and one with the more dominant marginal ridge. The maximum failure load was recorded in Newton's $(N)$.

A force vs. extension curve was dynamically plotted for each tooth (Figure 2). 


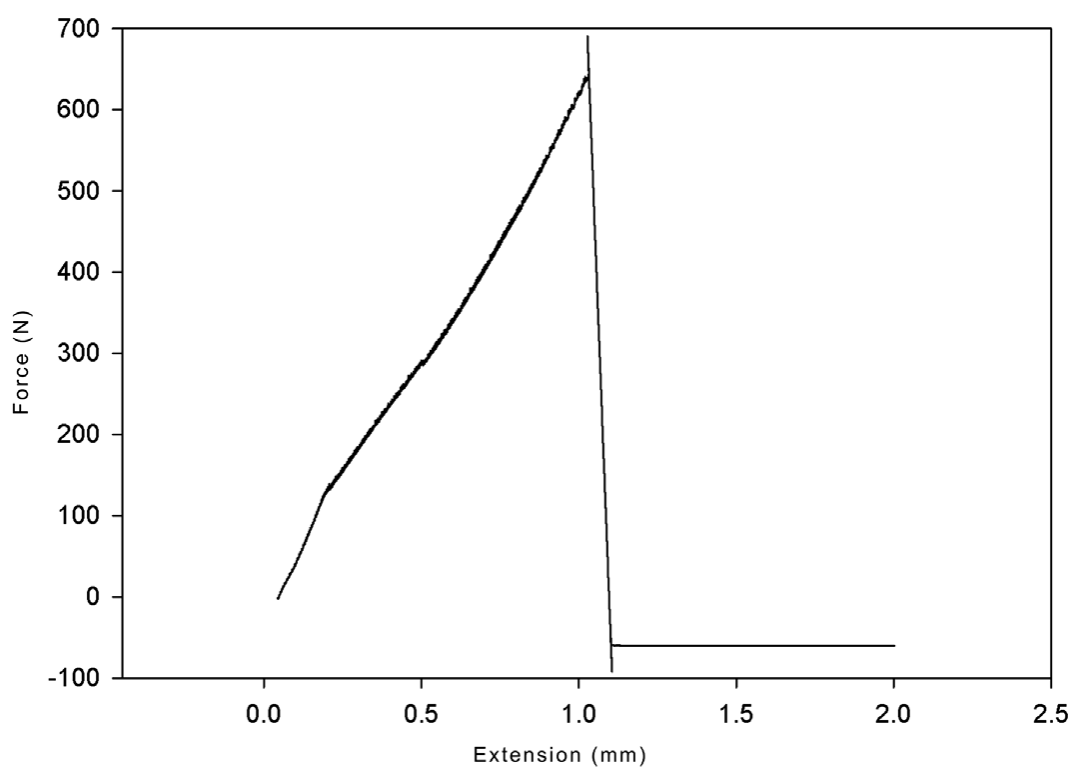

Figure 2. Representative force extension curve of fracture resistance tested on tooth sample for determination of maximum force of failure.

After mechanical testing, the specimens were examined for fracture patterns. According to Scotti and co-workers, distinction was made between restorable or nonrestorable fractures under optical microscope with a two-examiner agreement. A restorable fracture is above the CEJ, meaning that in case of fracture, the tooth can be restored, while a nonrestorable fracture extends below the CEJ and the tooth is likely to be extracted.[31]

Statistical analysis was conducted with SPSS 22.0 (IBM, USA). As the data were not normally distributed in all groups, the comparisons were performed with Kruskal-Wallis analysis of variance (ANOVA) with Dunn-Bonferroni post hoc pairwise comparisons. The level of significance was set at $p<0.05$.

\section{Results}

Table 1 summarizes the fracture thresholds for the different study groups. The control group exhibited the highest fracture resistance. The application of the DLFRC post and core technique yielded the highest fracture resistance among the restored groups. The fracture resistance of Group 2 (DLFRC post and core group) did not differ significantly from the intact teeth (control group). The rest of the groups proved to be significantly different from the control group in terms of fracture resistance. There was no statistically significant difference when comparing the restored groups regarding their fracture resistance. Therefore, the null hypothesis regarding fracture resistance was rejected.

In terms of fracture patterns, the tested groups 2, 3, 4, 5 were identical (Table 2). Only the control group and the FRC post showed dominantly repairable fractures. Therefore, the null hypothesis regarding fracture patterns was also rejected.

\section{Discussion}

In this study, maxillary premolars were used as they present an unfavorable anatomy in crown volume and crown to root proportion, making them more susceptible to cusp 
Table 1. Fracture thresholds of studied groups and the significance of their difference compared to the control group.

\begin{tabular}{lcccccc}
\hline Group & Sig. compared to control $(p$, post hoc $)$ & $N$ & Minimum $(N)$ & Maximum $(N)$ & Mean $(N)$ & SD \\
\hline Control & - & 12 & 605.85 & 1205.83 & 922.34 & 189.21 \\
Group 1 & 0.005 & 12 & 208.28 & 802.61 & 501.30 & 186.65 \\
Group 2 & 1.000 & 12 & 352.85 & 1171.19 & 727.98 & 287.37 \\
Group 3 & 0.009 & 12 & 123.59 & 865.93 & 511.61 & 225.20 \\
Group 4 & 0.005 & 12 & 216.67 & 748.44 & 456.24 & 189.75 \\
Group 5 & 0.023 & 12 & 303.64 & 682.83 & 536.35 & 126.41 \\
\hline
\end{tabular}

Notes: Group 1: glass fibre- reinforced post; Group 2: direct-layered glass fiber-reinforced composite core; Group 3: SFRC applied by an oblique incremental technique; Group 4: obliquely layered conventional composite and Group 5: torsion box with FRC net. As there was no significant difference among the restored groups in this respect, significances are shown as compared to the controls only.

Table 2. Fracture patterns.

\begin{tabular}{lcccccc}
\hline & Control & Group 1 & Group 2 & Group 3 & Group 4 & Group 5 \\
\hline Reparable & 0.66 & 0.58 & 0.33 & 0.33 & 0.33 & 0.33 \\
Irreparable & 0.33 & 0.42 & 0.66 & 0.66 & 0.66 & 0.66 \\
\hline
\end{tabular}

Notes: The numbers indicate relative frequencies ( $n=12$ in each group). Group 1: glass fibre- reinforced post; Group 2: direct-layered glass fiber-reinforced composite core; Group 3: SFRC applied by an oblique incremental technique; Group 4: obliquely layered conventional composite and Group 5: torsion box with FRC net.

fractures than other posterior teeth when submitted to occlusal load application.[10] An oblique load ( $45^{\circ}$ to the long axis of the tooth) was applied to the occlusal incline of the buccal cusp using a rounded loading tip, intended to simulate normal working side occlusal contacts.[3]

ETT demonstrate an increased risk of fracture, and therefore, an acceptable restoration, in addition to aesthetic considerations, should not only restore function, but should also aim to preserve and reinforce the remaining dental structures thus reducing the occurrence of catastrophic failures and increasing the longevity of the restoration.[32-35] However, there seems to be little evidence to guide the clinician toward the best restorative solution if only the access cavity needs restoring in a premolar tooth. $[4,9]$

According to several authors, posterior teeth with an endodontic access preparation and no other structural loss may succeed with a conservative bonded restoration. $[8,36,37]$ In the present study, the specimen restored with composite restorations applied with the oblique layering technique (Group 4) showed the lowest fracture resistance values among the restored groups; however, this was not statistically significantly lower compared to the other restored groups. These findings are in accordance with some studies showing that restored root-filled maxillary premolars without a fiber post showed similar fracture resistance to those when an FRC post was placed.[38-40] This could be attributed to the minimal invasive access cavity preparation in this study, leading to still acceptable internal splinting' with adhesively bonded composite restorations. Also, the inconsistency in the findings of different FRC post-related studies may be attributed to the difference in postspace preparation procedures. Preparing the root canal to receive a post with pilot drills and removing radicular dentine on purpose, might lead to cracks and defects that can concentrate stress and increase the possibility of tooth fracture.[41] For this reason, a minimal invasive postspace preparation was performed in this investigation, leading to the preservation of the individual, irregular root canal anatomy and shape. Because of this the inserted, smaller rigid FRC post could not fill out the root canal entirely, possibly leading 
to greater amount of luting composite in the prepared space. This could account for the inferior findings in the present study regarding the post-restored group as Group 1 was not statistically superior to the other restored groups.

SFRC is a dental restorative composite resin $[29,42,43]$ intended to be used in high stress bearing areas as a stress-breaker restorative material. Mechanical testing has shown major improvements in the load-bearing capacity, the flexural strength and also the fracture resistance of SFRC in comparison with conventional particulate filler composite resin. [44-48] In the current investigation, the group restored with obliquely layered SFRC (Group 3) reached higher fracture resistance figures compared to the ones restored with conventional composite (Group 4) or even the conventional FRC post group (Group 1); however, the difference was statistically not significant. This has been previously described in molar teeth with MOD cavities, where the SFRC-restored groups yielded better results than the conventional composite restored ones, yet the difference was not significant.[49]

While in the SFRC material the E-glass fibers are randomly oriented and possess isotropic features, leading to possible reinforcement in multiple directions, the E-glass fibers in the bidirectional pre-impregnated fiber-reinforced net (everStick Net) show orthotropic properties, therefore reinforcing the structure in two directions. [50,51] The threefold usage of FRC net (FRC box) together with the SFRC-restorative composite is aiming to reconstruct the integrity and strength of the opposing cavity walls. The values of the FRC box restorations showed an increase compared to Groups 1, 3 and 4, this technique could also not emulate the values measured in case of sound premolar teeth. However, in this study, there seems to be a clear tendency of increasing fracture resistance values toward the use of individualized FRC materials compared to conventional techniques (composite restoration or FRC postplacement). This observation is in accordance with the findings of Bijelic et al. [52]. The inferior, though not statistically different results of the FRC box group (Group 5) compared to the DLFRC post and core group (Group 2) can be explained by the coronal position of the FRC box, which can only keep the coronal part of the tooth together but does not reinforce the cervical and root part of the tooth.

Prefabricated FRC posts suffer from two main shortcomings in clinical settings: Insufficient bonding of the interfaces [53-55] and the fact that the post position is in the neutral axis of the root canal. Direct layering of SFRC into the root canal is intended to solve these drawbacks. Seyam et al. and other authors showed that a transparent post can transfer the light and aid the polymerization of composite resin in the root canal,[56-58] enabling layering in the hollow root canal space. However, there are investigations to oppose this statement $[59,60]$. The DLFRC post and core technique (Group 2) produced the highest fracture resistance values among the restored groups in the present study. These results seem to be in accordance with Garoushi et al. showing that the thicker the applied SFRC restoration the greater the fracture resistance is [61]. Although the numbers produced by Group 2 were not significantly higher than the rest of the restored groups, a positive tendency could be visible with the utilization of SFRC materials. Moreover, there was no statistically significant difference between the Group 2 and the intact teeth. This result suggests a move toward a biomimetic restorative concept. It has to be noted that the reported advantages come at the price of increased application time and technically more demanding clinical procedure as compared to Group 1. Development of materials, instruments and light curing equipment specifically for such purposes could be promising and could resolve the main shortcomings of the DLFRC post and core method as described in this investigation. 
Regarding fracture pattern, the tested groups were identical with dominantly unfavorable, irreparable fractures. Only the control group and Group 1 presented a shift toward favorable, repairable fractures. Therefore, the null hypothesis regarding fracture pattern was rejected. The DLFRC post and core technique according to the findings of this investigation might hold the potential of reinforcing the root and particularly the pericervical area, which is highly beneficial when shear forces are also present (e.g. $45^{\circ}$ loading). The DLFRC post and core concept theoretically could present a possibility to compensate for most of the known weaknesses of the presently accepted endo-restorative options with a not complicated, clinically feasible and reproducible methodology. Given these facts and the promising results in the current investigation, it is recommended to conduct further investigations particularly applying artificial ageing, cyclic loading until fracture, different cavity extensions and tooth groups in vitro.

The limitations of this investigation are the limited number of specimens, which makes it much more unlikely to exhibit statistical significance. It is also a limitation that maximal fracture resistance testing only indicates a certain physical property of the structure not giving information of the possibly clinically more relevant reaction to cyclic loading and ageing. Given the mentioned shortcomings the results and the novel method have to be implemented with caution. Therefore, the proposed techniques should require future testing in more clinically realistic situations. The proposed investigation could be deemed as a possible first, still critical step toward the development of clinically relevant future endo-restorative methods.

\section{Conclusions}

Within the limitations of this investigation, it can be concluded that natural teeth exhibit significantly higher fracture resistance then the endodontically treated and restored premolar teeth except for the DLFRC post and core restored group which did not show statistically significant difference compared to the control group. FRC posts exhibited more favorable fracture patterns then the other restored groups examined. The direct layered short fiber-reinforced post and core is a promising alternative to the accepted restorations of endodontically treated teeth, and as such should be further investigated.

\section{Acknowledgements}

The authors wish to thank Balázs P. Szabó PhD for his support in the fracture strength measurements. We also thank dean Prof. Katalin Nagy and dean Kinga Turzó PhD for their support in realizing this project.

\section{Disclosure statement}

No potential conflict of interest was reported by the authors.

\section{ORCID}

András Forster (iD http://orcid.org/0000-0002-3495-7105

Márk Fráter (DD http://orcid.org/0000-0002-0365-1613 


\section{References}

[1] Cecchin D, de Almeida JF, Gomes BP, et al. Effect of chlorhexidine and ethanol on the durability of the adhesion of the fiber post relined with resin composite to the root canal. J Endod. 2011;37:678-683.

[2] Dietschi D, Duc O, Krejci I, et al. Biomechanical considerations for the restoration of endodontically treated teeth: a systematic review of the literature - part 1. Composition and micro- and macrostructure alterations. Quintessence Int. 2007;38:733-743.

[3] Taha NA, Palamara JE, Messer HH. Fracture strength and fracture patterns of root filled teeth restored with direct resin restorations. J Dent. 2011;39:527-535.

[4] Mohammadi N, Kahnamoii MA, Yeganeh PK, et al. Effect of fiber post and cusp coverage on fracture resistance of endodontically treated maxillary premolars directly restored with composite resin. J Endod. 2009;35:1428-1432.

[5] Balkaya MC, Birdal IS. Effect of resin-based materials on fracture resistance of endodontically treated thin-walled teeth. J Prosthet Dent. 2013;109:296-303.

[6] Rocca GT, Krejci I. Crown and post-free adhesive restorations for endodontically treated posterior teeth: from direct composite to endocrowns. Eur J Esthet Dent. 2013;8:156-179.

[7] Tay FR, Pashley DH. Monoblocks in root canals: a hypothetical or a tangible goal. J Endod. 2007;33:391-398.

[8] Reeh ES, Messer HH, Douglas WH. Reduction in tooth stiffness as a result of endodontic and restorative procedures. J Endod. 1989;15:512-516.

[9] Wu Y, Cathro P, Marino V. Fracture resistance and pattern of the upper premolars with obturated canals and restored endodontic occlusal access cavities. J Biomed Res. 2010;24:474-478.

[10] Soares PV, Santos-Filho PC, Martins LR, et al. Influence of restorative technique on the biomechanical behavior of endodontically treated maxillary premolars. Part I: fracture resistance and fracture mode. J Prosthet Dent. 2008;99:30-37.

[11] Seow LL, Toh CG, Wilson NH. Strain measurements and fracture resistance of endodontically treated premolars restored with all-ceramic restorations. J Dent. 2015;43:126-132.

[12] Mondelli RF, Barbosa WF, Mondelli J, et al. Fracture strength of weakened human premolars restored with amalgam with and without cusp coverage. Am J Dent. 1998;11:181-184.

[13] Stappert CF, Att W, Gerds T, et al. Fracture resistance of different partial-coverage ceramic molar restorations: an in vitro investigation. J Am Dent Assoc. 2006;137:514-522.

[14] Scotti N, Scansetti M, Rota R, et al. The effect of the post length and cusp coverage on the cycling and static load of endodontically treated maxillary premolars. Clin Oral Invest. 2011;15:923-929.

[15] Bitter K, Noetzel J, Stamm O, et al. Randomized clinical trial comparing the effects of post placement on failure rate of postendodontic restorations: preliminary results of a mean period of 32 months. J Endod. 2009;35:1477-1482.

[16] Nothdurft FP, Seidel E, Gebhart F, et al. The fracture behavior of premolar teeth with class II cavities restored by both direct composite restorations and endodontic post systems. J Dent. 2008;36:444-449.

[17] Qualtrough AJ, Mannocci F. Tooth-colored post systems: a review. Oper Dent. 2003;28:86-91.

[18] Soares CJ, Soares PV, de Freitas Santos-Filho PC, et al. The influence of cavity design and glass fiber posts on biomechanical behavior of endodontically treated premolars. J Endod. 2008;34:1015-1019.

[19] Stockton L, Lavelle CL, Suzuki M. Are posts mandatory for the restoration of endodontically treated teeth? Dent Traumatol. 1998;14:59-63.

[20] Trope M, Maltz DO, Tronstad L. Resistance to fracture of restored endodontically treated teeth. Dent Traumatol. 1985;1:108-111.

[21] Zicari F, Van Meerbeek B, Scotti R, et al. Effect of fiber post length and adhesive strategy on fracture resistance of endodontically treated teeth after fatigue loading. J Dent. 2012;40:312-321.

[22] Meyenberg K. The ideal restoration of endodontically treated teeth-structural and esthetic considerations: a review of the literature and clinical guidelines for the restorative clinician. Eur J Esthet Dent. 2013;8:238-268. 
[23] Paolone G, Saracinelli M, Devoto W, et al. Esthetic direct restorations in endodontically treated anterior teeth. Eur J Esthet Dent. 2013;8:44-67.

[24] Maceri F, Martignoni M, Vairo G. Mechanical behaviour of endodontic restorations with multiple prefabricated posts: a finite-element approach. J Biomech. 2007;40:2386-2398.

[25] Le Bell-Ronnlof AM, Lassila LV, Kangasniemi I, et al. Load-bearing capacity of human incisor restored with various fiber-reinforced composite posts. Dent Mater. 2011;27:e107-e115.

[26] Garoushi S, Vallittu PK, Lassila LV. Direct restoration of severely damaged incisors using short fiber-reinforced composite resin. J Dent. 2007;35:731-736.

[27] Frater $\mathrm{M}$. The restorative use of fibre-reinforced materials in the posterior region [ $\mathrm{PhD}$ thesis]. Szeged, Hungary: University of Szeged; 2015.

[28] Frater M, Forster A, Jantyik A, et al. In vitro fracture resistance of premolar teeth restored with fibre-reinforced composite posts using a single or a multi-post technique. Aust Endod J; 2016. doi: 10.1111/aej.12150. [Epub ahead of print]

[29] Schneider SW. A comparison of canal preparations in straight and curved root canals. Oral Sur. Oral Med Oral Pathol. 1971;32:271-275.

[30] Magne P, Paranhos MP, Schlichting LH. Influence of material selection on the risk of inlay fracture during pre-cementation functional occlusal tapping. Dent Mater. 2011;27:109-113.

[31] Scotti N, Coero Borga FA, Alovisi M, et al. Is fracture resistance of endodontically treated mandibular molars restored with indirect onlay composite restorations influenced by fiber post insertion? J Dent. 2012;40:814-820.

[32] Batalha-Silva S, de Andrada MA, Maia HP, et al. Fatigue resistance and crack propensity of large MOD composite resin restorations: direct versus CAD/CAM inlays. Dent Mater. 2013;29:324331.

[33] Dejak B, Mlotkowski A. Finite element analysis of strength and adhesion of cast posts compared to glass fiber-reinforced composite resin posts in anterior teeth. J Prosthet Dent. 2011;105:115126.

[34] Torbjorner A, Fransson B. Biomechanical aspects of prosthetic treatment of structurally compromised teeth. Int J Prosthodont. 2004;17:135-141.

[35] Torres-Sanchez C, Montoya-Salazar V, Cordoba P, et al. Fracture resistance of endodontically treated teeth restored with glass fiber reinforced posts and cast gold post and cores cemented with three cements. J Prosthet Dent. 2013;110:127-133.

[36] Scotti N, Rota R, Scansetti M, et al. Influence of adhesive techniques on fracture resistance of endodontically treated premolars with various residual wall thicknesses. J Prosthet Dent. 2013;110:376-382.

[37] Steele A, Johnson BR. In vitro fracture strength of endodontically treated premolars. J Endod. 1999;25:6-8.

[38] Yamada Y, Tsubota Y, Fukushima S. Effect of restoration method on fracture resistance of endodontically treated maxillary premolars. Int J Prosthodont. 2004;17:94-98.

[39] Krejci I, Duc O, Dietschi D, et al. Marginal adaptation, retention and fracture resistance of adhesive composite restorations on devital teeth with and without posts. Oper Dent. 2003;28:127-135.

[40] Fokkinga WA, Le Bell AM, Kreulen CM, et al. Ex vivo fracture resistance of direct resin composite complete crowns with and without posts on maxillary premolars. Int Endod J. 2005;38:230-237.

[41] Siso SH, Hurmuzlu F, Turgut M, et al. Fracture resistance of the buccal cusps of root filled maxillary premolar teeth restored with various techniques. Int Endod J. 2007;40:161-168.

[42] Cailleteau JG, Rieger MR, Akin JE. A comparison of intracanal stresses in a post-restored tooth utilizing the finite element method. J Endod. 1992;18:540-544.

[43] Garoushi S, Vallittu PK, Lassila LV. Short glass fiber reinforced restorative composite resin with semi-inter penetrating polymer network matrix. Dent Mater. 2007;23:1356-1362.

[44] Garoushi S, Vallittu PK, Watts DC, et al. Polymerization shrinkage of experimental short glass fiber-reinforced composite with semi-inter penetrating polymer network matrix. Dent Mater. 2008;24:211-215.

[45] Garoushi S, Vallittu PK, Lassila LV. Fracture toughness, compressive strength and load-bearing capacity of short glass fiber-reinforced composite resin. Chin J Dent Res. 2011;14:15-19. 
[46] Vallittu PK. Flexural properties of acrylic resin polymers reinforced with unidirectional and woven glass fibers. J Prosthet Dent. 1999;81:318-326.

[47] Lassila LV, Nohrstrom T, Vallittu PK. The influence of short-term water storage on the flexural properties of unidirectional glass fiber-reinforced composites. Biomaterials. 2002;23:2221-2229.

[48] Turkaslan S, Bagis B, Akan E, et al. Fracture strengths of chair-side-generated veneers cemented with glass fibers. Niger J Clin Pract. 2015;18:240-246.

[49] Frater M, Forster A, Kereszturi M, et al. In vitro fracture resistance of molar teeth restored with a short fiber-reinforced composite material. J Dent. 2014;42:1143-1150.

[50] Fennis WM, Tezvergil A, Kuijs RH, et al. In vitro fracture resistance of fiber reinforced cuspreplacing composite restorations. Dent Mater. 2005;21:565-572.

[51] Basaran EG, Ayna E, Vallittu PK, et al. Load bearing capacity of fiber-reinforced and unreinforced composite resin CAD/CAM-fabricated fixed dental prostheses. J Prosthet Dent. 2013;109:88-94.

[52] Bijelic J, Garoushi S, Vallittu PK, et al. Short fiber reinforced composite in restoring severely damaged incisors. Acta Odontol Scand. 2013;71:1221-1231.

[53] Bell AM, Lassila LV, Kangasniemi I, et al. Bonding of fiber-reinforced composite post to root canal dentin. J Dent. 2005;33:533-539.

[54] Belli S, Eraslan O, Eskitascioglu G, et al. Monoblocks in root canals: a finite elemental stress analysis study. Int Endod J. 2011;44:817-826.

[55] Chieruzzi M, Pagano S, Pennacchi M, et al. Compressive and flexural behaviour of fiber reinforced endodontic posts. J Dent. 2012;40:968-978.

[56] Seyam RS, Mobarak EH. Reinforcement of teeth with simulated coronal fracture and immature weakened roots using resin composite cured by a modified layering technique. Oper Dent. 2014;39:E128-E136.

[57] Galhano GA, de Melo RM, Barbosa SH, et al. Evaluation of light transmission through translucent and opaque posts. Oper Dent. 2008;33:321-324.

[58] Aksornmuang J, Nakajima M, Panyayong W, et al. Effects of photocuring strategy on bonding of dual-cure one-step self-etch adhesive to root canal dentin. Dent Mater J. 2009;28:133-141.

[59] Goracci C, Corciolani G, Vichi A, et al. Light-transmitting ability of marketed fiber posts. J Dent Res. 2008;87:1122-1126.

[60] Faria e Silva AL, Arias VG, Soares LE, et al. Influence of fiber-post translucency on the degree of conversion of a dual-cured resin cement. J Endod. 2007;33:303-305.

[61] Garoushi S, Mangoush E, Vallittu M, et al. Short fiber reinforced composite: a new alternative for direct only restorations. Open Dent J. 2013;7:181-185. 


\section{In vitro fracture resistance of premolar teeth restored with fibre- reinforced composite posts using a single or a multi-post technique}

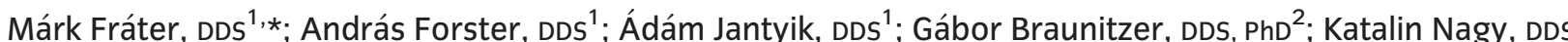
$\mathrm{PhD}^{2}$; and Simone Grandini, DDS, $\mathrm{PhD}^{3}$

1 Department of Operative and Esthetic Dentistry, Faculty of Dentistry, University of Szeged, Szeged, Hungary

2 Department of Oral Surgery, Faculty of Dentistry, University of Szeged, Szeged, Hungary

3 Department of Endodontics and Restorative Dentistry, Universita degli Studi di Siena, Siena, Italy

\section{Keywords}

bicuspid, fibreglass reinforced polymers, multipost, single post, tooth endodontically treated.

\section{Correspondence}

Dr. Márk Fráter, Faculty of Dentistry, University of Szeged, Tisza Lajos körút 64, Szeged 6722, Hungary. Email: meddentist.fm@gmail.com

doi: 10.1111/aej.12150

\begin{abstract}
The purpose of this study was to evaluate the reinforcing effect of fibre-reinforced composites (FRC) applied in premolar teeth with different techniques and minimally invasive post space preparation. Fifty extracted and endodontically treated premolar teeth were used. The teeth were divided into five groups $(n=10)$ depending on the restorative technique (Groups 1-5). Group 1: one single conventional post, Group 2: one main conventional and one collateral post, Group 3: one elastic post, Group 4: one main elastic and one collateral post, and Group 5: individual post formed of elastic posts. After cementation and core build-up, the specimens were submitted to static fracture resistance test. Fracture thresholds and fracture patterns were measured and evaluated. Group 4 showed the highest average fracture resistance among the tested groups. The multi-post techniques (group 2 and 4) exhibited statistically higher fracture resistance compared to group 1. Regarding fracture patterns, there was no statistically significant difference between the tested groups. Within the limitations of this study, the application of multiple elastic or conventional FRC posts or a single elastic post in the same root canal is beneficial in terms of fracture resistance compared to a single conventional FRC post. The elasticity or the number of posts did not influence the fracture patterns.
\end{abstract}

\section{Introduction}

Endodontically treated teeth (ETT) are structurally different from non-restored vital teeth, and they require specific restorative treatment (1). The differences include reduced moisture and dentin fracture resistance and decreased proprioception (2). According to Dietschi et al. (3), the consequences of these changes are negligible. The major issues with ETT seem to be the coronal destruction derived from caries, fractures of previous restorations, dentin loss due to the removal of the roof of the pulp chamber (4), and the weakening of the peri-cervical dentin during access preparation (5). As a result of the compromised structural integrity, an increased fracture tendency during normal function is notable (6). Thus, in most ETT, the use of intraradicular posts is rec- ommended to promote the retention of the final restoration and to biomechanically reinforce the remaining tooth structure (7). However, it has to be stated that if ETT still have substantial amount of remaining sound tooth structure, posts are not improving longevity of ETT but bear substantial risks when placing them $(8,9)$. In an attempt to address the problem of compromised structural integrity in ETT, the development and use of fibrereinforced composite (FRC) root canal posts have increased rapidly over the last 10 years (10).

Recent studies have shown that post space preparation weakens the remaining tooth structure further, thus paradoxically, the conventionally accepted process of strengthening the tooth may cause further increase in root fracture risk (11). This emphasises the importance of trying to preserve the original anatomy of the root canal 
and minimising dentin loss throughout the endo-restorative treatment. This leads to unique and irregular root canal forms in several cases, in which one FRC post cannot provide adequate mechanical friction on its own. Utilising multiple posts to treat wide, irregular endodontic cavities has already been proposed when restoring ETT (12). However, the use of this technique is limited when applying a minimally invasive approach in post space preparation.

To overcome the difficulties that irregular root canal forms pose, an elastic FRC post (everStick POST, GC Europe, Leuven) was introduced to the market in 2011 . This post is individually adaptable and its bonding and flexural properties (flexural strength: $1145 \mathrm{MPa}$, Young-modulus: $15 \mathrm{GPa}$ ) (13) appear to be superior to commercially available, prefabricated FRC posts (10).

The goal of the present in vitro study was to determine and compare the fracture resistance and fracture patterns of endodontically treated premolar teeth restored with different FRC posts in different configurations. The null hypotheses were the following: (1) The fracture resistance of the teeth restored with single or multiple posts would not be different. (2) The application of more elastic posts would not result in more favourable fracture patterns.

\section{Materials and methods}

Fifty upper premolar teeth extracted for periodontal or orthodontic reasons were selected for this study. The inclusion criteria were absence of caries or root cracks, no previous endodontic treatment, no posts or crowns, no resorption and the absence of lateral canals. Furthermore, buccolingual and mesiodistal radiographs of all teeth were taken and examined to evaluate root integrity and the number of canals present. To standardise procedures and materials, all teeth used in this study had one root canal in each root with a curvature of less than $5^{\circ}$, evaluated by Schneider's technique (14), and root length of $15 \pm 1 \mathrm{~mm}$ and rather similar mesiodistal and buccolingual dimensions $( \pm 10 \%)$ were selected.

The procedures of this study were approved by the Regional Ethics Committee for Human Medical Biological Research (University of Szeged, Hungary).

The freshly extracted teeth were immediately placed in $5.25 \% \mathrm{NaOCl}$ for $5 \mathrm{~min}$ and then stored in $0.9 \%$ saline solution at room temperature. The teeth were used within 6 months after the extraction. During specimen preparation, the soft tissue covering of the root surface was removed with hand scalers.

Before root canal treatment, all crowns were sectioned at the level of the cementoenamel junction (CEJ) perpendicular to the longitudinal axis, using a slow-speed, water-cooled diamond disc.
At the beginning of the root canal treatment, the working length was established using a direct method, by subtracting $1 \mathrm{~mm}$ from the actual root length determined by introducing a no. $10 \mathrm{~K}$-file (Maillefer-Dentsply, Ballaigues, Switzerland) until it was visible through the apical foramen. A crown down technique was used for instrumentation with Gates Glidden (Union Broach, York, PA) \#2 to \#4 drills and then the canals were instrumented using rotary ProTaper files (Dentsply, Maillefer, Ballaigues, Switzerland). The series of the ProTaper system (S1, S2, F1, F2, F3) was used for the preparation at the working length.

Irrigation was performed after every change of instrument with $2 \mathrm{ml}$ of $2.5 \% \mathrm{NaOCl}$ solution and the canal space was filled with irrigant during the instrumentation phase. A root canal lubricant (Glyde, Dentsply-Maillefer, Konstanz, Germany) was only used during the shaping of the coronal third. After shaping and cleaning, the roots were dried with $96 \%$ alcohol and paper points. Root canal filling was performed by matched-single-cone obturation with a master cone (F3 gutta-percha, Maillefer-Dentsply) matching the final instrument used for preparation and sealer (AH plus; Dentsply De Trey GmbH, Konstanz, Germany). The root access was temporarily filled with Clearfil SE Bond and Clearfil AP-X (Kuraray, Tokyo, Japan). The same composite was applied to the apical part of the root in order to prevent leakage through the apex. The teeth were then stored in an incubator (mco-18aic, Sanyo, Moriguchi, Osaka, Japan) for 1 week (at $37{ }^{\circ} \mathrm{C}, 100 \%$ relative humidity).

After 1 week of incubation, post space was prepared in the root portions of the teeth with a depth of $10 \mathrm{~mm}$, as measured from the CEJ on the buccal aspect of the tooth, but no post space preparation drill was used so that the individual anatomy could be preserved. Only the root canal filling was removed with size 3 Gates Glidden burs and ISO standard Hedstrom files, leaving a minimum apical seal of 4-6 $\mathrm{mm}$ of gutta-percha in the canal.

For the restorations, two different types of FRC posts were used: a prefabricated, conventional FRC post $(0,8$ GC Fiber Post, GC Europe, Leuven, Belgium) and an elastic FRC post $(0,9$ EverStick POST, GC Europe, Leuven, Belgium).

The conventional translucent FRC posts of $0.8 \mathrm{~mm}$ diameter (Fiber Post) were tried in and cleaned with alcohol afterwards. The posts did not receive any surface treatment. The elastic FRC posts were handled according to the manufacturer's instructions, with sterile tweezers. Regardless of the exact type, the main posts were placed in a way that $5.0 \mathrm{~mm}$ was left above the level of decoronation, and $10.0 \mathrm{~mm}$ was inserted into the root canal. This way, a uniform $15.0 \mathrm{~mm}$ fibre length was achieved. 
The teeth were randomly distributed in five study groups, each group consisting of 10 teeth.

Group 1 received one single conventional FRC post $(0.8 \mathrm{~mm})$. Group 2 received one main conventional FRC post and one collateral post ( $0.8 \mathrm{~mm}$ both) using a "multi-post technique". The collateral post was inserted next to the main post as apically as possible without causing manually perceivable stress but it was always deep enough to wedge the main post in the canal. Group 3 received one single elastic FRC post $(0.9 \mathrm{~mm})$. According to the manufacturer's instructions, the post was inserted into the root canal, and adapted to its form. Once adapted, the post was removed from the root canal with a needle-nose plier and light-cured for $40 \mathrm{~s}$ so that it would retain the shape of the canal. Group 4 received one main elastic FRC post and one elastic collateral post (0.9 mm both) using a multi-post technique. The collateral post was inserted next to the main post as apically as possible without causing manually perceivable stress. The posts were removed as one unit from the root canal with a needle-nose plier and then light-cured for $40 \mathrm{~s}$ maintaining their position together in the canal. Group 5 received as many elastic FRC posts $(0.9 \mathrm{~mm})$ as possible bundled according to the thickness of the root canal using the lateral condensation method described by Hatta et al. (14). These posts were gently removed as one unit with a needle-nose plier from the root canal, and then lightcured for $40 \mathrm{~s}$. It was confirmed in all cases that the elastic FRC posts were repositioned to their original position into the canal after light-curing. If resistance was met, the post surface was adjusted using carborundum point.

During the luting procedures, all groups received the same adhesive treatment by the same trained operator who completed a 3-year specialisation in restorative dentistry.

For bonding, a dual-cure one-step self-etch adhesive system (Gradia Core Self-Etching Bond, GC Europe, Leuven, Belgium) was used, according to the manufacturer's instructions. Luting of the posts and the core build-up was performed with a dual-cure resin composite core material (Gradia Core, GC Europe). Gradia Core was applied using its own automix cartridge with an 'elongation tip' for direct root canal application. After the insertion of the post(s), the composite core material was polymerised from the top of the post with an Optilux 501 quartz-tungsten-halogen light-curing unit for $60 \mathrm{~s}$ from each side (a total of $240 \mathrm{~s} /$ tooth).

In order to ensure the uniformity of the specimens, the composite resin core build-ups were standardised using cellulite core-forming matrices of the same size. These matrices were fabricated as vacuum formed foils by a dental technician modelled on a healthy premolar tooth, which was previously prepared for a crown with a $1 \mathrm{~mm}$ shoulder. The core build-up was prepolymerised for $20 \mathrm{~s}$, then glycerine gel (DeOx Gel; Ultradent Products Inc., Orange, CA, USA) was applied and final polymerisation was performed from each side for $40 \mathrm{~s}$ with an Optilux 501 quartz-tungsten-halogen light-curing unit. After the cementation procedures, the specimens were stored in physiological saline solution (isotonic saline solution $0.9 \%$ B. Braun, Melsungen, Germany) in an incubator (mco-18aic, Sanyo) for 1 week (at $37^{\circ} \mathrm{C}, 100 \%$ humidity) before the fracture test. The specimens were embedded as described by Frater et al. (15).

After embedding, all specimens were immediately subjected to a fracture resistance test using a universal loading device (5848 MicroTesterl; Instron, Norwood, MA, USA). Each test was performed at a cross-head speed of $0.5 \mathrm{~mm} \mathrm{~min}{ }^{-1}$. Load was applied at $45^{\circ}$ to the long axis of the tooth by adjusting a stainless steel ball-shaped stylus to the occlusal surface of the abutment in a stabile position (16). The failure loads were recorded in Newtons (N). A force vs. extension curve was dynamically plotted for each tooth.

After the mechanical testing, the specimens were examined for fracture patterns. A distinction was made between restorable or non-restorable fractures, following the protocol proposed by Scotti et al. (17), under optical microscope with a two-examiner agreement (Scotti et al., 2012). A restorable fracture was recognised as one above the CEJ, meaning that in case of fracture, the tooth could be re-restored, while a non-restorable fracture extends below the CEJ and extraction is likely to become necessary (18). Statistical analysis was conducted with SPSS 17.0 (SPSS Inc., Chicago, IL, USA). As the data were not normally distributed in all groups, the comparisons were performed with Kruskal-Wallis ANOva with post-hoc pairwise comparisons. The level of significance was set at $P<0.05$.

\section{Results}

The mean fracture resistance $(\mathrm{N})$ and the SD for each of the five experimental conditions are presented in Figure 1. As the table shows, group 4 (containing one main and one elastic FRC post) showed the highest average fracture resistance, however, this difference was only significant compared to group 1 (containing a single conventional FRC post) $(P=0.027)$. Group 2 (containing one main and one collateral conventional FRC post) showed significantly higher fracture resistance compared to group $1(P=0.038)$. However, neither of the multipost techniques yielded significantly better results than the single elastic post technique. According to the findings, null hypothesis 1 was accepted as multiple post restorations investigated did not show significantly higher fracture resistance in all set-ups. 


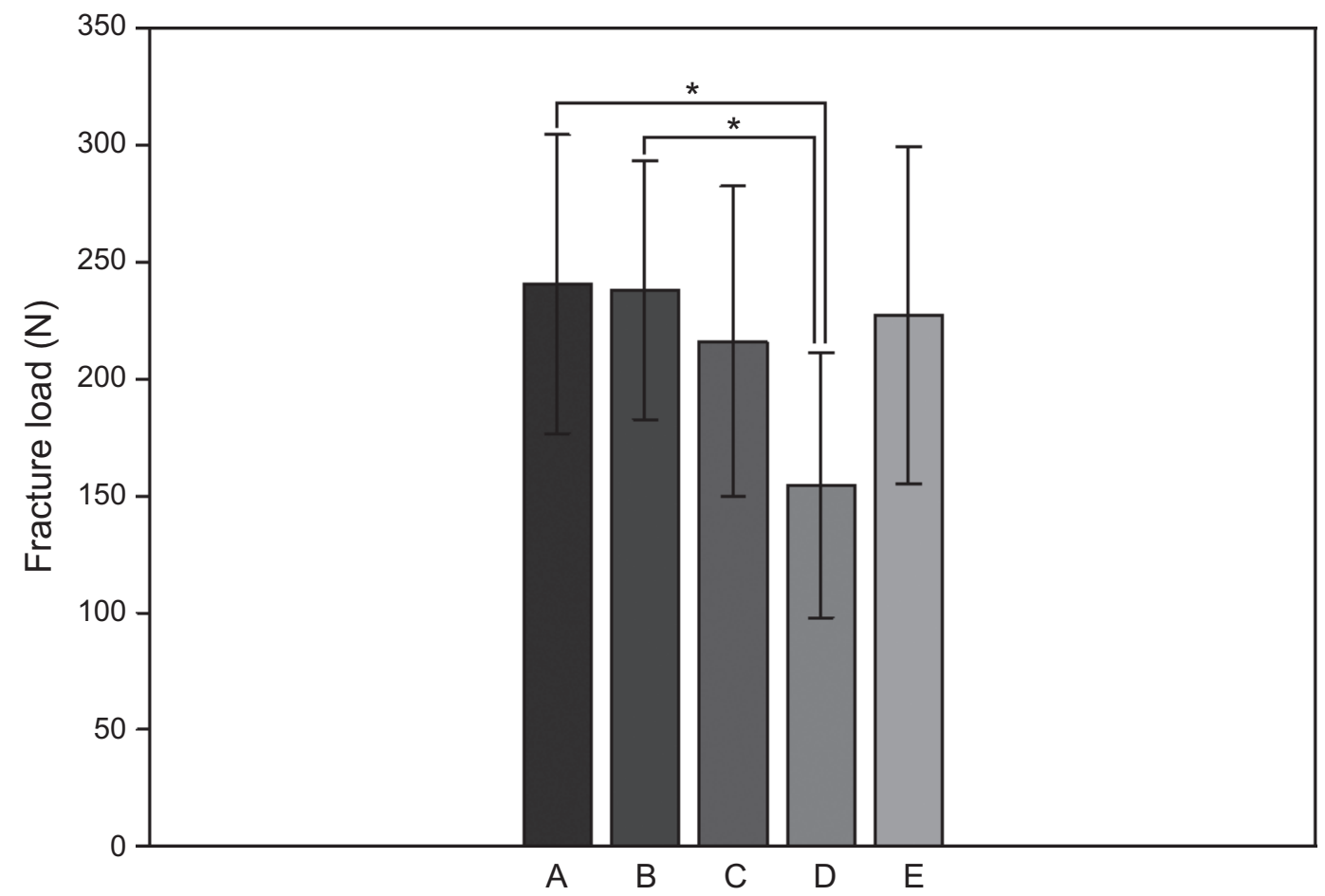

Figure 1 Fracture loads in the different study groups (mean \pm SD). A: multiple elastic posts B: multiple conventional FRC posts C: single elastic post D: single conventional FRC post E: lateral condensation with elastic posts. *Significant difference at the level $P<0.05$ (See also table).

There was no statistically significant difference when comparing the rest of the groups regarding their fracture resistance. In terms of fracture patterns, the tested groups were almost perfectly identical (see Table 1). Therefore, the null hypothesis 2, regarding fracture patterns was accepted. The application of more elastic posts would not result in more favourable fracture patterns.

\section{Discussion}

Restoration of non-vital teeth is a focal issue in restorative and prosthetic dentistry $(3,19)$, which is underlined by the fact that endodontic posts for the restoration of such teeth appeared as early as in the $1800 \mathrm{~s}$. It is highly recommended that post insertion should not be carried

Table 1 Descriptive statistics of the fracture loads measured in the different groups. The values are given in Newtons

\begin{tabular}{|c|c|c|c|c|c|}
\hline Group & $\mathrm{N}$ & Mean & Minimum & Maximum & SD \\
\hline Multiple elastic posts & 10 & 240.64 & 146.88 & 330.12 & 63.85 \\
\hline $\begin{array}{l}\text { Multiple conventional } \\
\text { FRC posts }\end{array}$ & 10 & 237.99 & 165.93 & 361.63 & 55.26 \\
\hline Single elastic post & 10 & 215.98 & 57.22 & 312.04 & 66.33 \\
\hline $\begin{array}{l}\text { Single conventional FRC } \\
\text { post }\end{array}$ & 10 & 154.50 & 65.99 & 271.22 & 56.63 \\
\hline $\begin{array}{c}\text { Lateral condensation } \\
\text { with elastic posts }\end{array}$ & 10 & 227.30 & 142.82 & 367.88 & 72.20 \\
\hline
\end{tabular}

out at the cost of sacrificing radicular dentin $(20,21)$. Studies have shown that post space preparation does not only weaken the tooth structure $(22,23)$ but it might also lead to cracks and defects that can concentrate stress and increase the possibility of tooth fracture and tooth loss (22). According to several authors up to $20 \%$ of ETT with radicular post suffer a vertical fracture (24-29).

It seems to be supported that dentin exhibits a fracture toughening mechanisms therefore reducing the possibility of crack progression $(4,29,30)$. For the mentioned reasons, a minimally invasive post space preparation protocol was performed. Consequentially, posts of the smallest available diameter $(0.8 \mathrm{~mm}$ GC Fiber Post; 0.9 mm everStick POST) were selected for the study.

This is in accordance with Sorensen et al. (31) who showed that a significant increase can be measured in the fracture resistance of restored teeth when the posts are

Table 2 The distribution of fracture patterns among the study groups

\begin{tabular}{lll}
\hline & Restorable & Non-restorable \\
\hline Multiple posts/elastic & $7(70 \%)$ & $3(30 \%)$ \\
Multiple posts/conventional & $7(70 \%)$ & $3(30 \%)$ \\
Single post/elastic & $7(70 \%)$ & $3(30 \%)$ \\
Single post/conventional & $7(70 \%)$ & $3(30 \%)$ \\
Lateral condensation/elastic & $6(60 \%)$ & $4(40 \%)$ \\
\hline
\end{tabular}


adapted closely to the canal walls. According to Maceri et al. (12), a multi-post technique may not only lead to better adaptation but will also possibly reduce pull out risk and induce restoration durability to long-term cyclic loading. Therefore, applying multiple posts in the same canal (multi-post technique) or using an individual post is aiming to achieve a better fit to the individual, preserved root canal anatomy possibly enhancing long-term clinical prognosis.

Through the use of a multi-post technique utilising small diameter posts, the operator is also able to fill large and irregular root cavities more efficiently than with a single, centrally positioned post (12).

The results of this study appear to favour the use of multiple posts in the same root canal. Both multi-post techniques (conventional FRC (group 2) and elastic FRC (group 4)) yielded significantly higher fracture resistance than the single post conventional FRC restoration (group 1). It seems supported by the findings that the elasticity of the post is not particularly important when applying a multi-post technique, as there was no statistical difference between the conventional and elastic multi-post techniques in terms of the fracture resistance of the restorations. It is interesting to note that neither of the two multi-post techniques yielded significantly different fracture resistance from the single elastic post technique. The use of a minimally invasive post space preparation therefore may explain the non-significance between the results when using a single elastic post and a multi-post technique as even a single elastic post can achieve a good fit, thus adequate stability in case of a preserved, relatively irregular root canal cross section. Therefore, the null hypothesis regarding fracture resistance was partially rejected (only for non-elastic FRC posts). A possible explanation is that the elasticity (and thus better adaptability) of the particular type of elastic post used in this study was enough to make up for the disadvantages of using a single post only. However, the limitations of this investigation cannot lead to this conclusion, so further studies on the adaptive properties of the elastic FRC posts are necessary.

The rationale behind experimenting with custom (individual) post techniques in spite of the advantages of the application of multiple posts is twofold: one of the reasons is that the problem of the insertion of geometrically uniform and symmetric single FRC post(s) into a root canal of irregularly changing diameter along its length is still not completely resolved. The other reason is that the amount of luting cement should be minimised, and the multi-post techniques, by nature, do not fully meet this requirement.

There are several methods to fabricate individual root canal posts $(1,14,32,33)$. In this study, the "lateral conden- sation method" of Hatta and colleagues was used (14). It is suggested that posts fabricated with this technique might contain a higher volume of FRC, which, in turn, may result in higher load-bearing capacity and a greater stability to the restoration. In the present study, the individual posts (group 5) yielded better results than restoration with a single FRC post (groups 1 and 3). However, the difference did not reach the level of statistical significance. These results are in agreement with those of Hatta et al. (14) and Le BellRonnlof et al. (34) in this respect.

Based on the present results, the fracture resistances yielded by the individual post technique and the two multi-post techniques were not significantly different. The reason might be the minimal invasive preparation of the root canal, which can limit the number of posts insertable to approximately the same depth thus making the cement-glass fibre ratio of the single-post techniques relatively similar to that of the multiple post techniques. This phenomena leads to the conclusion that most likely the preservation of tooth structure is the key influencing factor in term of mechanical behaviour of ETT as supported by Wandscher et al. (16).

Fracture of the post(s) or the restored tooth itself are among the most common failures of ETT restoration $(28,29)$. In the present study, no difference was found between the study groups regarding the fracture pattern. As for that matter, the results are observably uniform (see Table 2). Thus, the null hypothesis regarding fracture patterns was accepted. This contradicts the findings of Maceri et al. (12) who conclude that multi-post techniques would reduce the risk of irreversible root fractures. Nevertheless, it has to be noted that teeth examined by Maceri and co-workers have had a ferrule, and were restored with a crown making a fundamentally different set-up compared to that of the current investigation.

In the present investigation, single-root upper premolars were tested because they have been shown to be more susceptible to root fractures when submitted to occlusal loading after endodontic treatment (11). Fracture toughness tests, with their limitations, provide an indication of the load-bearing capacity of restorations in simulated clinical situations (35). To better represent a clinical scenario, the techniques used in this study could be expanded to include artificial ageing and cyclic loading experiments. The use of a crown would also achieve this aim and may change the failure patterns of the conventional FRC posts by protecting the luting agent around these posts from delamination and degradation $(36,37)$. The importance of crowns in relation to the retention of posts may also be highlighted $(38,39)$.

According to Nam et al. (2), conventional fibre posts do not improve the fracture resistance of teeth without a 
dental ferrule. This may not be the case when teeth are restored using the techniques described in this paper. There are potential clinical benefits to investigating these new restorations in further lab-based studies. The decision to not use crowns in this study was based on the observations of a number of authors where subtle differences in post behaviour and performance may be masked when teeth are definitively restored (18,40-43). Despite these recommendations, the lack of a crown makes it impossible to extrapolate the results of this investigation to a clinical situation and there is a need for further experiments to bridge this gap.

The tested specimens received an oblique load (45 degree to the long axis of the tooth) which appears to be the worst-case scenario in terms of the fracture resistance of ETT as described by Wandscher et al. (16). Applying this angle of force to teeth without a dental ferrule placed significant stress on the cervical aspect of the restored tooth (44) and heavy shear forces on the post/luting agent/radicular dentine interfaces. This should represent a worst-case occlusal loading scenario for these teeth and acid-test the integrity of the tested restorations and tooth structure.

The data demonstrate low fracture loads across the samples which can be attributed to the compromised tooth structure (no ferrule), unfavourable loading forces and a lack of crown restoration. This highlights the importance of these three factors in the clinical success of restored, endodontically treated teeth and the importance of further investigations to achieve meaningful information about the best way to restore these teeth clinically.

\section{Conclusions}

Within the limitations of this in vitro study, single rooted premolars restored in the absence of ferrule show significantly higher fracture resistance when a multi-post technique is used, compared to utilising a single conventional FRC post.

No statistically significant difference was observed between using conventional or elastic FRC posts for multiple post restorations.

The teeth restored with a single elastic FRC post exhibited significantly higher fracture resistance than those restored with a single conventional FRC post.

Fracture patterns were similarly favourable in all groups. Multi-post techniques are superior to singlepost techniques in terms of achieved fracture resistance, regardless of the type of posts. Single canal teeth restored with multiple posts achieved superior fracture resistance to teeth restored with single, conventional FRC posts.

\section{References}

1. Cecchin D, de Almeida JF, Gomes BP, Zaia AA, Ferraz CC. Influence of chlorhexidine and ethanol on the bond strength and durability of the adhesion of the fiber posts to root dentin using a total etching adhesive system. J Endod 2011; 37: 1310-5.

2. Nam SH, Chang HS, Min KS, Lee Y, Cho HW, Bae JM. Effect of the number of residual walls on fracture resistances, failure patterns, and photoelasticity of simulated premolars restored with or without fiber-reinforced composite posts. J Endod 2010; 36: 297-301.

3. Dietschi D, Duc O, Krejci I, Sadan A. Biomechanical considerations for the restoration of endodontically treated teeth: a systematic review of the literature-Part 1. Composition and micro- and macrostructure alterations. Quintessence Int 2007; 38: 733-43.

4. Al-Omiri MK, Mahmoud AA, Rayyan MR, Abu-Hammad O. Fracture resistance of teeth restored with post-retained restorations: an overview. J Endod 2010; 36: 1439-49.

5. Clark D, Khademi J. Modern molar endodontic access and directed dentin conservation. Dent Clin North Am 2010; 54: 249-73.

6. Schwartz RS, Robbins JW. Post placement and restoration of endodontically treated teeth: a literature review.

J Endod 2004; 30: 289-301.

7. Cecchin D, Farina AP, Guerreiro CA, Carlini-Junior B. Fracture resistance of roots prosthetically restored with intra-radicular posts of different lengths. J Oral Rehabil 2010; 37: 116-22.

8. Fokkinga WA, Kreulen CM, Bronkhorst EM, Creugers NH. Up to 17-year controlled clinical study on post-andcores and covering crowns. J Dent 2007; 35: 778-86.

9. Mangold JT, Kern M. Influence of glass-fiber posts on the fracture resistance and failure pattern of endodontically treated premolars with varying substance loss: an in vitro study. J Prosthet Dent 2011; 105: 387-93.

10. Bell AM, Lassila LV, Kangasniemi I, Vallittu PK. Bonding of fibre-reinforced composite post to root canal dentin. J Dent 2005; 33: 533-9.

11. Zicari F, Van Meerbeek B, Scotti R, Naert I. Effect of fibre post length and adhesive strategy on fracture resistance of endodontically treated teeth after fatigue loading. J Dent 2012; 40: 312-21.

12. Maceri F, Martignoni M, Vairo G. Mechanical behaviour of endodontic restorations with multiple prefabricated posts: a finite-element approach. J Biomech 2007; 40: 2386-98.

13. Lassila LV, Tanner J, Le Bell AM, Narva K, Vallittu PK. Flexural properties of fiber reinforced root canal posts. Dent Mater 2004; 20: 29-36.

14. Hatta M, Shinya A, Vallittu PK, Shinya A, Lassila LV. High volume individual fibre post versus low volume fibre post: the fracture load of the restored tooth. J Dent 2011; 39: 65-71. 
15. Frater M, Forster A, Kereszturi M, Braunitzer G, Nagy K. In vitro fracture resistance of molar teeth restored with a short fibre-reinforced composite material. J Dent 2014; 42: 1143-50.

16. Wandscher VF, Bergoli CD, Limberger IF, Ardenghi TM, Valandro LF. Preliminary results of the survival and fracture load of roots restored with intracanal posts: weakened vs nonweakened roots. Oper Dent 2014; 39: 541-55.

17. Scotti N, Coero Borga FA, Alovisi M, Rota R, Pasqualini D, Berutti E. Is fracture resistance of endodontically treated mandibular molars restored with indirect onlay composite restorations influenced by fibre post insertion? Journal of Dentistry 2012; 40: 814-20.

18. Batalha-Silva S, de Andrada MA, Maia HP, Magne P. Fatigue resistance and crack propensity of large MOD composite resin restorations: direct versus CAD/CAM inlays. Dental Materials 2013; 29: 324-31.

19. Dietschi D, Argente A, Krejci I, Mandikos M. In vitro performance of Class I and II composite restorations: a literature review on nondestructive laboratory trials-part II. Oper Dent 2013; 38: E182-200.

20. Meyenberg K. The ideal restoration of endodontically treated teeth - structural and esthetic considerations: a review of the literature and clinical guidelines for the restorative clinician. Eur J Esthet Dent 2013; 8: 238-68.

21. Paolone G, Saracinelli M, Devoto W, Putignano A. Esthetic direct restorations in endodontically treated anterior teeth. Eur J Esthet Dent 2013; 8: 44-67.

22. Bolhuis HPB, De Gee AJ, Feilzer AJ, Davidson CL. Fracture strength of different core build-up designs. Am J Dent 2001; 14: 286-90.

23. Manning KE, Yu DC, Yu HC, Kwan EW. Factors to consider for predictable post and core build-ups of endodontically treated teeth. Part I: Basic theoretical concepts. Journal 1995; 61: 685-8, 90, 93-5.

24. Fuss Z, Lustig J, Katz A, Tamse A. An evaluation of endodontically treated vertical root fractured teeth: impact of operative procedures. J Endod 2001; 27: 46-8.

25. Ferrari M, Vichi A, Garcia-Godoy F. Clinical evaluation of fiber-reinforced epoxy resin posts and cast post and cores. Am J Dent 2000; 13: 15B-8B.

26. Butz F, Lennon AM, Heydecke G, Strub JR. Survival rate and fracture strength of endodontically treated maxillary incisors with moderate defects restored with different post-and-core systems: an in vitro study. Int J Prosthodont 2001; 14: 58-64.

27. Lertchirakarn V, Palamara JE, Messer HH. Patterns of vertical root fracture: factors affecting stress distribution in the root canal. J Endod 2003; 29: 523-8.

28. Fuss Z, Lustig J, Tamse A. Prevalence of vertical root fractures in extracted endodontically treated teeth. Int Endod J 1999; 32: 283-6.
29. Tamse A, Fuss Z, Lustig J, Kaplavi J. An evaluation of endodontically treated vertically fractured teeth. J Endod 1999; 25: 506-8.

30. Kishen A, Asundi A. Experimental investigation on the role of water in the mechanical behavior of structural dentine. J Biomed Mater Res, Part A 2005; 73: 192-200.

31. Sorensen JA, Engelman MJ. Effect of post adaptation on fracture resistance of endodontically treated teeth. J Prosthet Dent 1990; 64: 419-24.

32. Eskitascioglu G, Belli S, Kalkan M. Evaluation of two post core systems using two different methods (fracture strength test and a finite elemental stress analysis). J Endod 2002; 28: 629-33.

33. Newman MP, Yaman P, Dennison J, Rafter M, Billy E. Fracture resistance of endodontically treated teeth restored with composite posts. J Prosthet Dent 2003; 89: 360-7.

34. Le Bell-Ronnlof AM, Lassila LV, Kangasniemi I, Vallittu PK. Load-bearing capacity of human incisor restored with various fiber-reinforced composite posts. Dent Mater 2011; 27: e107-15.

35. Ku CW, Park SW, Yang HS. Comparison of the fracture strengths of metal-ceramic crowns and three ceromer crowns. J Prosthet Dent 2002; 88: 170-5.

36. Mannocci F, Sherriff M, Watson TF. Three-point bending test of fiber posts. J Endod 2001; 27: 758-61.

37. Chieruzzi M, Pagano S, Pennacchi M, Lombardo G, D'Errico P, Kenny JM. Compressive and flexural behaviour of fibre reinforced endodontic posts. J Dent 2012; 40: $968-78$.

38. Goracci C, Fabianelli A, Sadek FT, Papacchini F, Tay FR, Ferrari $\mathrm{M}$. The contribution of friction to the dislocation resistance of bonded fiber posts. J Endod 2005; 31: 608-12.

39. Turner CH. Post-retained crown failure: a survey. Dent Update 1982; 9: 221, 4-6, 8-9 passim.

40. Heydecke G, Peters MC. The restoration of endodontically treated, single-rooted teeth with cast or direct posts and cores: a systematic review. J Prosthet Dent 2002; 87: 380-6.

41. Ambica K, Mahendran K, Talwar S, Verma M, Padmini G, Periasamy R. Comparative evaluation of fracture resistance under static and fatigue loading of endodontically treated teeth restored with carbon fiber posts, glass fiber posts, and an experimental dentin post system: an in vitro study. J Endod 2013; 39: 96-100.

42. Ozcan M, Valandro LF. Fracture strength of endodontically-treated teeth restored with post and cores and composite cores only. Oper Dent 2009; 34: 429-36.

43. Dietschi D, Duc O, Krejci I, Sadan A. Biomechanical considerations for the restoration of endodontically treated teeth: a systematic review of the literature, Part II (Evaluation of fatigue behavior, interfaces, and in vivo studies). Quintessence Int 2008; 39: 117-29.

44. Meira JB, Esposito CO, Quitero MF et al. Elastic modulus of posts and the risk of root fracture. Dent Traumatol 2009; 25: 394-8. 